https://helda.helsinki.fi

\title{
Inverse electron demand Diels-Alder click chemistry for pretargeted PET imaging and radioimmunotherapy
}

\section{Sarrett, Samantha M.}

2021-07

Sarrett , S M , Keinanen , O , Dayts , E J , Dewaele-Le Roi , G , Rodriguez , C , Carnazza , K E \& Zeglis , B M 2021, ' Inverse electron demand Diels-Alder click chemistry for pretargeted PET imaging and radioimmunotherapy ' , Nature Protocols , vol. 16 , no. 7 , pp. 3348-3381 . https://doi.org/10.1038/s41596-021-00540-2

http://hdl.handle.net/10138/339162

https://doi.org/10.1038/s41596-021-00540-2

acceptedVersion

Downloaded from Helda, University of Helsinki institutional repository.

This is an electronic reprint of the original article.

This reprint may differ from the original in pagination and typographic detail.

Please cite the original version. 


\section{PROTOCOL METADATA}

Manuscript number: NP-P200348B

Corresponding author and email address: Brian Zeglis, bz102@hunter.cuny.edu

Number of:

Figs: 8 - have requested 2 more. HPLC traces for the purification steps and a flow diagram outlining the order in which the steps of the procedure are done.

Tables: 2

Boxes: 1

List of SI: A supplementary method.

CFIs: None

Figs: ***Please have a look at the list of figure legends at the end of this document. I have added some text.

\section{EDITORIAL SUMMARY}

This approach leverages the rapid and bioorthogonal inverse electron demand Diels-Alder reaction between a radiolabeled tetrazine and a trans-cyclooctene-bearing antibody to enable pretargeted PET imaging and endoradiotherapy in a murine model of cancer.

\section{TWEET}

@KeinanenOuti@SamanthaSarrett@Cinderelliee_1

\section{Data Availability Statement (DAS)}

The data described in the "Anticipated Results" section of this protocol were derived from the following publications that are available in the public domain from the National Library of Medicine Database at https://pubmed.ncbi.nlm.nih.gov.

1. Membreno, R., Cook, B. E., Fung, K., Lewis, J. S. \& Zeglis, B. M. Click-mediated pretargeted radioimmunotherapy of colorectal carcinoma. Mol Pharm 15, 1729-1734, (2018).

2. Zeglis, B. M. et al. Optimization of a pretargeted strategy for the PET imaging of colorectal carcinoma via the modulation of radioligand pharmacokinetics. Mol Pharm 12, 3575-3587, (2015). 


\section{RELATED LINKS}

\section{Key reference(s) using this protocol}

[These are primary research papers where the protocol has been used. Limit of 5 . The reference is an example of the format used for this citation.]

1. Membreno, R. et al. Mol. Pharm. 15, 1729-1734, (2018). [https://pubs.acs.org/doi/10.1021/acs.molpharmaceut.8b00093]

2. Zeglis, B. M. et al. Mol. Pharm. 12, 3575-3587, (2015). [https://pubs.acs.org/doi/10.1021/acs.molpharmaceut.5b00294]

3. Adumeau, P. et al. Theranostics 6, 2267 (2016). [https://www.thno.org/v06p2267.htm]

4. Houghton, J. L. et al. Mol. Cancer Ther. 16, 124 (2017). [https://mct.aacrjournals.org/content/16/1/124]

5. Keinänen, $\mathrm{O}$. et al. Mol. Pharm. 6, 4416-4421, (2019). [https://pubs.acs.org/doi/10.1021/acs.molpharmaceut.9b00746]

\section{AUTHOR CHECKS:}

Has the author list changed since the first draft?

Have you referred to any unpublished observations? Are these from authors of this paper, or from another research group?

Protocol uses antibodies or cell lines? Please add RRIDs (Research Resource Identifiers). Either find or add to: http://scicrunch.org/resources.

https://scicrunch.org/resolver/RRID:CVCL 3886

Figures: if a figure has been used in previous publication, or is an adaptation of a previously published figure, please cite in the legend. 


\section{Leveraging Inverse Electron Demand Diels-Alder Click Chemistry for Pretargeted PET Imaging and Radioimmunotherapy}

Samantha M. Sarrett ${ }^{1,2, \S}$, Outi Keinänen ${ }^{1,3,4, \S}$, Eric J. Dayts ${ }^{1}$, Guillaume Dewaele-Le Roi ${ }^{1,5}$, Cindy Rodriguez ${ }^{1,5}$, Kathryn E. Carnazza ${ }^{6}$, Brian M. Zeglis ${ }^{1,2,3,5,7 *}$

${ }^{1}$ Department of Chemistry, Hunter College, City University of New York ${ }^{2}$ Ph.D. Program in Biochemistry, Graduate Center of the City University of New York ${ }^{3}$ Department of Radiology, Memorial Sloan Kettering Cancer Center ${ }^{4}$ Department of Chemistry, Radiochemistry, University of Helsinki, Helsinki, Finland ${ }^{5}$ Ph.D. Program in Chemistry, Graduate Center of the City University of New York ${ }^{6}$ Brain and Mind Research Institute \& Appel Institute for Alzheimer's Disease Research, Weill Cornell Medical College

${ }^{7}$ Department of Radiology, Weill Cornell Medical College

$\S$ These authors contributed equally.

Corresponding author: *Brian M. Zeglis. 413 East 69 ${ }^{\text {th }}$ Street, New York, NY, 10021. Phone: 212896-0433. Fax: 212-772-5332. E-mail: bz102@hunter.cuny.edu 


\begin{abstract}
Radiolabeled antibodies have shown promise as tools for both the nuclear imaging and endoradiotherapy of cancer, but the protracted circulation time of radioimmunoconjugates can lead to high radiation doses to healthy tissues. To circumvent this issue, we have developed an approach to positron emission tomography (PET) imaging and radioimmunotherapy (RIT) predicated on radiolabeling the antibody after it has reached its target within the body. This in vivo pretargeting strategy is based on the rapid and bioorthogonal inverse electron demand Diels-Alder reaction between tetrazine $(\mathrm{Tz})$ and trans-cyclooctene (TCO). Pretargeted PET imaging and radioimmunotherapy using TCO-modified antibodies in conjunction with Tz-bearing radioligands produce high activity concentrations in target tissues as well as reduced radiation doses to healthy organs compared to directly-labeled radioimmunoconjugates. Herein, we describe how to prepare a TCO-modified antibody (huA33-TCO) as well as how to synthesize two Tz-bearing radioligands: one labeled with the positron-emitting radiometal copper-64 $\left(\left[{ }^{64} \mathrm{Cu}\right] \mathrm{Cu}-\mathrm{SarAr}-\mathrm{Tz}\right)$ and one labeled with the $\beta$-emitting radiolanthanide lutetium-177 ([177 $\left.\mathrm{Lu}] \mathrm{Lu}-\mathrm{DOTA}-\mathrm{PEG}_{7}-\mathrm{Tz}\right)$. We also provide a detailed description of pretargeted PET and pretargeted radioimmunotherapy (PRIT) experiments in a murine model of human colorectal carcinoma. Proper training in both radiation safety and the handling of laboratory mice is required for the successful execution of this protocol.
\end{abstract}




\section{INTRODUCTION}

\section{Background}

Over the past two decades, radioimmunoconjugates have become increasingly important diagnostic and therapeutic tools in oncology. The ability of monoclonal antibodies (mAbs) to target tumor-associated antigens with high affinity and specificity has long made them effective vectors for the delivery of radionuclides to malignant tissue. The protracted circulation time of full-length immunoglobulins - i.e. they can take several days to reach their optimal biodistribution in the body - means that they must be labeled with radionuclides with multiday physical half-lives. Zirconium$89\left({ }^{89} \mathrm{Zr} ; \mathrm{t}_{1 / 2} \sim 3.3 \mathrm{~d}\right)$ and iodine-124 $\left({ }^{124} \mathrm{I} ; \mathrm{t}_{1 / 2} \sim 4.2 \mathrm{~d}\right)$ are typically employed for positron emission tomography (PET); indium-111 ( ${ }^{111} \mathrm{In} ; \mathrm{t}_{1 / 2} \sim 2.8 \mathrm{~d}$ ) is the current 'gold-standard' for single photon emission computed tomography (SPECT); and lutetium-177 $\left({ }^{177} \mathrm{Lu} ; \mathrm{t}_{1 / 2} \sim 6.7 \mathrm{~d}\right)$, iodine-131 $\left({ }^{131} \mathrm{I} ; \mathrm{t}_{1 / 2}\right.$ $\sim 8.0 \mathrm{~d})$, and actinium-225 $\left({ }^{225} \mathrm{Ac} ; \mathrm{t}_{1 / 2} \sim 10.0 \mathrm{~d}\right)$ are commonly used for radioimmunotherapy $(\mathrm{RIT})^{1-}$

5. Several antibody-based radiopharmaceuticals have emerged as clinical success stories, including $\left[{ }^{131} \mathrm{I}\right] \mathrm{I}-\mathrm{hu} 3 \mathrm{~F} 8$ for the treatment of pediatric neuroblastoma and an ever-expanding array of $\left[{ }^{89} \mathrm{Zr}\right] \mathrm{Zr}$ labeled antibodies for diagnostic and theranostic $\mathrm{PET}^{6-8}$. However, the unavoidable combination of long biological and physical half-lives can create high radiation dose rates to healthy tissues, a complication that has dampened enthusiasm for radioimmunoconjugates in the clinic.

Perhaps not surprisingly, several alternative approaches have been created in an attempt to circumvent this issue. For example, antibody fragments - e.g. F(ab), Fab, and sdAb - have attracted a great deal of attention as smaller format $(\sim 10-100 \mathrm{kDa})$ analogues of full-length immunoglobulins $(\sim 150 \mathrm{kDa})$ with more rapid pharmacokinetic profiles ${ }^{9}$. While such radiolabeled fragments have shown promise both in the laboratory and the clinic, their shorter biological half-lives come at a not insignificant price: lower tumor accretion and higher retention in the kidneys ${ }^{10}$. 
This protocol is focused on yet another alternative methodology that seeks to leverage all of the advantages of full-length immunoglobulins while skirting their pharmacokinetic - and thus dosimetric - drawbacks: in vivo pretargeting.

In vivo pretargeting is predicated on injecting the immunoglobulin and radionuclide separately and relying upon a biorthogonal ligation to join two components together within the body. Labeling the antibody with a fast-moving, small molecule radioligand after it has reached an optimal biodistribution in vivo - or at least has had a 'head start' - limits the circulation time of the assembled radioimmunoconjugate in the blood and enables the use of radionuclides with shorter half-lives that are normally incompatible with full-length IgG. As a result, this approach can produce high activity concentrations in target tissues alongside reduced radiation doses to healthy organs compared to traditional, directly-radiolabeled immunoconjugates.

The central feature of any pretargeting strategy is the mechanism of the in vivo combination of the vector and radionuclide. A handful of different approaches have been used, including the ligation of streptavidin and biotin ${ }^{11}$, the hybridization of complementary oligonucleotides ${ }^{12}$, and the ability of bispecific antibodies to bind both antigens and radiolabeled haptens ${ }^{13}$. While these strategies have produced promising preclinical and - in some cases - clinical results, each possesses significant intrinsic limitations (see Comparison with Other Methods). As a result, the development of novel approaches to in vivo pretargeting remains an unmet need.

\section{Development of the Protocol}

Our laboratory has worked for almost a decade to develop and optimize an approach to in vivo pretargeting based on the inverse electron demand Diels-Alder (IEDDA) reaction between 1,2,4,5tetrazine (Tz) and trans-cyclooctene (TCO) (Figure 1A). We have not been the only ones working in this field, of course. Indeed, several excellent teams have also been instrumental in the advancement of IEDDA-based pretargeting technology, most notably Jason S. Lewis and his group at Memorial 
Sloan Kettering Cancer Center, Raffaela Rossin and Mark Robillard and their coworkers at Tagworks Pharmaceuticals, and Matthias Herth and his laboratory at the University of Copenhagen. Rondon, et al. have recently published an excellent review summarizing the field's progress as a whole ${ }^{14}$.

The IEDDA ligation is a catalyst-free click chemistry transformation whose rapidity $\left(k_{2}>30,000\right.$ $\mathrm{M}^{-1} \mathrm{~S}^{-1}$ ) and bioorthogonality make it nearly ideal for in vivo applications ${ }^{15}$. This singular chemical technology underpins two of the most important advantages of this approach to pretargeting: its modularity and its reliance, unique amongst pretargeting strategies, on the formation of covalent bonds between the vector and the radioligand. IEDDA-based approaches for in vivo pretargeting generally rely upon two components - a TCO-modified monoclonal antibody (mAb) and a Tz-bearing radioligand - and four sequential steps: (i) the intravenous administration of the TCO-based immunoconjugate, (ii) an interval period during which the mAb-TCO accumulates within target tissue and clears from the blood, (iii) the intravenous administration of the radiolabeled tetrazine, and (iv) the click ligation of the two components in vivo followed by the rapid clearance of excess radioligand (Figure 1B). Over the years, however, several variations on this theme have emerged, including the use of clearing agents and the sequential administration of two different radioligands ${ }^{16-}$ ${ }^{18}$. Nonetheless, this original approach remains the simplest, most robust, and most well optimized.

Our initial foray into pretargeted PET imaging - which is predated in the literature by the pretargeted SPECT work of Rossin, et al. - employed a $\left[{ }^{64} \mathrm{Cu}\right] \mathrm{Cu}-\mathrm{NOTA}-\mathrm{Tz}$ radioligand and a TCOmodified variant of the colorectal cancer-targeting antibody huA33 (huA33-TCO) ${ }^{19,20}$. While this system produced promising imaging and biodistribution data in murine models of human colorectal carcinoma, the hepatobiliary clearance of the radioligand would prove an obstacle to clinical imaging. This result fueled the development of a second generation ${ }^{64} \mathrm{Cu}$-labeled radioligand $-\left[{ }^{64} \mathrm{Cu}\right] \mathrm{Cu}-$ SarAr-Tz - that combined rapid renal clearance and excellent in vivo performance in pretargeted PET and biodistribution experiments ${ }^{21}$. Around the same time, exhaustive structure-activity studies were performed to optimize ${ }^{18} \mathrm{~F}$ - and ${ }^{68} \mathrm{Ga}$-labeled tetrazines that facilitated pretargeted PET using 
radionuclides with even shorter half-lives ${ }^{22-24}$. While these efforts produced several highly effective radioligands and provided a number of important lessons in molecular design, none surpassed the in vivo performance of $\left[{ }^{64} \mathrm{Cu}\right] \mathrm{Cu}-\mathrm{SarAr}-\mathrm{Tz}$.

Pretargeted radioimmunotherapy (PRIT) experiments soon followed after the development of the PET systems. To this end, a Tz radioligand labeled with the $\beta$-emitting radiometal ${ }^{177} \mathrm{Lu}-\left[{ }^{177} \mathrm{Lu}\right] \mathrm{Lu}-$ DOTA-PEG7-Tz - was employed in conjunction with a pair of TCO-bearing immunoconjugates in murine models of colorectal cancer (huA33-TCO) and pancreatic ductal adenocarcinoma (5B1TCO $)^{24-27}$. In both cases, biodistribution studies revealed high activity concentrations in tumor tissue along with low levels of uptake in healthy organs. Furthermore, longitudinal therapy studies subsequently revealed the efficacy of ${ }^{177}$ Lu-PRIT, illustrating that this strategy produces a dosedependent therapeutic response in both murine models of disease. We have recently extended our exploration of IEDDA-based PRIT, with forays into radioligands bearing $\alpha$-emitting radionuclides (i.e. $\left.\left[{ }^{225} \mathrm{Ac}\right] \mathrm{Ac}-\mathrm{DOTA}-\mathrm{PEG}_{7}-\mathrm{Tz}\right)$, TCO-modified dendrimers designed to amplify tumoral activity concentration levels, and dual radionuclide systems that integrate PRIT with theranostic PET ${ }^{16,17,26,28}$. We are far from the only ones innovating in this space, however. A variety of other laboratories including, but not limited to, those mentioned previously - have produced ground-breaking work, including studies focused on alternative dienophile moieties, Tz-bearing masking agents, antibody fragment-based pretargeting, TCO-modified bone-seeking vectors, and nanoparticulate radioligands ${ }^{29-33}$.

We have previously described our approach to in vivo pretargeting in a protocol in the Journal of Visualized Experiments that discussed PRIT with huA33-TCO and $\left[{ }^{177} \mathrm{Lu}\right] \mathrm{Lu}-\mathrm{PEG}_{7}-\mathrm{DOTA}^{27}$. This protocol expands upon this earlier work by describing the synthesis of radioligands for both pretargeted PET $\left(\left[{ }^{64} \mathrm{Cu}\right] \mathrm{Cu}-\mathrm{SarArTz}\right)$ and radioimmunotherapy $\left(\left[{ }^{177} \mathrm{Lu}\right] \mathrm{Lu}-\mathrm{PEG}_{7}-\mathrm{DOTA}\right)$ and by providing detailed descriptions of in vivo imaging, biodistribution, and longitudinal therapy studies. In addition, we also provide a method for determining the TCO occupancy of immunoconjugates 
using Tz-PEG7-AF680 (see Box 1) as well as procedures for cell culture and the implantation of xenografts (see Supplemental Methods).

\section{Comparison with Other Methods}

The IEDDA reaction is not the first ligation to be harnessed for in vivo pretargeting. Several different 'molecular couples' have been used over the years, each with its own distinct set of advantages and disadvantages (Figure 2). The earliest approaches to pretargeting relied upon the extraordinarily strong binding interaction between streptavidin (a protein) and biotin (a small molecule). Indeed, strategies were developed that employed biotin-bearing immunoconjugates and streptavidin-based radioligands as well as streptavidin-bearing immunoconjugates and biotin-based radioligands $^{34}$. These methodologies produced excellent preclinical results and promising data in early trials. However, clinical trials revealed that many patients experienced mild to severe immune responses related to the streptavidin moieties ${ }^{35,36}$. This immunogenicity ultimately proved a fatal flaw for the approach that has not been overcome in nearly two decades.

Another, arguably more elegant strategy for in vivo pretargeting is predicated on the use of bispecific antibodies that can bind to both tumor antigens and radiolabeled haptens. Methods employing both chelator- and peptide-based haptens have been explored, with both producing excellent preclinical results ${ }^{37-39}$. Even more importantly, in vivo pretargeting using bispecific antibodies and radiolabeled variants of IMP288, an oligopeptide hapten, have produced extremely promising clinical results in recent years ${ }^{40}$. IMP288 is a histamine-succinyl-glycine (HSG) peptide with two important advantages: modularity - it can be modified with different chelators and radionuclides without dramatically affecting its binding to the bispecific antibody - and a pharmacokinetic profile that boasts rapid clearance from the blood and low levels of uptake in the kidneys $^{41,42}$. Yet despite this success, the construction of bispecific antibodies is complex and 
expensive, factors which dramatically reduce the modularity of this approach and can represent significant barriers to laboratories interested in exploring pretargeting.

The third major approach to pretargeting relies upon the hybridization of complementary oligonucleotide chains for the in vivo ligation of the two components. This strategy has employed both antibodies and affibody molecules as targeting vectors and has typically relied upon phosphorodiamidate morpholino oligomers (MORFs) and peptide nucleic acids (PNAs) rather than natural nucleic acids ${ }^{12,43}$. Unlike natural DNA and RNA, MORFs and PNAs are not prone to degradation via nucleases, giving them significantly increased in vivo stability ${ }^{44}$. Like IEDDA-based methods, oligonucleotide-based pretargeting has not yet reached the clinic, but it has produced promising preclinical results in murine models of skin and ovarian cancer. The clinical translation of this approach is anticipated in the near future, yet the inherent instability of oligonucleotides and the non-covalent nature of hybridization remain concerns going forward. Creating a covalent link between the antibody and radioligand will always be the ideal, as this removes the possibility of the dissociation of the radiolabeled hapten and its subsequent washout from the tumor.

Finally, a handful of publications have emerged in which other in vivo ligation mechanisms have been interrogated over the years, including the Staudinger reaction, the strain-promoted azide-alkyne cycloaddition, and the host-guest relationship between cucurbituril and adamantane $\mathrm{e}^{45-48}$. These methods, however, have either proven ineffective in vivo or have not been the subject of a large enough body of data to merit further discussion here.

\section{Limitations of the IEDDA approach}

It is important to carefully examine the drawbacks associated with IEDDA-based pretargeting as well. To begin, IEDDA-based pretargeting inevitably shares the issues common to all approaches to in vivo pretargeting. For example, in vivo pretargeting is most effective when the TCO-modified vector, usually a monoclonal antibody, is not internalized upon binding its molecular target. In this 
protocol, we employ huA33, a humanized mAb that targets the A33 antigen - a transmembrane glycoprotein that is expressed on $>95 \%$ of colorectal carcinomas - and has been shown to remain surface persistent after binding its molecular target ${ }^{49}$. While a variety of non-internalizing antibodies have been discovered, many are internalized upon binding their targets, a process that (understandably) can make pretargeting more difficult. That said, our laboratory and others have demonstrated that in vivo pretargeting can be successful using antibodies that are internalized at slow or moderate rates (e.g. the CA19.9-targeting mAb 5B1, about $40 \%$ of which has been shown to internalize in BxPC3 cells in $24 \mathrm{~h})^{50,51}$.

In addition, the intrinsic complexity of in vivo pretargeting is often held up as a potential impediment to its clinical viability. Typically, these worries are not centered around the efficacy of the methodology in humans but rather the increased logistical burden associated with translating multi-component systems (i.e. performing toxicology studies on and garnering regulatory approval for not one but two parts of a system). To some degree, these concerns are valid and inevitable; it is our hope, however, that these issues will become less daunting - and provoke fewer knee-jerk reactions - as more clinical trials emerge in the future.

The principal drawback unique to IEDDA-based pretargeting is the in vivo isomerization of transcyclooctene (TCO) to cis-cyclooctene (CCO). This transformation of reactive TCO to inert CCO reduces the number of reaction partners for the tetrazine radioligand, thereby decreasing the frequency of in vivo ligations and limiting the accumulation of radioactivity in target tissues. Pioneering work by Rossin, et al. determined that the in vivo stability half-life of TCO can range from $\sim 4$ to $\sim 10$ days depending on the structure of the moiety ${ }^{52}$. While the exact mechanism of this interconversion remains unknown, it is hypothesized that it stems from the interaction between TCO and circulating transition metals or, more likely, circulating transition metal-containing proteins ${ }^{53}$. A variety of attempts have been made to address this issue. One study, for example, has suggested that reducing the length of the linker between the vector and the TCO can increase the half-life of the 
latter ${ }^{54}$. Others have attempted to circumvent this problem by moving the tetrazine to the vector and using TCO-based radioligands, though this approach is somewhat suspect because $\mathrm{Tz}$ is even less stable in vivo than $\mathrm{TCO}^{55-57}$. In the absence of a clear mitigation strategy- and considering that some instability may be inevitable as part of the trade-off for rapid reactivity - the best "insurance" against isomerization may simply be to employ immunoconjugates with degrees of labeling of TCO as high as possible without compromising the biochemical integrity of the vector. In our hands, a range of 25 TCO per antibody have been shown to facilitate successful in vivo experiments without impairing the immunroeactivity of the antibody. To be sure, as IEDDA-based pretargeting enters the clinic, it will be important to interrogate the degree to which TCO isomerization occurs in human patients.

\section{Experimental Design}

Herein, we first describe the synthesis and characterization of three components of our IEDDAbased approach to pretargeting: a pair of radioligands $-\left[{ }^{64} \mathrm{Cu}\right] \mathrm{Cu}-\mathrm{SarAr}-\mathrm{Tz}$ (Figure 3) and $\left[{ }^{177} \mathrm{Lu}\right] \mathrm{Lu}-$ DOTA-PEG7-Tz (Figure 4) - and a single immunoconjugate, huA33-TCO (Figure 5). We then provide a detailed description of how to perform pretargeted PET imaging and PRIT experiments in athymic nude mice bearing subcutaneous SW1222 colorectal carcinoma xenografts. We selected these radioligands, this immunoconjugate, and this tumor model for the protocol at hand because they represent the best characterized and most effective systems that we have developed to date. Yet one of the greatest strengths of IEDDA-based pretargeting is the ease with which it can be adapted to new applications. Tetrazine-bearing radioligands have been synthesized using a range of nuclides, including ${ }^{11} \mathrm{C},{ }^{68} \mathrm{Ga},{ }^{18} \mathrm{~F},{ }^{64} \mathrm{Cu},{ }^{111} \mathrm{In},{ }^{44} \mathrm{Sc},{ }^{99 \mathrm{~m}} \mathrm{Tc}$, and ${ }^{225} \mathrm{Ac}^{26,58-64}$. Similarly, a variety of vectors including antibodies, antibody fragments, nanoparticles, peptides, and small molecules - have been modified with $\mathrm{TCO}^{33,60,65,66}$. Of course, the mass of the TCO-bearing construct injected as well as the interval time between the administrations must be optimized for each vector (vide infra). Readers interested in attempting pretargeted PET or PRIT with a TCO-modified IgG are encouraged to 
employ the optimized bioconjugation methods and ${ }^{64} \mathrm{Cu}$ - and ${ }^{177} \mathrm{Lu}$-labeled radioligands described in this protocol. Those seeking to leverage other types of targeting vectors or use different radionuclides are welcome to combine the framework of this protocol with experimental procedures found in the references we cite throughout.

\section{Validating Immunoreactivity}

Before embarking on a new set of in vivo experiments, it is important to confirm the immunoreactivity of the immunoconjugate. Historically, we have employed two types of immunoreactivity assays, both of which require radiolabeling and purifying the TCO-modified immunoconjugate. The first is a cell-based assay in which the radioimmunoconjugate is incubated with the antigen-expressing cells that will be used in the in vivo experiments ${ }^{67}$. The second is a beadbased assay in which the radioimmunoconjugate is incubated with NTA-tagged beads coated with His-tagged antigen ${ }^{68}$. Each method has a distinct set of advantages. The bead-based assay removes all of the variables associated with using live cells as well as the need for cell culture. The cell-based assay, on the other hand, provides information on the interaction between the radioimmunoconjugate and the cells that will subsequently be used in vivo. If the binding of the immunoconjugate to the cells that will be employed in vivo has been well-established previously, we recommend the bead-based assay. If not, the cell-based assay is likely more useful.

\section{Optimizing the Interval Between Injections}

One of the key variables to optimise in the context of in vivo pretargeting is the length of the interval time between the injections of the antibody and the radioligand. This has a significant influence on the success of the experiment. If the interval is too short, this can result in high activity concentrations in the blood due to the ligation of the radioligand with still-circulating immunoconjugate. On other hand, if the interval is too long, the number of click ligations at the tumor 
could be reduced due to the internalization of the immunoconjugate or the isomerization of TCO to CCO.

In the past, we have employed imaging experiments using a directly radiolabeled antibody to determine the point at which the immunoconjugate reaches an optimal biodistribution in vivo and thereby identify the appropriate injection interval. For example, imaging experiments with $\left[{ }^{89} \mathrm{Zr}\right] \mathrm{Zr}-$ DFO-huA33 in murine models of colorectal cancer illustrated that the radioimmunoconjugate reaches an optimal biodistribution between 1 and 4 days after injection, data which has lead us to use injection intervals of 24-96 $\mathrm{h}$ when performing pretargeting experiments with huA33-TCO. In the absence of biodistribution or imaging data, the biological half-life of the vector could be used as a general guidepost for choosing an appropriate injection interval, though there is no replacement for experimentation. In the end, we recommend that those developing a new pretargeting system explore several different intervals in order to identify the timing that produces the best in vivo results.

\section{Control Experiments}

In pretargeted PET imaging experiments, we have employed cohorts of animals treated with three sets of control conditions: (i) the radioligand alone; (ii) the radioligand in conjunction with an unmodified - i.e. TCO-less - vector (e.g. wildtype huA33); (iii) the TCO-bearing vector in conjunction with the radioligand in very low specificity activity. Perhaps not surprisingly, each of these conditions produced images with very low tumor-to-background contrast as well as minimal activity concentrations $($ i.e. $<0.5 \% \mathrm{ID} / \mathrm{g})$ in tumor tissue.

Armed with the PET data, we have typically used only two control conditions in longitudinal PRIT studies: the radioligand alone (at the highest dose employed for PRIT) as well as the TCOmodified immunoconjugate alone. In these experiments, the cohorts subjected to both control conditions experience dramatically more rapid tumor growth than those treated with even the lowest doses of PRIT (see Figure 8). Finally, in both PET and PRIT studies, a control cohort in which the 
radioligand alongside a non-targeted yet TCO-bearing vector (e.g. non-specific $\left.\mathrm{IgG}_{1}-\mathrm{TCO}\right)$ is advisable if the specificity of the vector has not previously been demonstrated. These control experiments should be performed during the in vivo evaluation of any new pretargeting system.

\section{Necessary Expertise}

Radiation Safety Training: Only personnel who have received proper radiation safety training should perform the parts of this protocol that involve radioactivity. Furthermore, these experiments must only be performed in authorized and regulated laboratory spaces that have been approved for work with radioactivity. Finally, survey meters, dosimeters, adequate shielding, and proper PPE must be used at all times.

Laboratory Animal Training: Only personnel who have received thorough training in the handling and use of mice for preclinical in vivo experimentation should perform the parts of the protocol that involve mice. Regulated and well-staffed animal facilities are required for all animal experiments, and all in vivo procedures must be performed according to institutional, state, and federal guidelines. Again, proper PPE must be used at all times during in vivo experimentation. 


\section{MATERIALS}

\section{Biological Materials}

- Athymic nude mice (007850, The Jackson Laboratory) bearing SW1222 human colorectal cancer xenografts (see Supporting Information for a protocol for xenograft implantation) !CAUTION All animal experiments should be performed according to institutional, state, and federal guidelines. All animal experiments in this protocol were performed in accordance with protocols approved by the institutional animal care and use committees (IACUC) of Memorial Sloan Kettering Cancer Center, Weill Cornell Medical College, and Hunter College.

\section{Reagents}

- $\left[{ }^{64} \mathrm{Cu}\right] \mathrm{CuCl}_{2}$ in $0.05 \mathrm{M} \mathrm{HCl}$ (MIR Cyclotron Facility, Washington University School of Medicine, St. Louis, MO, USA) !CAUTION Copper-64 represents a radiological hazard and must be used according to institutional, state, and federal regulations as well as ALARA (as low as reasonably achievable) principles. Proper shielding during the handling of all radioactive reagents, mixtures, glassware, and instruments is essential. Furthermore, it is critical that appropriate personal protective equipment, dosimeters, and survey meters are always used when handling radioactive material.

- $\left[{ }^{177} \mathrm{Lu}\right] \mathrm{LuCl}_{3}$ in $0.05 \mathrm{M} \mathrm{HCl}$ (PerkinElmer Life and Analytical Sciences, Wellesley, MA, USA) !CAUTION Lutetium-177 represents a radiological hazard and must be used according to institutional, state, and federal regulations as well as ALARA (as low as reasonably achievable) principles. Proper shielding during the handling of all radioactive reagents, mixtures, glassware, and instruments is essential. Furthermore, it is critical that appropriate personal protective equipment, dosimeters, and survey meters are always used when handling radioactive material. 
- Humanized A33 antibody (huA33, Olivia Newton-John Cancer Research Institute, Heidelberg, Australia) !CRITICAL Store antibodies according to the manufacturer's instructions.

- Bovine serum albumin (BSA, A9418, Sigma-Aldrich, St. Louis, MO, USA)

- Chelex ${ }^{\circledR} 100$ resin (100-200 mesh, sodium form, 143-2832, Bio-Rad Laboratories, Hercules, CA, USA)

- Dimethyl sulfoxide (DMSO, MT-25950CQC, ThermoFisher Scientific, Waltham, MA, USA) !CAUTION DMSO is a flammable liquid. DMSO may cause slight skin and eye irritation.

- Ethylenediaminetetraacetic acid (EDTA, AC327211000, ThermoFisher Scientific, Waltham, MA, USA) !CAUTION EDTA can cause serious eye damage and is hazardous to aquatic life.

- Hydrochloric acid (HCl, 6 M, 60-047-420, ThermoFisher Scientific, Waltham, MA, USA) !CAUTION Hydrochloric acid can cause severe skin burns and eye damage and may cause respiratory irritation if inhaled.

- Ultrapure water $\left(18.2 \mathrm{M} \Omega \mathrm{cm}^{-1}\right.$, Milli- $\mathrm{Q}^{\circledR}$ Advantage A10 Water Purification System, Z00Q0V0WW, MilliporeSigma, Burlington, MA, USA or equivalent)

- Phosphate-buffered saline (PBS, 10× solution, BP3991, ThermoFisher Scientific, Waltham, MA, USA)

- Sodium carbonate $\left(\mathrm{Na}_{2} \mathrm{CO}_{3}, \quad \mathrm{~S} 7795\right.$, Sigma-Aldrich, St. Louis, MO, USA) !CAUTION Sodium carbonate can cause serious eye irritation.

- (E)-Cyclooct-4-enyl 2,5-dioxo-1-pyrrolidinyl carbonate (TCO-NHS, 764523, Sigma-Aldrich, St. Louis, MO, USA)

- Acetic acid, $\left(\mathrm{C}_{2} \mathrm{H}_{4} \mathrm{O}_{2}, 99.8 \%\right.$, AC222140010, ThermoFisher Scientific, Waltham, MA, USA) !CAUTION Acetic acid can cause severe skin burns and eye damage and may cause respiratory irritation if inhaled. 
- Ammonium acetate ( $\mathrm{NH}_{4} \mathrm{OAc}, 372331$, Sigma-Aldrich, St. Louis, MO, USA)

- Acetonitrile (A998SK-4, ThermoFisher Scientific, Waltham, MA, USA) !CAUTION Acetonitrile is a highly flammable liquid and can cause acute oral, dermal, and inhalation toxicity.

- $\mathrm{N}$-boc-4-(bromomethyl)-benzylamine (54463, AstaTech, Bristol, PA, USA) !CAUTION Nboc-4-(bromomethyl)-benzylamine has acute oral toxicity and is potentially irritating to the skin.

- Benzylamino tetrazine $N$-hydroxysuccinimidyl ester (Tz-NHS, 764701, Sigma-Aldrich, St. Louis, MO, USA) !CAUTION Tz-NHS has acute oral and dermal toxicity.

- DiAmSar (SarAr-Bn-NH2, M-190, Macrocyclics, Inc., Plano, TX, USA)

- $N, N$-Dimethylformamide (DMF, anhydrous, 99.8\% AC448381000, ThermoFisher Scientific, Waltham, MA, US) !CAUTION DMF is a highly flammable liquid and may cause serious eye and respiratory irritation.

- Triethylamine (TEA, 219510500, Acros Organics, Fair Lawn, NJ, USA) !CAUTION TEA is a highly flammable liquid and has high oral, dermal, and respiratory toxicity.

- Trifluoroacetic acid (99+\% TFA, AAA1361414, ThermoFisher Scientific, Waltham, MA, USA) !CAUTION TFA is highly toxic and can cause severe skin burns, eye damage, and lung irritation.

- Boc-PEG7-amine (O-(2-aminoethyl)-O'-[2-(boc-amino)ethyl]hexaethylene glycol, 70023, Sigma-Aldrich, St. Louis, MO, USA)

- Dichloromethane $\left(\mathrm{CH}_{2} \mathrm{Cl}_{2}, \mathrm{DCM}, \mathrm{AC610300010,} \mathrm{ThermoFisher} \mathrm{Scientific,} \mathrm{Waltham,} \mathrm{MA,}\right.$ USA) !CAUTION DCM can cause skin irritation, eye irritation, drowsiness, and dizziness. DCM is also a suspected carcinogen.

- $\quad$-SCN-Bn-DOTA (B-205, Macrocyclics, Inc., Plano, TX, USA) 
- Centrifugal filters (Amicon ${ }^{\circledR}$ Ultra-4 centrifugal filters with a $50 \mathrm{kDa}$ cut-off, UFC8050, Sigma-Aldrich, St. Louis, MO, USA)

- UV-Vis spectrophotometer (Biospec Nano, Shimadzu, Columbia, MD, USA or equivalent)

- Analytical balance (XPE105, Mettler Toledo, Columbus, OH, USA or equivalent)

- Dose calibrator (Capintec CRC-15R Dose Calibrator, Capintec, Florham Park, NJ, USA or equivalent)

- $\quad 1.5$ mL Microcentrifuge tubes (Eppendorf ${ }^{\mathrm{TM}}$ LoBind Microcentrifuge Tubes: Protein, 13-698794, ThermoFisher Scientific, Waltham, MA, USA or equivalent)

- $50 \mathrm{~mL}$ Conical centrifuge tubes (Corning ${ }^{\mathrm{TM}}$ CentriStar $^{\mathrm{TM}}$ Cap, $50 \mathrm{~mL}$ Centrifuge Tubes, Sterile, 05-538-60, ThermoFisher Scientific, Waltham, MA, USA, or equivalent)

- Gamma counter (Automatic Wizard² Gamma Counter, Perkin Elmer, Waltham, MA, USA or equivalent)

- Heat lamp (Infrared Heating and Drying Lamp, 36547-009, VWR, Radnor, PA, USA or equivalent)

- Insulin syringes (14-826-79, ThermoFisher Scientific, Waltham, MA or equivalent)

- iTLC plates, glass microfiber chromatography paper impregnated with silica gel (NC0283947, ThermoFisher Scientific, Waltham, MA, USA, or equivalent)

- Ultrapure water system (Milli-Q ${ }^{\circledR}$ Advantage A10 Water Purification System, Z00Q0V0WW, MilliporeSigma, Burlington, MA, USA or equivalent)

- Mouse restrainer (TV-RED 150-STD, Braintree Scientific, Braintree, MA, USA or equivalent)

- Ethanol wipes (22-363-750, ThermoFisher Scientific, Waltham, MA, USA) !CAUTION Ethanol is highly flammable.

- Gauze (Dynarex Sterile Gauze Pads, 3353, Dynarex, Orangeburg, NY, USA or equivalent) 
- Mouse surgery kit (Kent Scientific Mouse Surgical Kit, 13-005-204, ThermoFisher Scientific, Waltham, MA, USA, or equivalent)

- Disposable culture tubes (DWK Life Sciences Kimble ${ }^{\mathrm{TM}}$ Plain Disposable Plastic Tubes 12x75mm Polystyreme, 13-674-60A, ThermoFisher Scientific, Waltham, MA, USA, or equivalent)

- Disposable culture tube caps (Simport $^{\mathrm{TM}}$ Scientific Flange Plug Caps, 22-045-563, ThermoFisher Scientific, Waltham, MA, USA, or equivalent)

- Positron emission tomography scanner (microPET Focus 120 dedicated small-animal scanner, Siemens Medical Solutions, Malvern, PA, USA, or equivalent)

- $\mathrm{pH}$ paper (1.09543.0001, Sigma-Aldrich, St. Louis, MO, USA, or equivalent)

- Pipette tips [ranging from $1-1000 \mu \mathrm{L}$, Fisherbrand ${ }^{\mathrm{TM}}$ SureOne ${ }^{\mathrm{TM}}$ Aerosol Barrier Pipette Tips, micropoint, 02-707-439 (0.1 - $10 \mu \mathrm{L}), 02-707-432(2-20 \mu \mathrm{L}), 02-707-430(20-200$ $\mu \mathrm{L})$, 02-707-404 (100 - $1000 \mu \mathrm{L})$, ThermoFisher Scientific, Waltham, MA, USA, or equivalent]

- Pipettes [ranging from $1-1000 \mu \mathrm{L}$, Brand $^{\circledR}$ Transferpette $^{\circledR}$ S pipette, adjustable single channel; Z646512 (0.5 - $10 \mu \mathrm{L})$, Z646520 (2 - $20 \mu \mathrm{L})$, Z646547 (20 - $200 \mu \mathrm{L}), \mathrm{Z} 646555$ $(100-1000 \mu \mathrm{L})$, Sigma-Aldrich, St. Louis, MO, USA or equivalent]

- Disposable PD-10 desalting columns (Sephadex ${ }^{\mathrm{TM}}$ G-25 Medium, 45-000-148, ThermoFisher Scientific, Waltham, MA, USA)

- Dry block heating and cooling shaker (Eppendorf ${ }^{\mathrm{TM}}$ Thermomixer $^{\circledR}$ F1.5, 05-412-500, ThermoFisher Scientific, Waltham, MA, USA or equivalent)

- TLC plate reader (Bioscan AR-2000 Radio-TLC plate reader + Winscan Radio-TLC software, Bioscan Inc., Santa Barbara, USA or equivalent)

- Tumor measuring device (Peira TM900, Ketelaarstaat 8, Belgium or equivalent) 
- Vortex mixer (VWR ${ }^{\circledR}$ Analog Vortex Mixer, 300-3200 rpm, 10153-838, Avantor, VWR, Radnor, PA, USA or equivalent)

- Filter units (Thermo Scientific ${ }^{\mathrm{TM}}$ Nalgene ${ }^{\mathrm{TM}}$ Rapid-Flow $^{\mathrm{TM}}$ Sterile Disposable Filter Units with $75 \mathrm{~mm}$ polyethersulfone (PES) membrane, $0.2 \mu \mathrm{m}$ pore size, 09-741-02, ThermoFisher Scientific, Waltham, MA, USA, or equivalent)

- Centrifuge for $1.5 \mathrm{~mL}$ microcentrifuge tubes (Eppendorf ${ }^{\circledR}$ Centrifuge 5430R, EP022620603, Sigma-Aldrich, St. Louis, MO, USA or equivalent)

- Tweezers (Fisherbrand ${ }^{\mathrm{TM}}$ High Precision Straight Broad Strong Point Tweezers/Forceps, 12000-128, ThermoFisher Scientific, Waltham, MA, USA, or equivalent)

- Permanent marker (Thermo Scientific ${ }^{\mathrm{TM}}$ Nalgene $^{\mathrm{TM}}$ Black Ink Lab Markers, 13-382-51, ThermoFisher Scientific, Waltham, MA, USA, or equivalent)

- $5 \mathrm{~mm}$ Thin wall precision NMR sample tube 7" L, 600MHz (535-PP-7, Wilmad-LabGlass, Vineland, NJ, USA or equivalent)

- Lyophilizer (FreeZone 2.5 Liter $-84{ }^{\circ} \mathrm{C}$ Benchtop Freeze Dryer, 7670520, Labconco, Kansas City, MO, USA or equivalent)

- Glass collection tubes, $3.5 \mathrm{~mL}$ (228-25315-91, Shimadzu, Columbia, MD, USA or equivalent)

- Glass Pasteur pipettes (Fisherbrand ${ }^{\mathrm{TM}}$ Disposable Soda-Lime Glass Pasteur Pipettes, 13-6786B, ThermoFisher Scientific, Waltham, MA, USA or equivalent)

- Pasteur pipette bulbs (Fisherbrand ${ }^{\mathrm{TM}}$ Dropper Bulbs, natural, $1 \mathrm{~mL}, 14-127-515$, ThermoFisher Scientific, Waltham, MA, USA or equivalent)

- High field nuclear magnetic resonance (NMR) spectrometer capable of performing ${ }^{1} \mathrm{H}$ and ${ }^{13} \mathrm{C}$ NMR analysis (Bruker Avance III $600 \mathrm{MHz}$, Bruker Avance DRX 500MHz, and/or Bruker Avance III 400MHz, Bruker Scientific LLC, Billerica, MA, USA or equivalent). 
- Reverse-phase high performance liquid chromatography (HPLC) system with analytical, semi-preparative, and preparative columns (degassing unit: DGU-20A 3R; pump system: LC20AP; communications bus module: CMB-20A; UV-Vis absorbance detector: SPD-M20A; fraction collector: FRC-10A; software: LabSolutions LC/GC; Shimadzu, Columbia, MD, USA or equivalent)

- Analytical HPLC column (Jupiter Proteo HPLC column, 00G-4053-B0, $250 \times 2$ mm, $5 \mu \mathrm{m}$, $300 \AA$ Å, Phenomenex, Torrance, CA, USA or equivalent)

- Semi-preparative HPLC column (Jupiter Proteo HPLC Column, 00G-4053-E0, $250 \times 4.6$ mm, $5 \mu \mathrm{m}, 300 \AA$, Phenomenex, Torrance, CA, USA or equivalent)

- Preparative HPLC column (Jupiter Proteo HPLC Column, 00G-4053-N0, $250 \times 10 \mathrm{~mm}, 5$ $\mu \mathrm{m}, 300 \AA$, Phenomenex, Torrance, CA, USA or equivalent)

- Magnetic stir bar (Z328650-10EA, Sigma-Aldrich, St. Louis, MO, USA)

- Magnetic stirrer hot plate (Z742542, Sigma-Aldrich, St. Louis, MO, USA)

- Mass spectrometer capable of performing electron-spray ionization (ESI) analysis (Agilent 6340 Ion Trap with Electron Transfer Dissociation (ETD) LC/MS system, Agilent, Santa Clara, CA, USA or equivalent)

- Single-neck $10 \mathrm{~mL}$ round-bottom flask (Z100633, Sigma-Aldrich, St Louis, MO, USA)

- Single-neck $25 \mathrm{~mL}$ round-bottom flask (Z278262, Sigma-Aldrich, St Louis, MO, USA)

- Needles (Hypodermic Needle Precision Glide ${ }^{\mathrm{TM}}$ Without Safety 26 Gauge 3/8 Inch Length, 14-826-10, ThermoFisher Scientific, Waltham, MA, USA)

- Vacuum evaporator (Biotage ${ }^{\circledR}$ V-10 Touch, V10-2XX, Biotage, Charlotte, NC, USA)

- $20 \mathrm{~mL}$ Scintillation vials (FisherBrand ${ }^{\mathrm{TM}} 20 \mathrm{~mL}$ Borosilicate Glass Scintillation Vials with White Urea Caps, 03-337-5, ThermoFisher Scientific, Waltham, MA, USA)

\section{Reagent Setup}


Chelex ${ }^{\circledR}$ ultrapure water $(1.0 \mathrm{~L})$

:CRITICAL We recommend treating all ultrapure water with Chelex ${ }^{\circledR}$ resin prior to performing radiometallations of chelator-bearing conjugates (e.g. SarAr-Tz and DOTA-PEG7-Tz) . Chelex ${ }^{\circledR}$ resin is a styrene divinylbenzene copolymer that acts as a chelating agent for polyvalent metal ions. Therefore, treating ultrapure water with the $\mathrm{Chelex}^{\circledR}$ resin will remove any metal ions that could interfere with the subsequent coordination of radiometals.

Add $5.0 \mathrm{~g}$ of $\mathrm{Chelex}^{\circledR}$ resin to $1.0 \mathrm{~L}$ of ultrapure water and stir the mixture overnight at room temperature $\left(20-25^{\circ} \mathrm{C}\right)$. Remove the resin by filtration using filter units. This water can be stored at room temperature for up to 1 year.

\section{$\underline{1 \times \text { Phosphate-buffered saline, } \mathrm{pH} 7.4 \text { buffer }(1.0 \mathrm{~L})}$}

Combine $100.0 \mathrm{~mL}$ of $10 \times$ PBS with $900.0 \mathrm{~mL}$ of ultrapure water and mix thoroughly. This buffer can be stored at room temperature for up to 1 year. If $1 \times$ PBS is used for diluting doses for mice injections, filter the solution using a sterile filter unit on the day of use.

\section{$\underline{0.25 \mathrm{M} \text { ammonium acetate buffer } \mathrm{pH} 5.5(100.0 \mathrm{~mL})}$}

Dissolve $1.927 \mathrm{~g}$ ammonium acetate in $95.0 \mathrm{~mL}$ Chelex $^{\circledR}$ ultrapure water. Adjust the $\mathrm{pH}$ to 5.5 with acetic acid $(\sim 0.65 \mathrm{~mL})$ and $\mathrm{pH}$ papers. Bring the volume to $100.0 \mathrm{~mL}$ with $\mathrm{Chelex}{ }^{\circledR}$ ultrapure water. This buffer can be stored at room temperature for up to 1 year. !CAUTION Acetic acid can cause severe skin burns and eye damage and may cause respiratory irritation if inhaled.

\section{$\underline{0.1 \mathrm{M} \mathrm{Na}} 2 \underline{\mathrm{CO}}_{3} \underline{(50.0 \mathrm{~mL})}$}

Dissolve $0.53 \mathrm{~g}$ of $\mathrm{Na}_{2} \mathrm{CO}_{3}$ in $50.0 \mathrm{~mL}$ ultrapure water. This solution can be stored at room temperature for up to 1 year. !CAUTION Sodium carbonate can cause serious eye irritation. 


\section{$\underline{25.0 \mathrm{mg} / \mathrm{mL} \text { TCO-NHS in DMSO }(1.0 \mathrm{~mL})}$}

Dissolve $25.0 \mathrm{mg}$ of TCO-NHS in $1.0 \mathrm{~mL}$ of DMSO. Mix the solution thoroughly using a vortex mixer, divide it into aliquots, and store the aliquots at $-80^{\circ} \mathrm{C}$ for up to 3 years. !CAUTION DMSO is a flammable liquid. DMSO may cause slight skin and eye irritation.

\section{$\underline{50 \mathrm{mM} \text { EDTA pH } 5.0(250.0 \mathrm{~mL})}$}

Add $5.65 \mathrm{~g}$ of EDTA to $200.0 \mathrm{~mL}$ of ultrapure water. Adjust the $\mathrm{pH}$ to 5.0 with $6.0 \mathrm{M} \mathrm{HCl}$ and pH papers. Bring the volume to $250.0 \mathrm{~mL}$ with ultrapure water. This solution can be stored at room temperature for up to 1 year. !CAUTION EDTA can cause serious eye damage and is hazardous to aquatic life. Hydrochloric acid can cause severe skin burns and eye damage and may cause respiratory irritation if inhaled.

\section{$\underline{1 \% \text { Bovine Serum Albumin in } 1 \times \text { phosphate-buffered saline }(100.0 \mathrm{~mL})}$}

Dissolve $1.0 \mathrm{~g}$ of bovine serum albumin in $100.0 \mathrm{~mL}$ of $1 \times$ PBS. Mix the solution thoroughly, divide it into aliquots, and store the aliquots at $-20{ }^{\circ} \mathrm{C}$ for up to 1 year.

HPLC eluent A $(0.1 \%$ TFA in ultrapure water, $1.0 \mathrm{~L})$

Add $1.0 \mathrm{~mL}$ of TFA to $999.0 \mathrm{~mL}$ of ultrapure water. This solvent can be stored at room temperature for up to 6 months. !CAUTION TFA is highly toxic and may cause severe skin burns, eye damage, and lung irritation. TFA should be avoided in the HPLC eluent when purifying bocprotected compounds, as it can hydrolyze the protecting group. For boc-protected compounds, use $1.0 \mathrm{~L}$ of pure $\mathrm{H}_{2} \mathrm{O}$ as eluent $\mathrm{A}$. 


\section{$\underline{\text { HPLC eluent B }(0.1 \% \text { TFA in acetonitrile, } 1.0 \mathrm{~L})}$}

Add $1.0 \mathrm{~mL}$ of TFA to $999.0 \mathrm{~mL}$ of acetonitrile. This solvent can be stored at room temperature for up to 6 months. !CAUTION Acetonitrile is a highly flammable liquid and can cause acute oral, dermal, and inhalation toxicity. TFA is highly toxic and may cause severe skin burns, eye damage, and lung irritation. TFA should be avoided in the HPLC eluent when purifying boc-protected compounds, as it can hydrolyze the protecting group. For boc-protected compounds, use 1.0 L of pure $\mathrm{MeCN}$ as eluent B.

\section{Equipment Setup}

\section{$\underline{\text { UV-Vis spectrophotometer }}$}

Turn on the instrument and replace the wiper cloth if necessary (one cloth can be used for 100 measurements). Choose the "protein quantification" parameters, with the settings set for monoclonal antibody measurements: molecular weight $=150,000 \mathrm{~g} / \mathrm{mol}$; extinction coefficient $=210,000 \mathrm{M}^{-1} \mathrm{~cm}^{-}$ ${ }^{1}$; concentration output $=\mu \mathrm{M}$. Next, add $1-3 \mu \mathrm{L}$ of $1 \times \mathrm{PBS}$ pH 7.4 to sensor using a $0.1-10 \mu \mathrm{L}$ pipette to obtain a blank measurement (repeat three times). Acquire a spectrum using $1.0 \mu \mathrm{L}$ of the antibody sample with five total replicates. The instrument will provide the absorbance value and automatically calculate the concentration of the antibody. Calculate the average of the five measurements to determine the total antibody concentration.

\section{Microcentrifuge}

Turn on the microcentrifuge and adjust the settings (temperature, speed, time) as needed. Use 1.5 $\mathrm{mL}$ microcentrifuge tubes with the lids closed tightly as well as counterbalances if necessary. 


\section{$\underline{\text { TLC chamber and plate }}$}

Add 2-3 mL of $50 \mathrm{mM}$ EDTA (pH 5) to a $50 \mathrm{~mL}$ conical centrifuge tube. Make a dot on the bottom of the iTLC plate using a pencil or permanent marker. Apply a drop $(\sim 1 \mu \mathrm{L})$ of the radioligand solution onto the mark and insert the iTLC plate into the centrifuge tube using tweezers. Wait for the solvent front to ascend the iTLC plate. When the solvent front is $1 \mathrm{~cm}$ from the top of the plate, use tweezers to remove the plate from the chamber. Dry the radio-iTLC plate in air. !CAUTION EDTA can cause serious eye damage and is hazardous to aquatic life.

\section{$\underline{\text { RadioTLC plate reader }}$}

Wrap the dried radio-iTLC plates in cellophane wrap to prevent the contamination of the instrument. Tape the iTLC plates to the plate reader and adjust the instrument markers so they line up with the iTLC plates. Turn on the P10 gas and, using the software provided, run the plate reader. Adjust the regions of interest (ROI) on the resulting chromatogram to determine the radiochemical purity of the solution.

\section{Dry block heating and cooling mixer}

Turn on the mixer and adjust the settings (i.e. RPM, temperature) as necessary. Use $1.5 \mathrm{~mL}$ microcentrifuge tubes with the lids closed tightly.

\section{Disposable PD-10 desalting columns}

Set up the PD-10 columns according to the manufacturer's instructions. Remove the cap and pour out the storage solution. Cut the sealed end of the column at the notch. Equilibrate the column with $25 \mathrm{~mL}$ of $1 \times \mathrm{PBS} \mathrm{pH} 7.4$ and discard the flow-through. The maximum sample volume for the column is $2.5 \mathrm{~mL}$. For sample volumes less than $2.5 \mathrm{~mL}$, add the sample volume and then add $1 \times \mathrm{PBS} \mathrm{pH}$ 7.4 buffer to the column after the sample has entered the packed bed completely to adjust the total 
volume up to $2.5 \mathrm{~mL}$. After allowing the sample and buffer to enter the packed bed completely, discard the flow-through. Subsequently, place a collection tube under the column, elute the column with $2.0 \mathrm{~mL} 1 \times$ PBS buffer, and collect the eluate. !CRITICAL It is critical to equilibrate the column, as UV-absorbing stabilizers are used during the packing of the column. Do not use more than $2.5 \mathrm{~mL}$ of total solution when loading the sample.

\section{Preparation of HPLC system}

Before using the HPLC system, de-gas and filter eluent A (water $+0.1 \%$ TFA) and eluent B (acetonitrile $+0.1 \%$ TFA). Wash the column with a mobile phase gradient of 95:5 to 5:95 (eluent A:eluent B) over 1 hour with a relatively low flow rate $(0.5 \mathrm{~mL} / \mathrm{min})$ before the injection of the sample. Finally, perform a purge (parameters set by manufacturer) on the HPLC lines with eluent A and eluent B before every run to ensure that no air bubbles are in the system. !CAUTION Acetonitrile is a highly flammable liquid and can cause acute oral, dermal, and inhalation toxicity. TFA is highly toxic and may cause severe skin burns, eye damage, and lung irritation.

\section{Lyophilization}

To prepare samples for lyophilization, weigh an empty container (typically a $50.0 \mathrm{~mL}$ conical centrifuge tube) with the cap on. Add the liquid samples to the container and cover again with the cap. Place the samples in a $-80{ }^{\circ} \mathrm{C}$ freezer upright for a minimum of 12 hours or expose them to liquid nitrogen for $\sim 30$ seconds. Once the samples are completely frozen, replace the original cap with a new cap that has been punctured several times with a needle. Be sure to keep the original cap for weighing the sample again after lyophilization. Wrap each container with aluminum foil if the protocol states that the samples are sensitive to light. Place them in the lyophilizer. Lyophilize the samples until all of the solvent has been removed. Replace the cap with holes with the original cap 
and re-weigh the container to determine the mass of the product. !CAUTION Take great care if handling liquid nitrogen; always use proper PPE (i.e. cryo gloves).

\section{$\underline{\text { Vacuum evaporator }}$}

To remove the solvent from a solution using a vacuum evaporator, transfer the solution to a 20.0 $\mathrm{mL}$ scintillation vial (the solution needs to occupy less than $1 / 4$ of the vial; if the volume of the solution is too great, transfer some to a separate vial or vials). Place the vial in the vacuum evaporator and adjust the parameters of the instrument according to the solvent being evaporated (refer to the manufacturer's instructions). Start the evaporation. After 30 minutes, stop the evaporation and check the progress. If the vial is completely dry, re-constitute the powder in the solvent of choice (as per the protocol). If the vial is not completely dry, repeat the evaporation for another 30 minutes. Continue this process until the vial is completely dry, and then re-constitute the powder in the solvent of choice (as per the protocol). 


\section{PROCEDURE 1 - SYNTHESIS OF TETRAZINE-BEARING PRECURSORS}

Synthesis

of

$N^{1}$-(4-(((Pivaloyloxy)amino)methyl)-benzyl)-3,6,10,13,16,19-

\section{hexaazabicyclo[6.6.6]icosane-1,8-diamine (SarAr-Bn-NHBoc) (timing 3 d)}

1. Combine $30.0 \mathrm{mg}(0.094 \mathrm{mmol})$ of diAmSar and $4.0 \mathrm{~mL}$ of anhydrous DMF in a $25.0 \mathrm{~mL}$ round-bottom flask and stir the solution vigorously with a magnetic stir bar and a magnetic stir plate. !CAUTION DMF is a highly flammable liquid and may cause serious eye and respiratory irritation.

2. Slowly add $37.0 \mathrm{mg}(0.12 \mathrm{mmol})$ of $\mathrm{N}$-boc-4-(bromomethyl)-benzylamine to the stirring slurry (add in 4 batches; $9.25 \mathrm{mg}, 9.25 \mathrm{mg}, 9.25 \mathrm{mg}, 9.25 \mathrm{mg}$ ). Between each addition, allow the solution to mix thoroughly. Continue stirring for $\sim 1-2$ minutes until the white solid has completely dissolved. !CAUTION $N$-boc-4-(bromomethyl)-benzylamine has acute oral toxicity and is potentially irritating to the skin. ?TROUBLESHOOTING

3. Add $34.0 \mathrm{mg}(0.32 \mathrm{mmol})$ of $\mathrm{Na}_{2} \mathrm{CO}_{3}$ to the mixture and continue to stir vigorously. !CAUTION Sodium carbonate can cause serious eye irritation.

4. Heat the slurry to $70{ }^{\circ} \mathrm{C}$ and continue stirring for 16 hours at $70{ }^{\circ} \mathrm{C}$. Over the course of the heating, the solution will slowly change from colorless to pale yellow.

5. After 16 hours, take a small aliquot from the reaction mixture, perform a 2-fold dilution with acetonitrile, and check the reaction via semi-preparative HPLC with a mobile phase gradient of 95:5 to 20:80 (water:acetonitrile) over 30 minutes with a flow rate of $2 \mathrm{~mL} / \mathrm{min}\left(t_{\mathrm{R}, \text { product }}=\right.$ $\sim 16$ minutes; potential impurities: $\left.t_{\mathrm{R}, \mathrm{bocNH}-\mathrm{Bn}-\mathrm{SarAr}-\mathrm{Bn}-\mathrm{NHBoc}}=\sim 17 \mathrm{~min}\right)$. If the reaction is not complete, allow the solution to incubate longer. !CRITICAL STEP Keep the reaction mixture away from heat, moisture, and light to prevent the degradation of the product. We recommend first diluting the reaction solution in water or acetonitrile prior to running the HPLC in order to prevent precipitation in the lines. We recommend using solvents without $0.1 \%$ TFA when purifying boc-protected compounds. 
6. Once the reaction is deemed complete, stop heating the solution. Dilute the reaction solution up to $6.0 \mathrm{~mL}$ with ultrapure water and aliquot $1000 \mu \mathrm{L}$ of the reaction mixture into $6 \times 1.5$ $\mathrm{mL}$ microcentrifuge tubes. If HPLC purification cannot be performed immediately following the reaction, we recommend separating the sample into $200 \mu \mathrm{L}$ aliquots in $1.5 \mathrm{~mL}$ microcentrifuge tubes and storing the crude product at $-80{ }^{\circ} \mathrm{C}$ until purification. PAUSE POINT The crude SarAr-Bn-NHBoc can be stored at $-80{ }^{\circ} \mathrm{C}$ for at least one month.

7. Purify the samples via semi-preparative HPLC with a mobile phase gradient of $95: 5$ to $20: 80$ (water:acetonitrile) over 30 minutes with a flow rate of $2 \mathrm{~mL} / \mathrm{min}\left(t_{\mathrm{R}, \text { product }}=\sim 16\right.$ minutes, potential impurities: $\left.t_{\mathrm{R}, \text { bocNH-Bn-SarAr-Bn-NHBoc }}=\sim 17 \mathrm{~min}\right)$. Collect the fractions $(\sim 3 \mathrm{~mL}$ per fraction, from 15.5-16.5 min, in a total of 1-2 fractions per run) in $3.5 \mathrm{~mL}$ glass collection tubes and combine them in a $50 \mathrm{~mL}$ conical centrifuge tube. !CAUTION Acetonitrile is a highly flammable liquid and can cause acute oral, dermal, and inhalation toxicity.

!CRITICAL STEP We recommend using solvents without the $0.1 \%$ TFA additive when purifying the boc-protected compound. ?TROUBLESHOOTING

8. Lyophilize the HPLC eluant to yield SarAr-Bn-NHBoc as a white powder (typical results: 35 mg, 0.065 mmol, 65-75\% yield) PAUSE POINT The purified SarAr-Bn-NHBoc can be stored as a solid at $4{ }^{\circ} \mathrm{C}$ for at least one year. ?TROUBLESHOOTING

9. Confirm the identity of the product with ESI-MS and ${ }^{1} \mathrm{H}-\mathrm{NMR}$.

\section{Synthesis of $\quad N^{1}$-(4-(aminomethyl)benzyl)-3,6,10,13,16,19-hexaazabicyclo[6.6.6]icosane-1,8-} diamine (SarAr-Bn-NH2) (timing $\sim 2$ d)

10. Combine $31.0 \mathrm{mg}(0.058 \mathrm{mmol})$ of SarAr-Bn-NHBoc and $2.0 \mathrm{~mL}$ of acetonitrile in a $10.0 \mathrm{~mL}$ round-bottom flask and stir vigorously with a magnetic stir bar and a magnetic stir plate. !CAUTION Acetonitrile is a highly flammable liquid and can cause acute oral, dermal, and inhalation toxicity. 
11. Place the setup in a water bath. Using a glass pipette, add $2.0 \mathrm{~mL}$ TFA dropwise to the vigorously stirring slurry. !CAUTION TFA is highly toxic and may cause severe skin burns, eye damage, and lung irritation. !CRITICAL STEP The reaction is exothermic and therefore must be performed in a water bath.

12. Continue stirring for 90 minutes at room temperature $\left(20-25^{\circ} \mathrm{C}\right)$.

13. Take a small aliquot from the reaction mixture $(\sim 20 \mu \mathrm{L})$, and check the reaction via HPLC with a mobile phase gradient of 95:5 to 20:80 (eluent A:eluent B) over 20 minutes with a flow rate of $6 \mathrm{~mL} / \mathrm{min}\left(t_{\mathrm{R}, \text { product }}=\sim 7\right.$ minutes; no major impurities observed $)$. If the reaction is deemed complete, continue with HPLC purification. If the purification cannot be performed immediately following the reaction, we recommend separating the sample into $200 \mu \mathrm{L}$ aliquots in $1.5 \mathrm{~mL}$ microcentrifuge tubes and storing the crude product at $-80{ }^{\circ} \mathrm{C}$ until purification. PAUSE POINT The crude SarAr-Bn-NH 2 can be stored at $-80{ }^{\circ} \mathrm{C}$ for at least one month. !CRITICAL STEP Keep the reaction mixture away from heat, moisture, and light to prevent the degradation of the product.

14. Remove the solvent completely via vacuum evaporation (as described in the Equipment Setup) to provide crude SarAr-Bn- $\mathrm{NH}_{2}$ as a yellow/brown oil.

15. Dissolve the product in $1.0 \mathrm{~mL}$ DMSO and $1.0 \mathrm{~mL}$ acetonitrile. !CAUTION DMSO is a flammable liquid. DMSO may cause slight skin and eye irritation. !CRITICAL STEP Keep the reaction mixture away from heat, moisture, and light to prevent the degradation of the product.

16. Purify the samples via preparative HPLC with a mobile phase gradient of $95: 5$ to $20: 80$ (eluent A:eluent B) over 20 minutes with a flow rate of $6 \mathrm{~mL} / \mathrm{min}\left(t_{\mathrm{R}, \text { product }}=\sim 7\right.$ minutes; no major impurities observed). Collect the purified fractions $(\sim 3 \mathrm{~mL}$ per fraction, from $6.5-7.5 \mathrm{~min}$, in a total of 2-3 fractions per run) in $3.5 \mathrm{~mL}$ glass collection tubes, and combine them in a 50 $\mathrm{mL}$ conical centrifuge tube. !CAUTION Acetonitrile is a highly flammable liquid and can 
cause acute oral, dermal, and inhalation toxicity. TFA is highly toxic and may cause severe skin burns, eye damage, and lung irritation. ?TROUBLESHOOTING

17. Lyophilize the HPLC eluant to yield SarAr-Bn-NH 2 as a white powder (typical results: 26 mg, 0.059 mmol, quantitative yield). PAUSE POINT The purified SarAr-Bn-NH${ }_{2}$ can be stored as a solid at $4{ }^{\circ} \mathrm{C}$ for at least one year. ?TROUBLESHOOTING

18. Confirm the identity of the product with ESI-MS and ${ }^{1} \mathrm{H}-\mathrm{NMR}$.

Synthesis $\quad$ of $\quad N^{1}-(4-(1,2,4,5-T e t r a z i n-3-y l) b e n z y l)-N^{5}-(4-((8-a m i n o-3,6,10,13,16,19-$ hexaazabicyclo[6.6.6]icosan-1-yl)amino)methyl)benzyl)glutaramide (SarAr-Tz) (timing 2 d)

19. Combine $5.0 \mathrm{mg}(0.013 \mathrm{mmol})$ of Tz-NHS and $400 \mu \mathrm{L}$ of anhydrous DMF in a $1.5 \mathrm{~mL}$ microcentrifuge tube and mix the solution thoroughly. !CAUTION Tz-NHS has acute oral and dermal toxicity. DMF is a highly flammable liquid and may cause serious eye and respiratory irritation. !CRITICAL STEP Tz-NHS is light sensitive; protect the reaction mixture from light. Our laboratory uses aluminum foil to cover the reaction vessel.

20. In a separate $1.5 \mathrm{~mL}$ microcentrifuge tube, combine $5.4 \mathrm{mg}(0.013 \mathrm{mmol})$ of SarAr-Bn-NH and $200 \mu \mathrm{L}$ of anhydrous DMF and agitate the solution at $500 \mathrm{rpm}$ on a dry block heating mixer at room temperature for 1-2 minutes. !CAUTION DMF is a highly flammable liquid and may cause serious eye and respiratory irritation.

21. Transfer the Tz-NHS solution into the stirring slurry of SarAr-Bn-NH 2 .

22. Add $2.79 \mu \mathrm{L}(0.020 \mathrm{mmol})$ of TEA to the stirring slurry. Continue stirring the solution for 2 hours at room temperature. !CAUTION TEA is a highly flammable liquid and has high oral, dermal, and respiratory toxicity. ?TROUBLESHOOTING

23. Take a small aliquot from the reaction mixture $(\sim 20 \mu \mathrm{L})$, perform a 2-fold dilution of the sample mixture with acetonitrile, and check the reaction via semi-preparative HPLC with a mobile phase gradient of 95:5 to 20:80 (eluent A:eluent B) over 15 minutes with a flow rate 
of $2 \mathrm{~mL} / \mathrm{min}\left(t_{\mathrm{R}, \text { product }}=9.5\right.$ minutes; no major impurities observed $)$. If the reaction is not complete, allow solution to incubate longer. !CRITICAL STEP Keep the reaction mixture away from heat, moisture, and light to prevent the degradation of the product. We recommend first diluting the reaction solution in water or acetonitrile prior to running the HPLC in order to prevent precipitation in the lines.

24. Once the reaction is complete, perform a 2-fold dilution of the reaction mixture with acetonitrile and continue with the HPLC purification. If the purification cannot be performed immediately following the reaction, we recommend separating the sample into $200 \mu \mathrm{L}$ aliquots in $1.5 \mathrm{~mL}$ microcentrifuge tubes and storing the crude product at $-80{ }^{\circ} \mathrm{C}$ until purification. !CRITICAL STEP Keep the reaction mixture away from heat, moisture, and light to prevent the degradation of the product. We recommend first diluting the reaction solution in water or acetonitrile prior to running HPLC in order to prevent precipitation in the lines. PAUSE POINT Crude SarAr-Tz can be stored at $-80{ }^{\circ} \mathrm{C}$ for at least one month.

25. Purify the samples via semi-preparative tive HPLC with a mobile phase gradient of 95:5 to 20:80 (eluent A:eluent B) over 15 minutes with a flow rate of $2 \mathrm{~mL} / \mathrm{min}\left(t_{\mathrm{R}, \text { product }}=9.5\right.$ minutes; no major impurities observed $)$. Collect the purified fractions $(\sim 3 \mathrm{~mL}$ per fraction, from 9.0-10.0 $\mathrm{min}$, in a total of 1-2 fractions per run) in $3.5 \mathrm{~mL}$ glass collection tubes, and then combine them in a $50 \mathrm{~mL}$ conical centrifuge tube. !CAUTION Acetonitrile is a highly flammable liquid and can cause acute oral, dermal, and inhalation toxicity. TFA is highly toxic and may cause severe skin burns, eye damage, and lung irritation. ?TROUBLESHOOTING

26. Cover the $50.0 \mathrm{~mL}$ conical centrifuge tube with aluminum foil to protect samples from light.

27. Lyophilize the HPLC eluant to yield SarAr-Tz as a pink powder (typical results: $3.9 \mathrm{mg}$, 0.0054 mmol, 40-45\% yield). PAUSE POINT The purified SarAr-Tz can be stored as a solid at $-80^{\circ} \mathrm{C}$ for 1 year. ?TROUBLESHOOTING 
28. Confirm the identity of the product with ESI-MS and ${ }^{1} \mathrm{H}-\mathrm{NMR}$.

\section{Synthesis of Tz-PEG $7-N H B o c$ (timing $\sim 1$ day)}

29. Dissolve $10.0 \mathrm{mg}(0.025 \mathrm{mmol})$ of Tz-NHS in $400 \mu \mathrm{L}$ of DMSO in $1.5 \mathrm{~mL}$ microcentrifuge tube. Mix the solution thoroughly. !CAUTION DMSO is a flammable liquid. DMSO may cause slight skin and eye irritation. Tz-NHS has acute oral and dermal toxicity. !CRITICAL STEP Tz-NHS is light sensitive; protect the reaction mixture from light. Our lab uses aluminum foil to cover the reaction vessel.

30. Add $15.0 \mathrm{mg}$ of Boc- $\mathrm{PEG}_{7}-\mathrm{NH}_{2}(0.032 \mathrm{mmol} ; 1.3 \mathrm{eq})$ to the solution and mix well.

31. Add $10.0 \mu \mathrm{L}$ of TEA $(7.2 \mathrm{mg} ; 0.072 \mathrm{mmol})$ to the solution and place mixture on a dry block heating mixer at $300 \mathrm{rpm}$ at $25^{\circ} \mathrm{C}$ for 30 minutes. !CAUTION TEA is a highly flammable liquid and has high oral, dermal, and respiratory toxicity. ?TROUBLESHOOTING

32. Take a small aliquot from the reaction mixture $(\sim 20 \mu \mathrm{L})$, perform a 2-fold dilution of the sample mixture with acetonitrile, and check the reaction progress via semi-preparative HPLC with a mobile phase gradient of 95:5 to 5:95 (water:acetonitrile) over 30 minutes with a flow rate of $2 \mathrm{~mL} / \mathrm{min}\left(t_{\mathrm{R}, \text { product }}=\sim 22\right.$ minutes; potential impurities: $t_{\mathrm{R}, \mathrm{Tz}-\mathrm{NHS}}=\sim 19$ minutes, $t_{\mathrm{R}, \mathrm{boc}-}$ PEG7-NH2 $=\sim 21$ minutes). !CRITICAL STEP Keep the reaction mixture away from heat, moisture, and light to prevent the degradation of the product. We recommend first diluting the reaction solution in water or acetonitrile prior to running the HPLC in order to prevent precipitation in the lines. We recommend using solvents without $0.1 \%$ TFA when purifying boc-protected compounds.

33. Once the reaction is complete, perform a 2-fold dilution of the reaction mixture with acetonitrile and continue with HPLC purification. If the purification is unable to be performed immediately following the reaction, we recommend separating the sample into $200 \mu \mathrm{L}$ aliquots in $1.5 \mathrm{~mL}$ microcentrifuge tubes and storing the crude product at $-80{ }^{\circ} \mathrm{C}$ until 
purification. !CRITICAL STEP Keep the reaction mixture away from heat, moisture, and light to prevent the degradation of the product. We recommend first diluting the reaction solution in water or acetonitrile prior to running the HPLC in order to prevent precipitation in the lines. We recommend using solvents without $0.1 \%$ TFA when purifying boc-protected compounds. PAUSE POINT Crude Tz-PEG $7-\mathrm{NHBoc}$ can be stored at $-80{ }^{\circ} \mathrm{C}$ for at least one week.

34. Purify the samples via semi-preparative HPLC with a mobile phase gradient of 95:5 to 5:95 (water:acetonitrile) over 30 minutes with a flow rate of $2 \mathrm{~mL} / \mathrm{min}\left(t_{\mathrm{R}, \text { product }}=\sim 22\right.$ minutes; potential impurities: $t_{\mathrm{R}, \mathrm{Tz}-\mathrm{NHS}}=\sim 19$ minutes, $t_{\mathrm{R} \text {,boc-PEG7-NH2 }}=\sim 21$ minutes). Collect the purified fractions ( $\sim 3 \mathrm{~mL}$ per fraction, from $20.5-21.5 \mathrm{~min}$, in a total of 1-2 fractions per run) in 3.5 $\mathrm{mL}$ glass collection tubes and then combine them in a $50 \mathrm{~mL}$ conical centrifuge tube. !CAUTION Acetonitrile is a highly flammable liquid and can cause acute oral, dermal, and inhalation toxicity. !CRITICAL STEP We recommend using solvents without the $0.1 \%$ TFA additive when purifying the boc-protected compound. ?TROUBLESHOOTING

35. Lyophilize the HPLC eluant to yield $\mathrm{Tz}_{2}-\mathrm{PEG}_{7}-\mathrm{NHBoc}$ as a bright pink powder (typical results: $16 \mathrm{mg}, 0.021 \mathrm{mmol}, 80-90 \%$ yield). PAUSE POINT The purified Tz-PEG 7 -NHBoc can be stored as a solid at $-20{ }^{\circ} \mathrm{C}$ for up to 6 months. ?TROUBLESHOOTING

36. Confirm the identity of the product with ESI-MS and ${ }^{1} \mathrm{H}-\mathrm{NMR}$.

\section{Synthesis of Tz-PEG $-\mathrm{NH}_{2}$ (timing $\sim 1$ day)}

37. In a $1.5 \mathrm{~mL}$ microcentrifuge tube, dissolve $10.0 \mathrm{mg}(0.014 \mathrm{mmol})$ of $\mathrm{Tz}-\mathrm{PEG}_{7}-\mathrm{NHBoc}$ in $400.0 \mu \mathrm{L}$ of $1: 1$, DCM:TFA and mix the solution thoroughly. !CAUTION TFA is highly toxic and may cause severe skin burns, eye damage, and lung irritation. DCM can cause skin irritation, eye irritation, drowsiness, and dizziness. DCM is also a suspected carcinogen.

38. Place the solution on a dry block heating mixer and agitate at $300 \mathrm{rpm}$ at $25^{\circ} \mathrm{C}$ for 30 minutes. 
39. Remove the solvent completely via vacuum evaporation (as described in the Equipment Setup) and reconstitute the residue in $0.5 \mathrm{~mL}$ ultrapure $\mathrm{H}_{2} \mathrm{O}$.

40. Take a small aliquot from the reaction mixture $(\sim 20 \mu \mathrm{L})$ and check the reaction progress via analytical HPLC with a mobile phase gradient of 95:5 to 5:95 (eluent A:eluent B) over 30 minutes with a flow rate of $1 \mathrm{~mL} / \mathrm{min}\left(t_{\mathrm{R}, \text { product }}=\sim 13\right.$ minutes; no major impurities observed $)$. If the reaction is deemed to be complete, filter the rest of the reaction mixture and continue on with HPLC purification. If the reaction is not complete, repeat steps $37-39$. If the purification is unable to be performed immediately following the reaction, we recommend separating the sample into $200 \mu \mathrm{L}$ aliquots in $1.5 \mathrm{~mL}$ microcentrifuge tubes and storing the crude product at $-80{ }^{\circ} \mathrm{C}$ until purification. PAUSE POINT The crude Tz-PEG $7-\mathrm{NH}_{2}$ can be stored at $-80^{\circ} \mathrm{C}$ for at least one month.

41. Purify the samples via preparative HPLC with a mobile phase gradient of 95:5 to 5:95 (eluent A:eluent B) over 30 minutes with a flow rate of $8 \mathrm{~mL} / \mathrm{min}\left(t_{\mathrm{R} \text {,product }}=\sim 15\right.$ minutes; no major impurities observed). Collect the purified fractions ( $\sim 3 \mathrm{~mL}$ per fraction, $14.5-15.5 \mathrm{~min}$, in a total of 3-4 fractions per run) in $3.5 \mathrm{~mL}$ glass collection tubes and combine them in a $50 \mathrm{~mL}$ conical centrifuge tube. !CAUTION Acetonitrile is a highly flammable liquid and can cause acute oral, dermal, and inhalation toxicity. TFA is highly toxic and may cause severe skin burns, eye damage, and lung irritation. ?TROUBLESHOOTING

42. Lyophilize the HPLC eluant to yield $\mathrm{Tz}-\mathrm{PEG}_{7}-\mathrm{NH}_{2}$ as a bright pink powder (typical results: $9 \mathrm{mg}, 0.013 \mathrm{mmol}$, 90-95\% yield). PAUSE POINT The purified Tz-PEG7-NH 2 can be stored as a solid at $-20^{\circ} \mathrm{C}$ for up to 6 months. ?TROUBLESHOOTING

43. Confirm the identity of the product with ESI-MS and ${ }^{1} \mathrm{H}-\mathrm{NMR}$ analysis.

\section{Synthesis of DOTA-PEG $7-T z$ (timing $\sim 1$ day)}


44. In a $1.5 \mathrm{~mL}$ microcentrifuge tube, dissolve $11.5 \mathrm{mg}(0.0176 \mathrm{mmol})$ of $\mathrm{Tz}-\mathrm{PEG}_{7}-\mathrm{NH}_{2}$ in 400 $\mu \mathrm{L}$ of DMSO. !CAUTION DMSO is a flammable liquid. DMSO may cause slight skin and eye irritation.

45. Add $14.8 \mathrm{mg}$ of $p$-SCN-Bn-DOTA $(0.0022 \mathrm{mmol} ; 1.2$ eq. $)$ to the solution and mix well.

46. Add $20.0 \mu \mathrm{L}$ of TEA $(14.8 \mathrm{mg} ; 0.15 \mathrm{mmol})$ to the solution and mix well. !CAUTION TEA is a highly flammable liquid and has high oral, dermal, and respiratory toxicity.

47. Place the solution on a dry block heating mixer and agitate at $300 \mathrm{rpm}$ at $25^{\circ} \mathrm{C}$ for 60 minutes. ?TROUBLESHOOTING

48. Take a small aliquot from the reaction mixture $(\sim 20 \mu \mathrm{L})$, perform a 2-fold dilution of the sample mixture with acetonitrile, and check the reaction progress via semi-preparative HPLC with a mobile phase gradient of 95:5 to 5:95 (eluent A:eluent B) over 30 minutes with a flow rate of $2 \mathrm{~mL} / \mathrm{min}\left(t_{\mathrm{R}, \text { product }}=\sim 18\right.$ minutes; potential impurities: $t_{\mathrm{R}, \mathrm{p}-\mathrm{SCN}-\mathrm{Bn}-\mathrm{DOTA}}=\sim 21$ minutes, and $t_{\mathrm{R}, \mathrm{Tz}-\mathrm{PEG} 7-\mathrm{NH} 2}=\sim 15$ minutes). If the reaction is not complete, allow the solution to incubate longer. !CRITICAL STEP Keep the reaction mixture away from heat, moisture, and light to prevent the degradation of the product. We recommend first diluting the reaction solution in water or acetonitrile prior to running the HPLC in order to prevent precipitation in the lines.

49. Once the reaction is complete, perform a 2-fold dilution of the sample mixture with acetonitrile and continue with the HPLC purification. If the purification is unable to be performed immediately following the reaction, we recommend separating the sample into 200 $\mu \mathrm{L}$ aliquots in $1.5 \mathrm{~mL}$ microcentrifuge tubes and storing the crude product at $-80{ }^{\circ} \mathrm{C}$ until purification. !CRITICAL STEP Keep the reaction mixture away from heat, moisture, and light to prevent the degradation of the product. We recommend first diluting the reaction solution in water or acetonitrile prior to running the HPLC in order to prevent precipitation in the lines. PAUSE POINT Crude DOTA-PEG7-Tz can be stored at $-80{ }^{\circ} \mathrm{C}$ for at least one month. 
50. Purify the samples via semi-preparative HPLC with a mobile phase gradient of 95:5 to 5:95 (eluent A:eluent B) over 30 minutes with a flow rate of $2 \mathrm{~mL} / \mathrm{min}\left(t_{\mathrm{R}, \text { product }}=\sim 18\right.$ minutes; potential impurities: $t_{\mathrm{R}, \mathrm{p}-\mathrm{SCN}-\mathrm{Bn}-\mathrm{DOTA}}=\sim 21$ minutes, and $t_{\mathrm{R}, \mathrm{Tz}-\mathrm{PEG} 7-\mathrm{NH} 2}=\sim 15$ minutes). Collect the purified fractions ( $\sim 3 \mathrm{~mL}$ per fraction, $15.5-16.5 \mathrm{~min}$, in a total of 1-2 fractions per run) in $3.5 \mathrm{~mL}$ glass collection tubes and combine them in a $50 \mathrm{~mL}$ conical centrifuge tube. !CAUTION Acetonitrile is a highly flammable liquid and can cause acute oral, dermal, and inhalation toxicity. TFA is highly toxic and may cause severe skin burns, eye damage, and lung irritation. ?TROUBLESHOOTING

51. Lyophilize the HPLC eluant to yield DOTA-PEG7-Tz as a bright pink powder (typical results: $15.4 \mathrm{mg}, 0.0128 \mathrm{mmol}, 70-75 \%$ yield). PAUSE POINT The purified DOTA-PEG - Tz can be stored as a solid at $-20{ }^{\circ} \mathrm{C}$ for up to 6 months. ?TROUBLESHOOTING

52. Confirm the identity of the product with ESI-MS and ${ }^{1} \mathrm{H}-\mathrm{NMR}$. 


\section{PRETARGETING EXPERIMENTS}

:CAUTION All hazardous chemicals should be used by trained personnel using protocols approved by an environmental health and safety officer. Only personnel who have received proper radiation safety training should perform the parts of this protocol that involve radioactivity. Furthermore, these experiments must only be performed in authorized and regulated laboratory spaces that that have been approved for work with radioactivity. Finally, survey meters, dosimeters, adequate shielding, and proper PPE must be used at all times.

!CAUTION Only personnel who have received thorough training in the use of mice for preclinical in vivo experimentation should perform the parts of the protocol that involve mice. Regulated and well-staffed animal facilities are required for all animal experiments, and all in vivo procedures must be performed according to institutional, state, and federal guidelines. Again, proper PPE must be used at all times during in vivo experimentation.

\section{Preparation and purification of huA33-TCO (timing $\sim 3 \mathrm{~h}$ )}

1. Take the vial containing the manufacturer-supplied solution of huA33 antibody $(1.0 \mathrm{~mL})$ from the freezer and let it thaw slowly to room temperature $\left(20-25^{\circ} \mathrm{C}\right)$.

2. Measure the concentration of this solution with a UV-Vis spectrophotometer (for the sake of this protocol, the concentration of our $1.0 \mathrm{~mL}$ antibody solution was $9.8 \mathrm{mg} / \mathrm{mL}$ ).

\section{Preparation of the antibody, huA33}

$<$ CRITICAL $>$ Purify and concentrate the huA33 using a PD-10 desalting column and an Amicon ${ }^{\circledR}$ Ultra-4 centrifugal filter. 
3. Equilibrate three PD-10 desalting columns (see Equipment Setup).

4. Add one third of the $1.0 \mathrm{~mL}$ sample $(0.33 \mathrm{~mL})$ to each PD-10 desalting column and allow the solution to enter the packed bed completely.

5. Discard the flow-through.

6. Add $2.17 \mathrm{~mL}$ of $1 \times$ PBS $\mathrm{pH} 7.4$ to each column and allow the solution to enter the packed bed completely.

7. Discard the flow-through.

8. Elute each column using $2.0 \mathrm{~mL}$ of $1 \times$ PBS $\mathrm{pH} 7.4$ into an Amicon ${ }^{\circledR}$ Ultra-4 centrifugal filter (three centrifugal filters in total).

9. Centrifuge the Amicon ${ }^{\circledR}$ Ultra-4 centrifugal filters at $3500 \mathrm{~g}$ for $15 \mathrm{~min}$ and discard the flow-through.

10. Combine the solutions from the three Amicon ${ }^{\circledR}$ Ultra- 4 centrifugal filters $(3 \times \sim 0.2$ $\mathrm{mL}$ after centrifugation) into a microcentrifuge tube. Wash out each Amicon ${ }^{\circledR}$ Ultra-4 centrifugal filter using the same $0.2 \mathrm{~mL}$ of $1 \times \mathrm{PBS}$ pH 7.4 and combine this with the antibody solution in the microcentrifuge tube, bringing the total volume up to $\sim 0.8$ mL. ?TROUBLESHOOTING

11. Mix this solution gently using a vortex mixer on a low setting.

12. Measure the concentration of the purified huA33 solution using a UV-Vis spectrophotometer (in this case, the $0.8 \mathrm{~mL}$ solution had a concentration of 11 $\mathrm{mg} / \mathrm{mL}$ ). PAUSE POINT You can prepare aliquots of purified huA33 and store them at $-80{ }^{\circ} \mathrm{C}$ for up to five years. ?TROUBLESHOOTING

\section{Reaction with TCO-NHS}


13. Adjust the $\mathrm{pH}$ of the huA33 solution $(8.8 \mathrm{mg}, 58.7 \mathrm{nmol}$, in $0.8 \mathrm{~mL} 1 \times \mathrm{PBS} \mathrm{pH} 7.4)$ to 8.8 9.0 using $0.1 \mathrm{M} \mathrm{Na}_{2} \mathrm{CO}_{3}(\sim 0.04 \mathrm{~mL})$ and $\mathrm{pH}$ paper. !CAUTION Sodium carbonate can cause serious eye irritation.

14. Slowly add $25.0 \mu \mathrm{L}$ of TCO-NHS in DMSO $(25 \mathrm{mg} / \mathrm{mL}, 40$ molar equivalents $)$ to the huA33 solution. !CAUTION DMSO is a flammable liquid and may cause slight skin and eye irritation. !CRITICAL STEP We recommend using a reaction stoichiometry of 40:1 (TCONHS:huA33). To avoid precipitation, add the TCO-NHS slowly by gently swirling the pipette tip in the mixture while continuously pushing more TCO-NHS into the mixture at a rate of about $2 \mu \mathrm{L} / \mathrm{s}$.

15. Incubate the reaction mixture on an agitating dry block heating mixer for 1 hour at $25{ }^{\circ} \mathrm{C}$ at $500 \mathrm{rpm}$.

\section{huA33-TCO Purification}

$<$ CRITICAL $>$ Purify and concentrate the huA33-TCO using a PD-10 desalting column as well as an Amicon ${ }^{\circledR}$ Ultra-4 centrifugal filter.

16. Equilibrate two PD-10 desalting columns (see Equipment Setup).

17. Add half of the sample ( $\sim 0.6 \mathrm{~mL})$ to each PD-10 desalting column and allow the solution to enter the packed bed completely.

18. Discard the flow-through.

19. Add $1.9 \mathrm{~mL}$ of $1 \times \mathrm{PBS} \mathrm{pH} 7.4$ to each column and allow the solution to enter the packed bed completely.

20. Discard the flow-through.

21. Elute each column using $2.0 \mathrm{~mL}$ of $1 \times \mathrm{PBS}$ pH 7.4 into an Amicon ${ }^{\circledR}$ Ultra-4 centrifugal filter (two centrifugal filters in total). 
22. Centrifuge the Amicon ${ }^{\circledR}$ Ultra-4 centrifugal filters at $3500 \mathrm{~g}$ for $15 \mathrm{~min}$ and discard the flowthrough.

23. Combine the solutions from the two Amicon ${ }^{\circledR}$ Ultra- 4 centrifugal filters $(2 \times \sim 0.2 \mathrm{~mL}$ after centrifugation) into a $1.5 \mathrm{~mL}$ microcentrifuge tube. Wash out each Amicon ${ }^{\circledR}$ Ultra-4 centrifugal filter using the same $0.2 \mathrm{~mL}$ of $1 \times \mathrm{PBS} \mathrm{pH} 7.4$ and combine this with the antibody solution in the microcentrifuge tube, bringing the total volume up to $\sim 0.6 \mathrm{~mL}$. ?TROUBLESHOOTING

24. Mix this solution gently using a vortex mixer on a low setting.

25. Measure the concentration of the purified huA33-TCO solution using a UV-Vis spectrophotometer (in this case, the $0.6 \mathrm{~mL}$ solution had a concentration of $13.3 \mathrm{mg} / \mathrm{mL}$ ). PAUSE POINT Aliquots of purified huA33-TCO can be stored at $-80^{\circ} \mathrm{C}$ for up to two years. ?TROUBLESHOOTING

26. Determine the TCO occupancy of huA33-TCO using Tz-PEG7-AF680 (Box 1). ?TROUBLESHOOTING

27. Alternatively, determine the TCO occupancy of huA33-TCO by performing MALDITOF mass spectrometry on both the native antibody and the TCO-modified immunoconjugate. Use the following equation to determine the degree of labeling (DOL).

(mass of modified antibody - mass of native antibody)
mass of modification
$=$ number of TCO per antibody on average

?TROUBLESHOOTING

Radiolabeling of Tetrazine-Bearing Radioligands

CRITICAL If you want to perform pretargeted PET imaging, continue with step 28. If you want to perform pretargeted radioimmunotherapy, skip to step 39. 


\section{Radiolabeling of SarAr-Tz with $\left[{ }^{64} \mathrm{Cu}\right] \mathrm{CuCl}_{2}$ (timing $\left.\sim 1 \mathrm{~h}\right)$}

$<$ CRITICAL> If the $\beta$-emitting therapeutic isotope ${ }^{67} \mathrm{Cu}$ is available, these procedures can also be used to synthesize a therapeutic radioligand $-\left[{ }^{67} \mathrm{Cu}\right] \mathrm{Cu}$-SarAr-Tz - that can be used in lieu of $\left[{ }^{177} L u\right] L u-P E G_{7}-D O T A-T z$ and thus enable the creation of an identical theranostic pair of radioligands: $\left[{ }^{64} \mathrm{Cu}\right] \mathrm{Cu}$-SarAr-Tz for pretargeted PET and $\left[{ }^{67} \mathrm{Cu}\right] \mathrm{Cu}$-SarAr-Tz for pretargeted radioimmunotherapy.

!CAUTION Copper-64 represents a radiological hazard and must be used according to institutional, state, and federal regulations as well as ALARA (as low as reasonably achievable) principles. Proper shielding during the handling of all radioactive reagents, mixtures, glassware, and instruments is essential. Furthermore, it is critical that appropriate personal protective equipment, dosimeters, and survey meters are always used when handling radioactive material.

28. Dilute $36.0 \mu \mathrm{L}$ of the SarAr-Tz stock solution $(12.9 \mu \mathrm{g}, 18 \mathrm{nmol}, 0.36 \mathrm{mg} / \mathrm{mL}$ in DMSO, see Procedure 1) with $200.0 \mu \mathrm{L}$ of $\mathrm{NH}_{4} \mathrm{Oac}$ buffer (0.25 M, pH 5.5). !CAUTION DMSO is a flammable liquid. DMSO may cause slight skin and eye irritation.

29. Add $380 \mathrm{MBq}(10.3 \mathrm{mCi})$ of $\left[{ }^{64} \mathrm{Cu}\right] \mathrm{CuCl}_{2}$ in $0.05 \mathrm{M} \mathrm{HCl}$ to the reaction solution. !CAUTION Hydrochloric acid can cause severe skin burns and eye damage and may cause respiratory irritation if inhaled. !CRITICAL STEP For the in vivo pretargeting experiments, we recommend administering a 1:1 ratio of $\left[{ }^{64} \mathrm{Cu}\right] \mathrm{Cu}-\mathrm{SarAr}-\mathrm{Tz}$ :huA33-TCO. For example, using the amounts listed in steps $37-38$, a $14.8 \mathrm{MBq}(0.4 \mathrm{mCi})$ dose of $\left[{ }^{64} \mathrm{Cu}\right] \mathrm{Cu}-\mathrm{SarAr}-\mathrm{Tz}$ will give each mouse $0.7 \mathrm{nmol}$ (equivalent to the $0.7 \mathrm{nmol}$ dose of huA33-TCO each mouse will receive). If a higher radioactivity dose per mouse is desired (while maintaining a 1:1 molar ratio of the two components), we recommend increasing the activity of $\left[{ }^{64} \mathrm{Cu}\right] \mathrm{CuCl}_{2}$ used in step 29 and keeping the amount of tetrazine precursor the same. 
30. Incubate the reaction mixture on an agitating dry block heating mixer at $500 \mathrm{rpm}$ at $37^{\circ} \mathrm{C}$ for 15 minutes.

\section{Radio-iTLC to Determine the Progress of $\left[{ }^{64} \mathrm{Cu}\right] \mathrm{Cu}-\mathrm{SarAr-Tz}$ Radiolabeling}

31. Apply a small droplet $(1 \mu \mathrm{L})$ of the reaction mixture at the baseline of the iTLC plate.

32. Insert the iTLC plate into a TLC chamber containing $50 \mathrm{mM}$ EDTA ( $\mathrm{pH} 5.0$ ). !CAUTION EDTA can cause serious eye damage and is hazardous to aquatic life.

33. Allow the solvent front to reach $\sim 1 \mathrm{~cm}$ from the top of the iTLC plate and then remove the plate from the chamber.

34. Dry the iTLC plate in air.

35. Wrap the iTLC plate in cellophane wrap to prevent the contamination of the instrument.

36. Analyze the iTLC plate on a radio-iTLC reader to determine the progress of the reaction. Free ${ }^{64} \mathrm{Cu}^{2+}$ will be chelated by EDTA and will travel with the solvent front, while $\left[{ }^{64} \mathrm{Cu}\right] \mathrm{Cu}-\mathrm{SarAr}-$ $\mathrm{Tz}$ will remain at the baseline. The radiochemical purity should be $>99 \%$. ?TROUBLESHOOTING

\section{Prepare for injection into mice}

37. Dilute the reaction mixture with sterile $1 \times \mathrm{PBS} \mathrm{pH} 7.4$ to a concentration of $148 \mathrm{MBq}(4$ $\mathrm{mCi} / \mathrm{mL}$. Each mouse will receive a $0.1 \mathrm{~mL}$ dose containing $0.7 \mathrm{nmol}$ of $\left[{ }^{64} \mathrm{Cu}\right] \mathrm{Cu}-\mathrm{SarAr}-\mathrm{Tz}$ [14.8 MBq $(0.4 \mathrm{mCi})]$.

38. Draw $0.1 \mathrm{~mL}$ of the solution of $\left[{ }^{64} \mathrm{Cu}\right] \mathrm{Cu}-\mathrm{SarAr}-\mathrm{Tz}$ into each insulin syringe. Determine the final weight of each syringe containing the solution of radiotracer. Measure the activity of each syringe by placing it into a lead-shielded dose calibrator and recording the activity along with the date and time. Each syringe should contain $14.8 \mathrm{MBq}(0.4 \mathrm{mCi})$. !CRITICAL STEP 
Ensure that there are no air bubbles in the syringes. Refer to your institution's guidelines to determine the maximum volume that may be injected into each mouse.

\section{Radiolabeling of DOTA-PEG $7-\mathrm{Tz}$ with $\left[{ }^{177} \mathrm{Lu}\right] \mathrm{LuCl}_{3}$ (timing $\sim 1.5 \mathrm{~h}$ )}

!CAUTION Lutetium-177 represents a radiological hazard and must be used according to institutional, state, and federal regulations as well as ALARA (as low as reasonably achievable) principles. Proper shielding during the handling of all radioactive reagents, mixtures, glassware, and instruments is essential. Furthermore, it is critical that appropriate personal protective equipment, dosimeters, and survey meters are always used when handling radioactive material.

39. Dilute $13.0 \mu \mathrm{L}$ of the DOTA-PEG7-Tz stock solution $(29.9 \mu \mathrm{g}, 24.8 \mathrm{nmol}, 2.3 \mathrm{mg} / \mathrm{mL}$ in DMSO; see Procedure 1) with $200.0 \mu \mathrm{L}$ of $\mathrm{NH}_{4} \mathrm{OAc}$ buffer (0.25 M, pH 5.5). !CAUTION DMSO is a flammable liquid. DMSO may cause slight skin and eye irritation.

40. Add $1.26 \mathrm{GBq}(34.1 \mathrm{mCi})\left[{ }^{177} \mathrm{Lu}\right] \mathrm{LuCl}_{3}$ in $0.05 \mathrm{M} \mathrm{HCl}$ to the reaction solution. !CAUTION Hydrochloric acid can cause severe skin burns and eye damage and may cause respiratory irritation if inhaled. !CRITICAL STEP For in vivo PRIT experiments, we

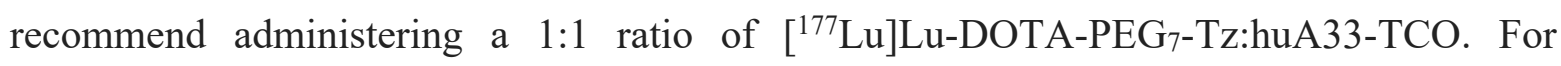
example, using the amounts listed in steps 49-50, a $37 \mathrm{MBq}(1 \mathrm{mCi})$ dose of $\left[{ }^{177} \mathrm{Lu}\right] \mathrm{Lu}-$ DOTA-PEG7-Tz will give each mouse $0.7 \mathrm{nmol}$ (equivalent to the $0.7 \mathrm{nmol}$ dose of huA33TCO each mouse will receive). If a higher radioactivity dose per mouse is desired (while maintaining a 1:1 molar ratio of the two components), we recommend increasing the activity of $\left[{ }^{177} \mathrm{Lu}\right] \mathrm{LuCl}_{3}$ used in step 40 and keeping the amount of tetrazine precursor the same.

41. Incubate the reaction mixture on an agitating dry block heating mixer at $700 \mathrm{rpm}$ at $37^{\circ} \mathrm{C}$ for $30 \mathrm{~min}$.

iTLC to monitor $\left[{ }^{177} \mathrm{Lu}\right] \mathrm{Lu}-\mathrm{DOTA}-\mathrm{PEG}_{7}-\mathrm{Tz}$ radiolabeling 
42. After incubation, determine the progress of $\left[{ }^{177} \mathrm{Lu}\right] \mathrm{Lu}-\mathrm{DOTA}-\mathrm{PEG}_{7}-\mathrm{Tz}$ radiolabeling with radio-iTLC.

43. Apply small droplet $(1 \mu \mathrm{L})$ of the reaction mixture at the baseline of the iTLC plate.

44. Insert the iTLC plate into a TLC chamber containing $50 \mathrm{mM}$ EDTA ( $\mathrm{pH}$ 5.0). !CAUTION EDTA can cause serious eye damage and is hazardous to aquatic life.

45. Allow the solvent front to reach $\sim 1 \mathrm{~cm}$ from the top of the iTLC plate and then remove the plate from the chamber.

46. Dry the iTLC plate in air.

47. Wrap the iTLC plate in cellophane wrap to prevent the contamination of the instrument.

48. Analyze the iTLC plate on a radio-iTLC reader to determine the progress of the reaction. Free ${ }^{177} \mathrm{Lu}^{3+}$ will be chelated by EDTA and will travel with the solvent front, while $\left[{ }^{177} \mathrm{Lu}\right] \mathrm{Lu}-$ DOTA-PEG $7-T z$ will remain at the baseline. The radiochemical purity should be $>99 \%$. ?TROUBLESHOOTING

\section{Prepare for injection into mice}

49. Dilute the reaction mixture with sterile $1 \times \mathrm{PBS} p H 7.4$ to a concentration of $370 \mathrm{MBq}(10$ $\mathrm{mCi} / \mathrm{mL}$. Each mouse will receive a $0.1 \mathrm{~mL}$ dose containing $0.7 \mathrm{nmol}$ of $\left[{ }^{177} \mathrm{Lu}\right] \mathrm{Lu}-\mathrm{DOTA}-$ $\mathrm{PEG}_{7}-\mathrm{Tz}(37.0 \mathrm{MBq}(1 \mathrm{mCi}))$.

50. Draw $0.1 \mathrm{~mL}$ of the $\left[{ }^{177} \mathrm{Lu}\right] \mathrm{Lu}-\mathrm{DOTA}-\mathrm{PEG}_{7}-\mathrm{Tz}$ solution into each insulin syringe. Determine the final weight of each syringe with the radiotracer. Measure the activity of each syringe by placing it into a lead-shielded dose calibrator and recording the activity along with the date and time. Each syringe should contain $37.0 \mathrm{MBq}(1 \mathrm{mCi})$ ! CRITICAL STEP Ensure that there are no air bubbles in the syringes. Refer to your institution's guidelines to determine the maximum volume that may be injected into each mouse. 


\section{In Vivo Pretargeting Experiments}

!CAUTION Only personnel who have received thorough training in the use of mice for preclinical in vivo experimentation should perform the parts of the protocol that involve mice. Regulated and well-staffed animal facilities are required for all animal experiments, and all in vivo procedures must be performed according to institutional, state, and federal guidelines. Again, proper PPE must be used at all times during in vivo experimentation.

!CRITICAL The nature of protocol-writing means that some of the steps that we have already described (i.e. the synthesis of the radioligands) should actually take place after some of the steps described below (i.e. injection of huA33-TCO). To be clear, the radioligand precursors $-\mathrm{SarAr}-\mathrm{Tz}$ and DOTA-PEG7-Tz - should be prepared well in advance of any in vivo experiments. And the radioligands themselves - either $\left[{ }^{64} \mathrm{Cu}\right] \mathrm{Cu}-\mathrm{SarAr}-\mathrm{Tz}$ or $\left[{ }^{177} \mathrm{Lu}\right] \mathrm{Lu}-\mathrm{DOTA}-\mathrm{PEG}_{7}-\mathrm{Tz}$ - should always be prepared immediately before administration to the animals and thus during the interval period between injections.

51. Warm the mice bearing SW1222 tumors under a heat lamp to promote venodilation $(\sim 25 \mathrm{~cm}$ away from the lamp for 3-4 minutes; see Supplemental Methods for the procedure used for the implantation of subcutaneous xenografts).

52. Place one mouse in the restraining device.

53. Clean the mouse's tail thoroughly with a sterile ethanol wipe.

54. Locate the lateral tail vein and insert the needle of the syringe containing huA33-TCO $(0.1$ $\mathrm{mg}, 0.7 \mathrm{nmol}$, in $0.1 \mathrm{~mL} 1 \times \mathrm{PBS}$ ), bevel up, into the vein towards the head of the mouse.

55. Inject the huA33-TCO solution into the vein slowly $(0.1 \mathrm{~mL}$ injected over a period of $\sim 3$ seconds) and then carefully withdraw the needle.

56. Gently hold a piece of gauze over the injection site and apply pressure to prevent the formation of a hematoma ( $\sim 30$ seconds).

57. Return the mouse to its cage. 
58. Repeat steps 51-57 with the rest of the mice.

59. Wait for the desired interval time prior to the radiosynthesis and administration of the radioligand. We have successfully used interval times ranging from 1 to 5 days for this huA33TCO/SW1222 system.

60. Warm the mice under a heat lamp to cause venodilation $(\sim 25 \mathrm{~cm}$ away from the lamp for $3-4$ $\min )$.

61. Take one mouse at a time and place it in the restraining device to prepare for PET imaging or radioimmunotherapy studies.

62. Perform the PET imaging experiment as described in option A or the radioimmunotherapy experiment as described in option B.

\section{A: Pretargeted PET Imaging}

i. Clean the mouse's tail thoroughly with a sterile ethanol wipe.

ii. Locate the lateral tail vein and insert the needle of the syringe containing $\left[{ }^{64} \mathrm{Cu}\right] \mathrm{Cu}-\mathrm{SarAr}-\mathrm{Tz}[(14.8 \mathrm{MBq}(0.4 \mathrm{mCi}), 0.7 \mathrm{nmol}$, prepared in step 38], bevel up, into the vein towards the head of the mouse.

iii. Inject the $\left[{ }^{64} \mathrm{Cu}\right] \mathrm{Cu}-\mathrm{Sar} A r-\mathrm{Tz}$ solution into the vein slowly $(0.1 \mathrm{~mL}$ injected over a period of $\sim 3$ seconds) and carefully withdraw the needle.

iv. Gently hold a piece of gauze over the injection site and apply pressure to prevent the formation of a hematoma ( $\sim 30$ seconds).

v. Return the mouse to its cage.

vi. Repeat steps $i-v$ with the rest of the mice.

vii. Measure the activity and weight of each syringe after administration to determine the dose administered. 
viii. Perform the PET imaging at the desired timepoints after the administration of the radioligand. With this $\left[{ }^{64} \mathrm{Cu}\right] \mathrm{Cu}-\mathrm{SarAr}-\mathrm{Tz} / \mathrm{huA} 33-\mathrm{TCO} / \mathrm{SW} 1222$ system, we have found that $4,12,24$, and 48 hour imaging timepoints work best.

\section{?TROUBLESHOOTING}

\section{B: Pretargeted Radioimmunotherapy (PRIT)}

i. Clean the mouse's tail thoroughly with a sterile ethanol wipe.

ii. Locate the lateral tail vein and insert the needle of the syringe containing $\left[{ }^{177} \mathrm{Lu}\right] \mathrm{Lu}-\mathrm{DOTA}-\mathrm{PEG}_{7}-\mathrm{Tz}$ [37 MBq (1 mCi), $0.7 \mathrm{nmol}$, prepared in step 50], bevel up, into the vein towards the head of the mouse.

iii. Inject the $\left[{ }^{177} \mathrm{Lu}\right] \mathrm{Lu}-\mathrm{DOTA}-\mathrm{PEG}_{7}-\mathrm{Tz}$ solution into the vein slowly $(0.1 \mathrm{~mL}$ injected over a period of $\sim 3$ seconds) and carefully withdraw the needle.

iv. Gently hold a piece of gauze over the injection site and apply pressure to prevent hematoma formation ( $\sim 30$ seconds).

v. Return the mouse to its cage.

vi. Repeat steps i-v with the other mice.

vii. Measure the activity and weight of each syringe after administration to determine the dose administered.

viii. Follow the tumor growth and well-being of the mice at least twice a week for the duration of the experiment by measuring the size of the xenografts using either calipers or a tumor measurement device (e.g. Peira TM900), weighing the mice, and observing their behavior for any signs of distress.

\section{Ex Vivo Biodistribution}

$<$ CRITICAL $>$ Biodistribution experiments can be useful companion procedures for both pretargeted PET imaging and PRIT. Biodistribution data can provide a quantitative measure of the activity 
concentrations produced in tumor tissue as well as healthy organs, can help validate PET imaging results, and can facilitate dosimetry calculations for PET imaging and - even more critically radioimmunotherapy.

!CRITICAL Ex vivo biodistribution experiments require smaller doses of radioactivity compared to the PRIT experiments. When preparing radioligands for $e x$ vivo biodistribution studies (steps 28-50), modify the radiolabeling procedure so that the final injection activity of $\left[{ }^{64} \mathrm{Cu}\right] \mathrm{Cu}-\mathrm{SarAr}-\mathrm{Tz}$ and $\left[{ }^{177} \mathrm{Lu}\right] \mathrm{Lu}-\mathrm{DOTA}-\mathrm{PEG}_{7}-\mathrm{Tz}$ is 11.1 $\mathrm{MBq}(0.30 \mathrm{mCi}, 0.7 \mathrm{nmol})$. When altering the radiolabeling procedure for ex vivo biodistribution studies, it is critical that the mass of the radioligand does not change, only the specific activity; the molar ratios of the radioligand and the antibody need to remain equal.

63. Administer the radioligand of choice as described in Step 62A $\left(\left[{ }^{64} \mathrm{Cu}\right] \mathrm{Cu}-\mathrm{SarAr}-\mathrm{Tz}\right)$ or $62 \mathrm{~B}$ $\left(\left[{ }^{177} \mathrm{Lu}\right] \mathrm{Lu}-\mathrm{DOTA}-\mathrm{PEG}_{7}-\mathrm{Tz}\right)$. With $\left[{ }^{64} \mathrm{Cu}\right] \mathrm{Cu}-\mathrm{SarAr}-\mathrm{Tz}$, we have found that 4,12 , and 24 hour timepoints are the most informative in a biodistribution study. With $\left[{ }^{177} \mathrm{Lu}\right] \mathrm{Lu}-\mathrm{DOTA}-\mathrm{PEG} 7 \mathrm{Tz}$, we have found that $4,24,72$, and 120 hour timepoints work best.

64. At the appropriate timepoint, euthanize the mice in the selected cohort using $\mathrm{CO}_{2}$ asphyxiation (or whichever euthanasia methods are listed in the laboratory's animal protocol).

65. Collect the blood via cardiac heart puncture and use a surgery kit to dissect each mouse and collect the desired tissues. For a typical biodistribution study, we collect 14 tissues: blood, tumor, heart, lungs, liver, spleen, stomach, small intestine, large intestine, kidneys, muscle, bone, skin, and tail. Place each organ into pre-weighed and labeled biodistribution tubes.

66. To prepare radioactivity standards, pipette 5-10 $\mu \mathrm{L}$ of the radioligand employed into four preweighed tubes. 
67. Weigh the standards as well as the tubes containing the organs.

68. Measure all the tubes with a gamma counter that has been calibrated for ${ }^{64} \mathrm{Cu}$ or ${ }^{177} \mathrm{Lu}$. !CRITICAL STEP Gamma counters typically decay correct radioactivity values to the same time point. We usually set the gamma counter to decay correct all of the measurements to the start of the measurement cycle. This way the values given by the gamma counter can be directly compared to one another. The standards should always be measured alongside the tissuecontaining tubes. ?TROUBLESHOOTING

69. Calculate the average activity concentration of the standards with the following equation:

$$
A c_{s t d}=\frac{\frac{A_{s t d 1}}{m_{s t d 1}}+\frac{A_{s t d 2}}{m_{s t d 2}}+\frac{A_{s t d 3}}{m_{s t d 3}}+\frac{A_{s t d 4}}{m_{s t d 4}}}{4}
$$

where $\mathrm{Ac}_{\text {std }}=$ the average activity concentration of standards $(\mathrm{cpm} / \mathrm{g}), \mathrm{A}_{\text {stdi }}=$ the activity of standard $\mathrm{i}(\mathrm{cpm})$, and $\mathrm{m}_{\mathrm{stdi}}=$ the mass of standard $\mathrm{i}(\mathrm{g})$.

70. Calculate total injected activity for each animal with following equation:

$$
A_{i}=A c_{s t d} \times m_{i}
$$

where $A_{i}=$ the total injected activity for mouse $i(c p m), A c_{s t d}=$ the average activity concentration of the standards $(\mathrm{cpm} / \mathrm{g})$, and $\mathrm{m}_{\mathrm{i}}=$ the mass of radioligand injected in mouse $\mathrm{i}(\mathrm{g})$.

71. Calculate the percentage of injected dose per gram of tissue $(\% \mathrm{ID} / \mathrm{g})$ with following equation:

$$
\% I D / g_{\text {organ } i}=100 \% \times \frac{\frac{A_{\text {organ } i}}{A_{i}}}{m_{\text {organ } i}}
$$


where $A_{\text {organ }} \mathrm{i}=$ the activity of the organ from mouse $\mathrm{i}(\mathrm{cpm})$, and $\mathrm{A}_{\mathrm{i}}=$ the total injected activity for mouse $\mathrm{i}(\mathrm{cpm})$, and $\mathrm{m}_{\text {organ } \mathrm{i}}=$ the mass of organ $\mathrm{i}(\mathrm{g})$. 


\section{TROUBLESHOOTING}

Troubleshooting advice can be found in Tables 1 and 2 .

Table 1 Troubleshooting for Procedure 1

\begin{tabular}{|c|c|c|c|}
\hline Step(s) & Problem & Possible Explanation & Solution \\
\hline 2 & $\begin{array}{l}\text { The N-boc-4- } \\
\text { (bromomethyl)- } \\
\text { benzylamine does not } \\
\text { dissolve completely. }\end{array}$ & $\begin{array}{l}\text { The reaction mixture is too } \\
\text { concentrated }\end{array}$ & $\begin{array}{l}\text { Add anhydrous DMF to } \\
\text { the reaction mixture until } \\
\text { the solution becomes } \\
\text { clear. }\end{array}$ \\
\hline 7,34 & $\begin{array}{l}\text { The yield of the boc- } \\
\text { protected product is low. }\end{array}$ & $\begin{array}{l}\text { The intermediates were deprotected } \\
\text { during purification. }\end{array}$ & $\begin{array}{l}\text { Ensure that the HPLC } \\
\text { solvents do not contain } \\
\text { TFA. }\end{array}$ \\
\hline $\begin{array}{l}7,16,25, \\
34,41,50\end{array}$ & $\begin{array}{l}\text { The product is impure } \\
\text { according to HPLC }\end{array}$ & $\begin{array}{l}\text { The product was exposed to light, } \\
\text { moisture, and/or heat. }\end{array}$ & $\begin{array}{l}\text { Repeat the HPLC } \\
\text { purification or perform } \\
\text { the reaction again. }\end{array}$ \\
\hline $\begin{array}{l}7,16,25, \\
34,41,50\end{array}$ & $\begin{array}{l}\text { The product is impure } \\
\text { according to HPLC }\end{array}$ & $\begin{array}{l}\text { The reaction } \\
\text { contaminated. }\end{array}$ & $\begin{array}{l}\text { Ensure proper lab } \\
\text { techniques are followed } \\
\text { while performing these } \\
\text { reactions. Make sure all } \\
\text { solvents and starting } \\
\text { reagents are fresh and } \\
\text { pure before beginning. }\end{array}$ \\
\hline 8 & $\begin{array}{l}\text { The yield of the isolated } \\
\text { product is low. }\end{array}$ & $\begin{array}{l}\text { Water in the reaction mixture may } \\
\text { have affected the formation of the } \\
\text { product. }\end{array}$ & $\begin{array}{l}\text { Ensure that the DMF is } \\
\text { anhydrous and that the } \\
\text { reaction is performed in a }\end{array}$ \\
\hline
\end{tabular}




\begin{tabular}{|c|c|c|c|}
\hline & & & $\begin{array}{l}\text { moisture-free } \\
\text { environment. }\end{array}$ \\
\hline $\begin{array}{l}8,17,27, \\
35,42,51\end{array}$ & $\begin{array}{l}\text { The yield of the isolated } \\
\text { product is low. }\end{array}$ & $\begin{array}{l}\text { The incubation time for the reaction } \\
\text { was too short. }\end{array}$ & $\begin{array}{l}\text { Increase the incubation } \\
\text { time. }\end{array}$ \\
\hline $\begin{array}{l}8,17,27, \\
35,42,51\end{array}$ & $\begin{array}{l}\text { The yield of the isolated } \\
\text { product is low. }\end{array}$ & $\begin{array}{l}\text { The reaction either failed or was } \\
\text { incomplete. }\end{array}$ & $\begin{array}{l}\text { Repeat the reaction; } \\
\text { ensure all solvents and } \\
\text { starting reagents are fresh } \\
\text { and pure before } \\
\text { beginning. }\end{array}$ \\
\hline $22,31,47$ & $\begin{array}{l}\text { The reaction solution } \\
\text { turns orange or pale } \\
\text { yellow. }\end{array}$ & The tetrazine moiety has degraded. & $\begin{array}{l}\text { Reduce the amount of } \\
\text { TEA in the reaction } \\
\text { mixture. }\end{array}$ \\
\hline $22,31,47$ & $\begin{array}{l}\text { The reaction solution } \\
\text { turns orange or pale } \\
\text { yellow. }\end{array}$ & The tetrazine moiety has degraded. & $\begin{array}{l}\text { Ensure that the reaction } \\
\text { vessel is protected from } \\
\text { light. }\end{array}$ \\
\hline $22,31,47$ & $\begin{array}{l}\text { The reaction solution } \\
\text { turns orange or pale } \\
\text { yellow. }\end{array}$ & The tetrazine moiety has degraded. & $\begin{array}{l}\text { Ensure that the DMSO } \\
\text { and TEA are anhydrous. }\end{array}$ \\
\hline 51 & $\begin{array}{l}\text { The yield of the isolated } \\
\text { product is low. }\end{array}$ & $\begin{array}{l}\text { The } p \text {-SCN-Bn-DOTA was not fully } \\
\text { dissolved or precipitated during the } \\
\text { reaction. }\end{array}$ & $\begin{array}{l}\text { Add the p-SCN-Bn- } \\
\text { DOTA to the reaction } \\
\text { mixture slowly and } \\
\text { vortex the reaction } \\
\text { mixture thoroughly to } \\
\text { ensure dissolution. }\end{array}$ \\
\hline
\end{tabular}


Table 2 Troubleshooting for Procedure 2

\begin{tabular}{|c|c|c|c|}
\hline Step(s) & Problem & Possible Explanation & Solution \\
\hline 10,23 & $\begin{array}{l}\text { The residual volume in } \\
\text { the Amicon }{ }^{\circledR} \text { Ultra- } 4 \\
\text { centrifugal filter is too } \\
\text { large }(>0.5 \mathrm{~mL}) \text {. }\end{array}$ & $\begin{array}{l}\text { The filter is clogged because of too } \\
\text { much mAb. }\end{array}$ & $\begin{array}{l}\text { Reduce the amount of } \\
\text { mAb used per Amicon }{ }^{\circledR} \\
\text { Ultra-4 centrifugal filter } \\
\text { unit. }\end{array}$ \\
\hline 10,23 & $\begin{array}{l}\text { The residual volume in } \\
\text { the Amicon }{ }^{\circledR} \text { Ultra- } 4 \\
\text { centrifugal filter is too } \\
\text { large }(>0.5 \mathrm{~mL}) .\end{array}$ & More time is needed for filtration. & $\begin{array}{l}\text { Centrifuge the unit for } \\
\text { another } 10 \text { min and repeat } \\
\text { until a desired volume is } \\
\text { reached }\end{array}$ \\
\hline 12,25 & $\begin{array}{l}\text { A low absorbance signal } \\
\text { is obtained at } 280 \mathrm{~nm} \\
\text { during UV-Vis } \\
\text { measurements. }\end{array}$ & $\begin{array}{l}\text { The concentration of antibody is too } \\
\text { low for the instrument to detect. }\end{array}$ & $\begin{array}{l}\text { Concentrate the sample } \\
\text { further with an Amicon }{ }^{\circledR} \\
\text { Ultra-4 centrifugal filter. }\end{array}$ \\
\hline 12,25 & $\begin{array}{l}\text { A low absorbance signal } \\
\text { is obtained at } 280 \mathrm{~nm} \\
\text { during UV-Vis } \\
\text { measurements. }\end{array}$ & $\begin{array}{l}\text { The sample was lost during } \\
\text { purification. }\end{array}$ & $\begin{array}{l}\text { Double check the } \\
\text { calculations for the } \\
\text { volume of antibody } \\
\text { solution and buffer added } \\
\text { to the PD-10 column. } \\
\text { Ensure that it was not } \\
\text { greater than } 2.5 \text { mL. } \\
\text { Review the instructions }\end{array}$ \\
\hline
\end{tabular}




\begin{tabular}{|c|c|c|c|}
\hline & & & $\begin{array}{l}\text { for preparing PD-10 } \\
\text { desalting columns. }\end{array}$ \\
\hline 26 & $\begin{array}{l}\text { The degree of labeling of } \\
\text { TCO on the antibody is } \\
\text { too low (as determined } \\
\text { via the Tz-PEG } 7-A F 680 \\
\text { method). }\end{array}$ & $\begin{array}{l}\text { Not enough Tz-PEG7-AF680 was } \\
\text { added to the solution to react with all } \\
\text { of the TCO moieties on the antibody. }\end{array}$ & $\begin{array}{l}\text { Increase the ratio of } \mathrm{Tz}- \\
\mathrm{PEG}_{7}-\mathrm{AF} 680: \mathrm{TCO}-\mathrm{mAb} \text {. }\end{array}$ \\
\hline 26 & $\begin{array}{l}\text { The degree of labeling of } \\
\text { TCO on the antibody is } \\
\text { too low (as determined } \\
\text { via the Tz-PEG } 7-A F 680 \\
\text { method). }\end{array}$ & $\begin{array}{l}\text { The reaction of Tz-PEG }-\mathrm{AF} 680 \text { and } \\
\text { TCO-huA33 was incomplete or } \\
\text { unsuccessful. }\end{array}$ & $\begin{array}{l}\text { Incubate the mixture } \\
\text { longer. }\end{array}$ \\
\hline 27 & $\begin{array}{l}\text { The degree of labeling of } \\
\text { TCO on the antibody is } \\
\text { negative (as determined } \\
\text { via MALDI). }\end{array}$ & A calculation error was made. & $\begin{array}{l}\text { Double-check the } \\
\text { equation used to calculate } \\
\text { the DOL using MALDI. }\end{array}$ \\
\hline 26,27 & $\begin{array}{l}\text { The degree of labeling of } \\
\text { TCO on the antibody is } \\
\text { zero (as determined via } \\
\text { either method). }\end{array}$ & $\begin{array}{l}\text { The } \mathrm{pH} \text { of the TCO-NHS/mAb } \\
\text { conjugation reaction was incorrect. }\end{array}$ & $\begin{array}{l}\text { Make sure the } \mathrm{pH} \text { of the } \\
\text { reaction is } 8.8-8.9 \text { before } \\
\text { adding the TCO-NHS }\end{array}$ \\
\hline 26,27 & $\begin{array}{l}\text { The degree of labeling of } \\
\text { TCO on the antibody is } \\
\text { zero (as determined via } \\
\text { either method). }\end{array}$ & $\begin{array}{l}\text { The TCO-NHS was added too } \\
\text { quickly, leading to the formation of a } \\
\text { precipitate. }\end{array}$ & $\begin{array}{l}\text { Make sure to add the } \\
\text { TCO-NHS slowly. While } \\
\text { adding it, gently swirl the } \\
\text { pipette tip around in the } \\
\text { solution to mix. }\end{array}$ \\
\hline
\end{tabular}




\begin{tabular}{|c|c|c|c|}
\hline 26,27 & $\begin{array}{l}\text { The degree of labeling of } \\
\text { TCO on the antibody is } \\
\text { zero (as determined via } \\
\text { either method). }\end{array}$ & $\begin{array}{l}\text { The } \mathrm{mAb} \text { solution contained } \\
\text { compounds that interfered with the } \\
\text { conjugation reaction. }\end{array}$ & $\begin{array}{l}\text { Purify the mAb solution } \\
\text { carefully before } \\
\text { conjugation. }\end{array}$ \\
\hline 26,27 & $\begin{array}{l}\text { The degree of labeling of } \\
\text { TCO on the antibody is } \\
\text { too low (as determined } \\
\text { via either method). }\end{array}$ & $\begin{array}{l}\text { The molar ratio of TCO-NHS:mAb in } \\
\text { the bioconjugation reaction was too } \\
\text { low. }\end{array}$ & $\begin{array}{l}\text { Increase the amount of } \\
\text { TCO-NHS added to the } \\
\text { reaction vial while } \\
\text { keeping amount of } \\
\text { antibody the same. }\end{array}$ \\
\hline 26,27 & $\begin{array}{l}\text { The degree of labeling of } \\
\text { TCO on the antibody is } \\
\text { too low (as determined } \\
\text { via either method). }\end{array}$ & $\begin{array}{l}\text { The TCO-NHS conjugation reaction } \\
\text { was not allowed to incubate for } \\
\text { enough time. }\end{array}$ & $\begin{array}{l}\text { Increase the incubation } \\
\text { time of the reaction. }\end{array}$ \\
\hline 36 & $\begin{array}{l}\text { The radiolabeling of } \\
{\left[{ }^{64} \mathrm{Cu}\right] \mathrm{Cu}-\mathrm{SarAr}-\mathrm{Tz} \text { is }} \\
\text { not quantitative and/or } \\
\text { exhibits low } \\
\text { radiochemical purity. }\end{array}$ & $\begin{array}{l}\text { The radiolabeling reaction was } \\
\text { incomplete. }\end{array}$ & $\begin{array}{l}\text { Increase the incubation } \\
\text { time of the reaction. }\end{array}$ \\
\hline 36 & $\begin{array}{l}\text { The radiolabeling of } \\
{\left[{ }^{64} \mathrm{Cu}\right] \mathrm{Cu}-\mathrm{SarAr}-\mathrm{Tz} \text { is }} \\
\text { not quantitative and/or } \\
\text { exhibits low } \\
\text { radiochemical purity. }\end{array}$ & $\begin{array}{l}\text { The radiolabeling was performed at } \\
\text { the wrong } \mathrm{pH} \text {. }\end{array}$ & $\begin{array}{l}\text { Prepare new buffers and } \\
\text { double-check the } \mathrm{pH} \text { of } \\
\text { said buffers during the } \\
\text { radiolabeling process } \\
\text { using pH papers. }\end{array}$ \\
\hline 36 & $\begin{array}{l}\text { The radiolabeling of } \\
{\left[{ }^{64} \mathrm{Cu}\right] \mathrm{Cu}-\mathrm{SarAr}-\mathrm{Tz} \text { is }}\end{array}$ & $\begin{array}{l}\text { The radionuclide in the stock solution } \\
\text { has low specific activity. }\end{array}$ & $\begin{array}{l}\text { Check with the producers } \\
\text { of the radionuclide to }\end{array}$ \\
\hline
\end{tabular}




\begin{tabular}{|c|c|c|c|}
\hline & $\begin{array}{l}\text { not quantitative and/or } \\
\text { exhibits low } \\
\text { radiochemical purity. }\end{array}$ & & $\begin{array}{l}\text { ensure that the specific } \\
\text { activity of the } \\
\text { radionuclide is sufficient. }\end{array}$ \\
\hline 36 & $\begin{array}{l}\text { The radiolabeling of } \\
{\left[{ }^{64} \mathrm{Cu}\right] \mathrm{Cu}-S a r A r-T z \text { is }} \\
\text { not quantitative and/or } \\
\text { exhibits low } \\
\text { radiochemical purity. }\end{array}$ & $\begin{array}{l}\text { Not enough precursor was added to } \\
\text { the radiolabeling reaction. }\end{array}$ & $\begin{array}{l}\text { Make sure the correct } \\
\text { amount of precursor was } \\
\text { used. }\end{array}$ \\
\hline 48 & $\begin{array}{l}\text { The radiolabeling of } \\
{\left[{ }^{177} \mathrm{Lu}\right] \mathrm{Lu}-\mathrm{DOTA}-\mathrm{PEG}_{7-}} \\
\mathrm{Tz} \text { is not quantitative } \\
\text { and/or exhibits low } \\
\text { radiochemical purity. }\end{array}$ & The click reaction was incomplete. & $\begin{array}{l}\text { Increase the incubation } \\
\text { time of the reaction. }\end{array}$ \\
\hline 48 & $\begin{array}{l}\text { The radiolabeling of } \\
{\left[{ }^{177} \mathrm{Lu}\right] \mathrm{Lu}-\mathrm{DOTA}-\mathrm{PEG}_{7}-} \\
\mathrm{Tz} \text { is not quantitative } \\
\text { and/or exhibits low } \\
\text { radiochemical purity. }\end{array}$ & $\begin{array}{l}\text { The radiolabeling was performed at } \\
\text { the wrong } \mathrm{pH} \text {. }\end{array}$ & $\begin{array}{l}\text { Prepare new buffers and } \\
\text { double-check the } \mathrm{pH} \text { of } \\
\text { said buffers during the } \\
\text { radiolabeling process } \\
\text { using } \mathrm{pH} \text { papers. }\end{array}$ \\
\hline 48 & $\begin{array}{l}\text { The radiolabeling of } \\
{\left[{ }^{177} \mathrm{Lu}\right] \mathrm{Lu}-\mathrm{DOTA}-\mathrm{PEG}_{7}-} \\
\mathrm{Tz} \text { is not quantitative } \\
\text { and/or exhibits low } \\
\text { radiochemical purity. }\end{array}$ & $\begin{array}{l}\text { The radionuclide in the stock solution } \\
\text { has low specific activity. }\end{array}$ & $\begin{array}{l}\text { Check with the producers } \\
\text { of the radionuclide to } \\
\text { ensure that specific } \\
\text { activity of the } \\
\text { radionuclide is sufficient. }\end{array}$ \\
\hline
\end{tabular}




\begin{tabular}{|c|c|c|c|}
\hline 48 & $\begin{array}{l}\text { The radiolabeling of } \\
{\left[{ }^{177} \mathrm{Lu}\right] \mathrm{Lu}-\mathrm{DOTA}-\mathrm{PEG}_{7-}} \\
\mathrm{Tz} \text { is not quantitative } \\
\text { and/or exhibits low } \\
\text { radiochemical purity. }\end{array}$ & $\begin{array}{l}\text { Not enough precursor was added to } \\
\text { the radiolabeling reaction. }\end{array}$ & $\begin{array}{l}\text { Make sure the correct } \\
\text { amount of precursor was } \\
\text { used. }\end{array}$ \\
\hline 36,48 & $\begin{array}{l}\text { The peaks in the radio- } \\
\text { ITLC chromatogram are } \\
\text { smeared. }\end{array}$ & $\begin{array}{l}\text { The iTLC plate was smeared from } \\
\text { wrapping the plate with plastic wrap. }\end{array}$ & $\begin{array}{l}\text { Make sure that the plate is } \\
\text { completely air-dried } \\
\text { before wrapping it in } \\
\text { plastic wrap. }\end{array}$ \\
\hline $\begin{array}{l}62 \mathrm{a}(\mathrm{viii}), \\
68\end{array}$ & $\begin{array}{l}\text { High concentrations of } \\
{ }^{64} \mathrm{Cu} \text { are observed in the } \\
\text { liver. }\end{array}$ & $\begin{array}{l}\text { There is free }\left[{ }^{64} \mathrm{Cu}\right] \mathrm{Cu}^{2+} \text { in the } \\
\text { injectate. }\end{array}$ & $\begin{array}{l}\text { Check the radiochemical } \\
\text { purity of the radioligand. }\end{array}$ \\
\hline $\begin{array}{l}62 \mathrm{a}(\mathrm{viii}), \\
68\end{array}$ & $\begin{array}{l}\text { Low activity } \\
\text { concentrations are } \\
\text { observed in the tumor. }\end{array}$ & $\begin{array}{l}\text { The wrong molar ratio of } \mathrm{mAb}-\mathrm{TCO} \\
\text { and Tz radioligand were used. }\end{array}$ & $\begin{array}{l}\text { Check the molar ratio of } \\
\text { the two components } \\
\text { administered to ensure } \\
\text { that it is } \sim 1: 1 \text {. }\end{array}$ \\
\hline $\begin{array}{l}62 \mathrm{a}(\mathrm{viii}), \\
68\end{array}$ & $\begin{array}{l}\text { Low activity } \\
\text { concentrations are } \\
\text { observed in the tumor. }\end{array}$ & $\begin{array}{l}\text { The mAb-TCO has been rapidly } \\
\text { internalized in the tumor. }\end{array}$ & $\begin{array}{l}\text { If the } \mathrm{mAb} \text { is internalized } \\
\text { rapidly, in vivo } \\
\text { pretargeting is not a } \\
\text { viable method. }\end{array}$ \\
\hline $\begin{array}{l}62 \mathrm{a}(\mathrm{viii}), \\
68\end{array}$ & $\begin{array}{l}\text { Low activity } \\
\text { concentrations are } \\
\text { observed in the tumor. }\end{array}$ & $\begin{array}{l}\text { The interval time between the } \\
\text { injection of the two components is } \\
\text { too long. }\end{array}$ & $\begin{array}{l}\text { Shorten the interval time } \\
\text { between } \\
\text { administration of the two } \\
\text { components. }\end{array}$ \\
\hline
\end{tabular}




\begin{tabular}{|c|c|c|c|}
\hline $\begin{array}{c}\text { 62a(viii), } \\
68\end{array}$ & $\begin{array}{l}\text { Low activity } \\
\text { concentrations are } \\
\text { observed in the tumor. }\end{array}$ & $\begin{array}{l}\text { The radioligand was not prepared } \\
\text { correctly. }\end{array}$ & $\begin{array}{l}\text { Validate the synthesis of } \\
\text { the radioligand in } \\
\text { question via HPLC. See } \\
\text { the rows above that } \\
\text { address troubleshooting } \\
\text { the preparation of the } \\
\text { radioligands. }\end{array}$ \\
\hline $\begin{array}{l}\text { 62a(viii), } \\
68\end{array}$ & $\begin{array}{l}\text { Low activity } \\
\text { concentrations are } \\
\text { observed in the tumor. }\end{array}$ & $\begin{array}{l}\text { The mAb-TCO conjugate was not } \\
\text { prepared correctly. }\end{array}$ & $\begin{array}{l}\text { See the rows above that } \\
\text { address troubleshooting } \\
\text { the preparation of the } \\
\text { immunoconjugate. }\end{array}$ \\
\hline $\begin{array}{l}62 \mathrm{a}(\mathrm{viii}), \\
68\end{array}$ & $\begin{array}{l}\text { Low activity } \\
\text { concentrations are } \\
\text { observed in the tumor. }\end{array}$ & $\begin{array}{l}\text { The mAb has lost immunoreactivity } \\
\text { due to improper handling. }\end{array}$ & $\begin{array}{l}\text { Ensure that the antibody } \\
\text { and immunoconjugate are } \\
\text { handled and stored in an } \\
\text { appropriate manner. }\end{array}$ \\
\hline 62a(viii), & $\begin{array}{l}\text { Low activity } \\
\text { concentrations are } \\
\text { observed in the tumor. }\end{array}$ & $\begin{array}{l}\text { The mAb has lost immunoreactivity } \\
\text { due to the conjugation of TCO } \\
\text { moieties in the antigen-binding } \\
\text { domains. }\end{array}$ & $\begin{array}{l}\text { Perform the } \\
\text { bioconjugation reaction } \\
\text { again and be sure to } \\
\text { perform } \\
\text { immunoreactivity assays } \\
\text { to ensure that the } \\
\text { conjugation did not affect } \\
\text { the reactivity of the } \\
\text { antibody. If needed, } \\
\text { decrease the DOL of the }\end{array}$ \\
\hline
\end{tabular}




\begin{tabular}{|c|c|c|c|}
\hline & & & $\begin{array}{l}\text { immunoconjugate to } \\
\text { reduce the likelihood that } \\
\text { TCOs are affecting the } \\
\text { antigen-binding domains }\end{array}$ \\
\hline $\begin{array}{l}62 \mathrm{a}(\mathrm{viii}), \\
68\end{array}$ & $\begin{array}{l}\text { Low activity } \\
\text { concentrations are } \\
\text { observed in the tumor. }\end{array}$ & $\begin{array}{l}\text { The TCO has isomerized to } \mathrm{CCO} \text { and } \\
\text { is thus no longer reactive. }\end{array}$ & $\begin{array}{l}\text { Prepare a new batch of } \\
\text { mAb-TCO and store it } \\
\text { appropriately. }\end{array}$ \\
\hline $\begin{array}{l}62 \mathrm{a}(\mathrm{viii}), \\
68\end{array}$ & $\begin{array}{l}\text { High activity } \\
\text { concentrations are } \\
\text { observed in the blood. }\end{array}$ & $\begin{array}{l}\text { Free antibody is still circulating at the } \\
\text { time of the injection of the } \\
\text { radioligand. }\end{array}$ & $\begin{array}{l}\text { Increase the interval time } \\
\text { between } \\
\text { administration of the } \\
\text { mAb-TCO and the } \\
\text { radioligand. }\end{array}$ \\
\hline $\begin{array}{l}62 \mathrm{a}(\mathrm{viii}), \\
68\end{array}$ & $\begin{array}{lr}\text { High } & \text { activity } \\
\text { concentrations } & \text { are } \\
\text { observed in healthy } \\
\text { tissues. }\end{array}$ & $\begin{array}{l}\text { The reactivity of the } \\
\text { immunoconjugate has been } \\
\text { compromised so that it is not binding } \\
\text { its target. }\end{array}$ & $\begin{array}{l}\text { See the sections above } \\
\text { that address ensuring the } \\
\text { biological integrity of the } \\
\text { immunoconjugate. }\end{array}$ \\
\hline $\begin{array}{l}62 \mathrm{a}(\mathrm{viii}), \\
68\end{array}$ & $\begin{array}{lr}\text { High } & \text { activity } \\
\text { concentrations } & \text { are } \\
\text { observed in healthy } \\
\text { tissues. }\end{array}$ & $\begin{array}{l}\text { The target of the immunoconjugate is } \\
\text { present in healthy tissues }\end{array}$ & $\begin{array}{l}\text { This immunoconjugate } \\
\text { may not be suitable for } \\
\text { this approach. }\end{array}$ \\
\hline
\end{tabular}




\section{TIMING}

Procedure 1

Steps 1-9, synthesis of SarAr-Bn-NHBoc: 3 d

Steps 10-18, synthesis of SarAr-Bn-NH $\mathrm{NH}_{2}: 2 \mathrm{~d}$

Steps 19-28, synthesis of SarAr-Tz: $2 \mathrm{~d}$

Steps 29-36, synthesis of Tz-PEG7-NHBoc: $1 \mathrm{~d}$

Steps 37-43, synthesis of Tz-PEG7 $-\mathrm{NH}_{2}: 1 \mathrm{~d}$

Steps 44-52, synthesis of DOTA-PEG7-Tz: $1 \mathrm{~d}$

Procedure 2

Steps 1-26, preparation and purification of huA33-TCO: $3 \mathrm{~h}$

Steps 28-38, radiolabeling of SarAr-Tz with $\left[{ }^{64} \mathrm{Cu}\right] \mathrm{CuCl}_{2}: 1 \mathrm{~h}$

Steps 39-50, radiolabeling of DOTA-PEG $-\mathrm{Tz}$ with $\left[{ }^{177} \mathrm{Lu}\right] \mathrm{LuCl}_{3}: 1.5 \mathrm{~h}$

Steps 51-61, injection of huA33-TCO vector (highly variable depending on the size and number of the cohorts used): $2 \mathrm{~h}$

Step 62A, injection of PET radiotracer (highly variable depending on the size and number of the cohorts used): $2 \mathrm{~h}$ 
Step 62A(viii), pretargeted PET imaging (for each PET time point, highly variable depending on the size and number of the cohorts used): $2 \mathrm{~h}$

Step 62B, injection of PRIT radiotracer (highly variable depending on the size and number of the cohorts used): $2 \mathrm{~h}$

Step 62B(viii), checking on well-being of mice and measuring tumor sizes for PRIT (for each time point, highly variable depending on the size and number of the cohorts used): $2 \mathrm{~h}$ 


\section{ANTICIPATED RESULTS}

\section{Analytical Data for SarAr-Bn-NHBoc}

white powder (typical results: $35 \mathrm{mg}, 0.065 \mathrm{mmol}, 65-75 \%$ yield)

${ }^{1}$ H NMR (600 MHz, DMSO-d $)$ ppm: $\delta=7.38-7.50(\mathrm{~m}, 4 \mathrm{H}), 4.18(\mathrm{~m}, 2 \mathrm{H}), 2.31-3.98$ (m, 42H), $1.35(\mathrm{~s}, 9 \mathrm{H})$.

ESI-MS(+): $\mathrm{m} / \mathrm{z}=534.5[\mathrm{M}+\mathrm{H}]^{+}$.

HRMS (ESI): $\mathrm{m} / \mathrm{z}$ calcd. for $\mathrm{C}_{27} \mathrm{H}_{52} \mathrm{~N}_{9} \mathrm{O}_{2}:$ 534.4244; found: 534.4250 .

\section{SarAr-Bn-NH2}

White powder (typical results: $26 \mathrm{mg}, 0.059 \mathrm{mmol}$, quantitative yield)

${ }^{1}$ H NMR (600 MHz, DMSO-d6) ppm: $\delta=7.55(\mathrm{~d}, 2 \mathrm{H}), 7.51(\mathrm{~d}, 2 \mathrm{H}), 4.23(\mathrm{~m}, 2 \mathrm{H}), 2.56-4.05(\mathrm{~m}$, 27H), $1.35(\mathrm{~s}, 9 \mathrm{H})$.

ESI-MS(+): $\mathrm{m} / \mathrm{z}=434.4[\mathrm{M}+\mathrm{H}]^{+}$.

HRMS (ESI): $\mathrm{m} / \mathrm{z}$ calcd. for $\mathrm{C}_{22} \mathrm{H}_{44} \mathrm{~N}_{9}$ : 434.3720; found: 434.3715 .

\section{SarAr-Tz}

Pink powder (typical results: $3.9 \mathrm{mg}, 0.0054 \mathrm{mmol}, 40-45 \%$ yield)

${ }^{1} \mathbf{H}$ NMR (600 MHz, D $\mathbf{2}$ ), $\boldsymbol{\delta}$, ppm: 10.25 (s, 1H), 8.31 (d, 2H), 7.46 (d, 2H), 7.22-7.27 (m, 4H), $4.39(\mathrm{~m}, 2 \mathrm{H}), 4.24(\mathrm{~m}, 3 \mathrm{H}), 2.46-3.95(\mathrm{~m}, 24 \mathrm{H}), 2.41-2.44(\mathrm{~m}, 4 \mathrm{H}), 1.83(\mathrm{~m}, 2 \mathrm{H})$.

${ }^{13}$ C NMR (125 MHz, D $\mathbf{2}$ ): $\boldsymbol{\delta}=21.7,34.7,42.5,42.7,47.4,52.5,55.9,57.2,58.8,60.1,116.2$ (TFA), $127.7,128.0,128.5,130.3,135.4,138.5,143.5,157.3,162.9$ (TFA), $166.3,175.7,175.8$.

ESI-MS(+): $\mathrm{m} / \mathrm{z}=717.6[\mathrm{M}+\mathrm{H}]^{+}$.

HRMS (ESI): $\mathrm{m} / \mathrm{z}$ calcd. for $\mathrm{C}_{36} \mathrm{H}_{57} \mathrm{~N}_{14} \mathrm{O}_{2}$ : 717.4789; found: 717.4788 . 


\section{Tz-PEG $7-N H B o c$}

bright pink powder (typical results: $16 \mathrm{mg}, 0.021 \mathrm{mmol}, 80-90 \%$ yield)

${ }^{1}$ H NMR (500 MHz, DMSO), $\boldsymbol{\delta}$, ppm: 10.52 (s, 1H), 8.50 (m, 3H), 7.82 (t, 1H), 7.46 (d, 2H), 6.69 $(\mathrm{t}, 1 \mathrm{H}), 4.33(\mathrm{~d}, 2 \mathrm{H}), 3.42(\mathrm{~m}, 22 \mathrm{H}), 3.33(\mathrm{t}, 2 \mathrm{H}), 3.31(\mathrm{t}, 2 \mathrm{H}), 3.12(\mathrm{q}, 2 \mathrm{H}), 2.99(\mathrm{q}, 2 \mathrm{H}), 2.12(\mathrm{t}, 2 \mathrm{H})$, $2.03(\mathrm{t}, 2 \mathrm{H}), 2.12(\mathrm{t}, 2 \mathrm{H}), 1.70(\mathrm{q}, 2 \mathrm{H}), 1.29(\mathrm{~s}, 9 \mathrm{H})$.

ESI-MS(+): $m / z(\%)=753.1[\mathrm{M}+\mathrm{H}]^{+}$

HRMS (ESI): $m / z$ calculated for $\mathrm{C}_{35} \mathrm{H}_{57} \mathrm{~N}_{7} \mathrm{O}_{11} \mathrm{Na}$ : 774.4005; found: 774.4014 .

UV-Vis: $\varepsilon_{525}=530 \mathrm{M}^{-1} \mathrm{~cm}^{-1}$.

\section{Tz-PEG $-\mathbf{N H}_{2}$}

bright pink powder (typical results: $9 \mathrm{mg}, 0.013 \mathrm{mmol}, 90-95 \%$ yield)

${ }^{1}$ H NMR (500 MHz, DMSO), $\boldsymbol{\delta}$, ppm: 10.58 (s, 1H), 8.46 (m, 2H), 7.87 (t, 1H), 7.75 (d, 2H), 7.52 $(\mathrm{d}, 1 \mathrm{H}), 4.40(\mathrm{~d}, 2 \mathrm{H}), 3.60-3.50(\mathrm{~m}, 26 \mathrm{H}), 3.40(\mathrm{t}, 2 \mathrm{H}), 3.32(\mathrm{bs}, 2 \mathrm{H}), 3.20(\mathrm{q}, 2 \mathrm{H}), 2.99(\mathrm{bs}, 2 \mathrm{H})$, $2.19(\mathrm{t}, 2 \mathrm{H}), 2.12(\mathrm{t}, 2 \mathrm{H}), 1.79(\mathrm{q}, 2 \mathrm{H})$.

$\operatorname{ESI-MS(+):~} m / z(\%)=652.9[\mathrm{M}+\mathrm{H}]^{+}$

HRMS (ESI): $m / z$ calculated for $\mathrm{C}_{30} \mathrm{H}_{50} \mathrm{~N}_{7} \mathrm{O}_{9}: 652.3670$; found: 652.3676 .

UV-Vis: $\varepsilon_{525}=535 \mathrm{M}^{-1} \mathrm{~cm}^{-1}$.

\section{DOTA-PEG $7-T z$}

bright pink powder (typical results: $15.4 \mathrm{mg}, 0.0128 \mathrm{mmol}, 70-75 \%$ yield)

${ }^{1}$ H NMR (600 MHz, DMSO), $\boldsymbol{\delta}$, ppm: 12.2 (bs, 4H), $11.74(\mathrm{~s}, 1 \mathrm{H}) 10.59$ (s, 1H), 8.55 (t, 1H, J = $5.9 \mathrm{~Hz}), 8.51(\mathrm{t}, 1 \mathrm{H}, \mathrm{J}=5.9 \mathrm{~Hz}), 8.46(\mathrm{~d}, 2 \mathrm{H}, \mathrm{J}=8.2 \mathrm{~Hz}), 7.79(\mathrm{~d}, 2 \mathrm{H}, \mathrm{J}=8.2 \mathrm{~Hz}), 7.55(\mathrm{~d}, 2 \mathrm{H}, \mathrm{J}=$ 
$8.3 \mathrm{~Hz}), 7.44(\mathrm{~d}, 2 \mathrm{H}, \mathrm{J}=8.2 \mathrm{~Hz}), 7.42(\mathrm{t}, 1 \mathrm{H}, \mathrm{J}=7.7 \mathrm{~Hz}), 4.42(\mathrm{~d}, 2 \mathrm{H}, \mathrm{J}=5.9 \mathrm{~Hz}), 3.80-3.40(\mathrm{~m}$, $38 \mathrm{H}), 2.51(\mathrm{~s}, 1 \mathrm{H}), 2.69(\mathrm{t}, 1 \mathrm{H}, \mathrm{J}=6.0 \mathrm{~Hz}), 2.50-2.30(\mathrm{~m}, 16 \mathrm{H}), 2.09(\mathrm{t}, 4 \mathrm{H}, \mathrm{J}=7.0 \mathrm{~Hz})$.

${ }^{13}$ C NMR (600 MHz, DMSO), $\delta$, ppm: 173.88, 173.16, 170.96, 169.99, 169.31, 165.89, 158.61, $146.09,145.41,132.69,130.77,128.80,128.47,128.22,70.36,70.13,70.11,70.07,70.06,67.35$, $66.68,42.25,42.18,40.48,36.65,36.59,35.17,32.64,31.19,28.94,27.28$.

ESI-MS(-): $m / z(\%)=1203.0[\mathrm{M}-\mathrm{H}]^{-} ; 601.8[\mathrm{M}-2 \mathrm{H}]^{-2}$

HRMS (ESI): $m / z$ calculated for $\mathrm{C}_{50} \mathrm{H}_{76} \mathrm{~N}_{11} \mathrm{O}_{15} \mathrm{~S}: 1202.5642$; found: 1203.5741 .

UV-Vis: $\varepsilon_{525}=500 \mathrm{M}^{-1} \mathrm{~cm}^{-1}$.

\section{Preparation of huA33-TCO}

The preparation of huA33-TCO is a straightforward task. The huA33-TCO immunoconjugate prepared as described in this protocol has between 2 and 5 TCO groups per antibody (this occupancy is determined as described in Box 1) and has an immunoreactive fraction of $>0.90$ (when labeled with $\left.\left[{ }^{64} \mathrm{Cu}\right] \mathrm{Cu}-\mathrm{SarAr}-\mathrm{Tz}\right)$.

\section{Radiosynthesis of $\left[{ }^{64} \mathrm{Cu}\right] \mathrm{Cu}-\mathrm{Sar} \mathrm{Ar}-\mathrm{Tz}$}

The radiolabeling of SarAr-Tz is likewise relatively simple. The reaction is typically complete after 15 minutes, affording $\left[{ }^{64} \mathrm{Cu}\right] \mathrm{Cu}-\mathrm{SarAr}-\mathrm{Tz}$ in $>99 \%$ radiochemical yield, $>99 \%$ radiochemical purity, and a molar activity of 15.3-16.4 GBq $(413.4-443.3 \mathrm{mCi}) / \mu \mathrm{mol}(\mathrm{n}=3)$ without any need for further purification (Figure 6).

\section{Radiosynthesis of $\left[{ }^{177} \mathrm{Lu}\right] \mathrm{Lu}-\mathrm{DOTA}-\mathrm{PEG}_{7}-\mathrm{Tz}$}

The radiolabeling of DOTA-PEG $7-\mathrm{Tz}$ is also a facile endeavor. The reaction is usually complete after 30 minutes, affording $\left[{ }^{177} \mathrm{Lu}\right] \mathrm{Lu}-\mathrm{DOTA}-\mathrm{PEG}_{7}-\mathrm{Tz}$ in $>99 \%$ radiochemical yield, $>99 \%$ 
radiochemical purity, and a molar activity of 46.8-71.1 GBq $(1.264-1.921 \mathrm{Ci}) / \mu \mathrm{mol}(\mathrm{n}=3)$ without any need for further purification (Figure 6).

\section{Pretargeted PET Imaging}

The pretargeted PET imaging experiments described in this protocol were performed in athymic nude mice bearing A33 antigen-expressing SW1222 human colorectal carcinoma xenografts. For the pretargeted PET imaging, the mice were first injected with huA33-TCO (100 $\mu \mathrm{g}, 0.7 \mathrm{nmol})$ via tail vein injection and then administered $\left[{ }^{64} \mathrm{Cu}\right] \mathrm{Cu}-\mathrm{SarAr}-\mathrm{Tz}[14.8 \mathrm{MBq}(0.4 \mathrm{mCi}), 0.7 \mathrm{nmol}$, also via the tail vein] 24, 48, or 120 hours later. For the pretargeted biodistribution study, huA33-TCO (100 $\mu \mathrm{g}$, $0.7 \mathrm{nmol}$ ) was administered to athymic nude mice bearing SW1222 xenografts 24,48 , or 120 hours prior to the injection of $\left[{ }^{64} \mathrm{Cu}\right] \mathrm{Cu}-\mathrm{SarAr}[11.1 \mathrm{MBq}(0.30 \mathrm{mCi}), 0.7 \mathrm{nmol}]$. Critically, both the mass of the huA33-TCO immunoconjugate and the 1:1 molar ratio of the two components were selected based on values from the literature; indeed, the excellent work of Duijnhoven, et al. was particularly important with regard to chosen molar ratio ${ }^{29}$. In light of the $12.7 \mathrm{~h}$ half-life of ${ }^{64} \mathrm{Cu}$ and the rapid pharmacokinetic profile of $\left[{ }^{64} \mathrm{Cu}\right] \mathrm{Cu}-\mathrm{SarAr}-\mathrm{Tz}$, we have found that timepoints of 4,12 , and $24 \mathrm{~h}$ after the administration of the radioligand are best suited for the collection of PET images and tissue samples.

Both the PET images and biodistribution data reveal the accumulation of $\left[{ }^{64} \mathrm{Cu}\right] \mathrm{Cu}-\mathrm{SarAr}-\mathrm{Tz}$ in tumor tissue as early as 4 hours post-injection (p.i)., with the activity concentration in the xenograft increasing over the course of the experiment to maximum values between $8-10 \% \mathrm{ID} / \mathrm{g}$ by 24 hours p.i (Figure 7). Indeed, even as early as 4 hours p.i., the tumor is easily the most readily visualized tissue. The activity concentrations in healthy organs generally remain low $(<1 \% \mathrm{ID} / \mathrm{g})$ throughout the experiment, with the highest level of background uptake is in the kidneys (typically $2 \% \mathrm{ID} / \mathrm{g}$ at 24 h p.i.). The activity concentration in the blood decreases relatively slowly over the course of the study, likely due to ligations between $\left[{ }^{64} \mathrm{Cu}\right] \mathrm{Cu}-\mathrm{SarAr}-\mathrm{Tz}$ and circulating huA33-TCO that create ${ }^{64} \mathrm{Cu}-$ 
labeled huA33 in the blood that subsequently accumulates in the tumor. The frequency of these click reactions - and thus the activity concentration in the blood - can be reduced by increasing the interval time between the administration of the two components. For example, the activity concentration in the blood at 24 hours p.i. drops from $2.6 \pm 0.2 \% \mathrm{ID} / \mathrm{g}$ to $0.7 \pm 0.2 \% \mathrm{ID} / \mathrm{g}$ upon increasing the interval time from 24 hours to 120 hours. It is important to note, however, that extending the interval time can also decrease tumoral accretion - albeit to a lesser degree - likely due to the increased isomerization of TCO to CCO over longer lag times. To wit, the tumoral activity concentration at 24 hours p.i. decreases from $7.4 \pm 2.0 \% \mathrm{ID} / \mathrm{g}$ to $4.3 \pm 1.0 \% \mathrm{ID} / \mathrm{g}$ when the lag time is increased from 24 to 120 hours. Critically, control experiments employing $\left[{ }^{64} \mathrm{Cu}\right] \mathrm{Cu}-\mathrm{SarAr}-\mathrm{Tz}$ alone, $\left[{ }^{64} \mathrm{Cu}\right] \mathrm{Cu}-\mathrm{SarAr}-\mathrm{Tz}$ in conjunction with unmodified huA33, and huA33-TCO in conjunction with low specific activity $\left[{ }^{64} \mathrm{Cu}\right] \mathrm{Cu}-\mathrm{SarAr}-\mathrm{Tz}$ produce only minimal activity concentrations in the tumor $(<0.5 \% \mathrm{ID} / \mathrm{g})$ (see Experimental Design)

\section{Pretargeted Radioimmunotherapy}

The most fundamental difference between the pretargeted PET and PRIT experiments is the use of $\left[{ }^{64} \mathrm{Cu}\right] \mathrm{Cu}-\mathrm{SarAr}-\mathrm{Tz}$ in the former and $\left[{ }^{177} \mathrm{Lu}\right] \mathrm{Lu}-\mathrm{DOTA}-\mathrm{PEG}_{7}-\mathrm{Tz}$ in the latter. The biodistribution data for the PRIT system mirror that produced by huA33-TCO and $\left[{ }^{64} \mathrm{Cu}\right] \mathrm{Cu}-\mathrm{SarAr}-\mathrm{Tz}$ from the PET studies (Figure 8A). In the biodistribution experiments, huA33-TCO (100 $\mu \mathrm{g}, 0.7 \mathrm{nmol})$ was administered to athymic nude mice bearing SW1222 xenografts 24, 48, or 72 hours prior to the injection of $\left[{ }^{177} \mathrm{Lu}\right] \mathrm{Lu}-\mathrm{DOTA}-\mathrm{PEG}_{7}-\mathrm{Tz}[11.1 \mathrm{MBq}(0.30 \mathrm{mCi}), 0.7 \mathrm{nmol}]$. Activity concentrations in the tumor are substantial at early time points $(\sim 5 \% \mathrm{ID} / \mathrm{g}$ at 4 hours p.i.) and increase with time, ultimately reaching $15-20 \% \mathrm{ID} / \mathrm{g}$ by 120 hours p.i. Generally speaking, uptake in healthy tissues remains low. However, the gradual decrease in the activity concentrations in the blood suggests that $\left[{ }^{177} \mathrm{Lu}\right] \mathrm{Lu}-\mathrm{DOTA}-\mathrm{PEG}_{7}-\mathrm{Tz}-$ like $\left[{ }^{64} \mathrm{Cu}\right] \mathrm{Cu}-\mathrm{SarAr}-\mathrm{Tz}$ - combines with circulating huA33-TCO to create ${ }^{177} \mathrm{Lu}$-labeled huA33 that remains in the blood before accumulating in the tumor. As in the 
PET experiments, longer injection intervals produce decreased activity concentrations in the blood but also reduced tumoral uptake values as well.

Longitudinal therapy studies clearly demonstrate the efficacy of this approach. Significant reductions in tumor growth are observed in the SW1222 xenograft-bearing mice receiving huA33TCO $(100 \mu \mathrm{g}, 0.7 \mathrm{nmol})$ followed 24 hours later by $18.5,37.0$, or $55.5 \mathrm{MBq}(0.5,1.0$, or $1.5 \mathrm{mCi})$ of $\left.{ }^{[177} \mathrm{Lu}\right] \mathrm{Lu}-\mathrm{DOTA}-\mathrm{PEG}_{7}-\mathrm{Tz}(0.7 \mathrm{nmol}$ in each case) (Figure $8 B)$. Following a brief initial period of growth, the xenografts in the mice of each experimental cohort decrease in size dramatically, while those in the animals of the two control groups receiving only one half of the PRIT system - i.e. either huA33-TCO alone or $55.5 \mathrm{MBq}(1.5 \mathrm{mCi})\left[{ }^{177} \mathrm{Lu}\right] \mathrm{Lu}-\mathrm{DOTA}-\mathrm{PEG}_{7}-\mathrm{Tz}$ alone - continue to grow unabated. A Kaplan-Meier plot underscores the potency of ${ }^{177}$ Lu-PRIT: while the mice of the two control cohorts exhibited median survival times of 20-25 days after the injection of the radiotracer, all of the mice in the three experimental cohorts survived for the duration of the 10 half-life (70 day) investigation (Figure 8C). 


\section{BOX 1: PREPARATION OF Tz-PEG7-AF680 AND DETERMINATION OF TCO OCCUPANCY OF huA33-TCO}

\section{Additional Reagents}

- NHS-AF680 (A37567, ThermoFisher Scientific, Waltham, MA, USA)

\section{PROCEDURE}

\section{Synthesis of Tz-PEG $7-A F 680$ (timing $\sim 1$ day)}

1. In a $1.5 \mathrm{~mL}$ microcentrifuge tube, dissolve $1.0 \mathrm{mg}$ of $\mathrm{Tz}-\mathrm{PEG}_{7}-\mathrm{NH}_{2}$ (Procedure 1$)(0.0015$ mmol) in $400 \mu \mathrm{L}$ of DMSO. !CAUTION DMSO is a flammable liquid and may cause slight skin and eye irritation.

2. Add $2.0 \mathrm{mg}$ of NHS-AF680 (0.0021 mmol; 1.4 eq. $)$ to the solution and mix thoroughly.

3. Add $10.0 \mu \mathrm{L}$ of TEA $(7.3 \mathrm{mg} ; 0.072 \mathrm{mmol})$ to the solution and mix thoroughly. !CAUTION TEA is a highly flammable liquid and has high oral, dermal, and respiratory toxicity.

4. Place the solution on a dry block heating mixer and agitate at $300 \mathrm{rpm}$ at $25^{\circ} \mathrm{C}$ for 30 minutes.

5. Take a small aliquot from the reaction mixture $(\sim 20 \mu \mathrm{L})$, perform a 2-fold dilution with acetonitrile, and check the reaction via preparative HPLC with a mobile phase gradient of 95:5 to 5:95 (eluent A:eluent B) over 30 minutes with a flow rate of $7 \mathrm{~mL} / \mathrm{min}\left(t_{\mathrm{R}, \text { product }}=\sim 17\right.$ minutes; potential impurities: $t_{\mathrm{R}, \mathrm{Tz}-\mathrm{PEG} 7-\mathrm{NH} 2:} \sim 14$ minutes). If the reaction is deemed to be complete, filter the rest of the reaction mixture and continue on with HPLC purification. If the reaction is not complete, allow the reaction to incubate for longer or repeat steps $1-4$. If the purification is unable to be performed immediately following the reaction, we recommend separating the sample into $200 \mu \mathrm{L}$ aliquots in $1.5 \mathrm{~mL}$ microcentrifuge tubes and storing the crude product at $-80{ }^{\circ} \mathrm{C}$ until purification. 
6. Purify the samples via preparative HPLC with a mobile phase gradient of 95:5 to 5:95 (eluent A:eluent $\mathrm{B})$ over 30 minutes with a flow rate of $7 \mathrm{~mL} / \mathrm{min}\left(t_{\mathrm{R}, \text { product }}=\sim 17\right.$ minutes; potential

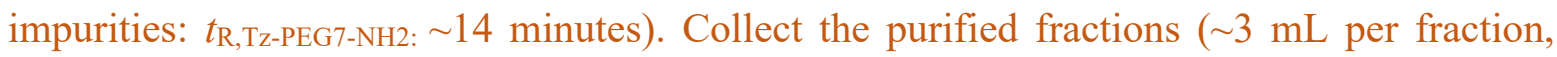
16.5-17.5 min, in total of 2-3 fractions per run) in $3.5 \mathrm{~mL}$ glass collection tubes and combine them in a $50 \mathrm{~mL}$ conical centrifuge tube. !CAUTION Acetonitrile is a highly flammable liquid and can cause acute oral, dermal, and inhalation toxicity. TFA is highly toxic and may cause severe skin burns, eye damage, and lung irritation.

7. Lyophilize the HPLC eluant to yield Tz-PEG7-AF680 as a deep blue powder (typical results: $2.0 \mathrm{mg}, 0.0013 \mathrm{mmol}, 79 \%$ yield). PAUSE POINT The purified Tz-PEG7-AF680 can be stored as a solid at $-20{ }^{\circ} \mathrm{C}$ for up to 6 months. Make sure to protect sample from light by wrapping container in aluminum foil.

\section{Determination of the TCO occupancy of huA33-TCO (timing 1 day)}

Performing this assay once per prepared batch of huA33-TCO is sufficient.

1. Dilute an aliquot of the huA33-TCO solution $(50.0 \mu \mathrm{g}, 0.33 \mathrm{nmol})$ to $0.3 \mathrm{~mL} 1 \times \mathrm{PBS} \mathrm{pH} 7.4$ in a $1.5 \mathrm{~mL}$ microcentrifuge tube $(1.1 \mu \mathrm{M})$.

2. Add $10.0 \mu \mathrm{L}$ of a $0.5 \mathrm{mM}$ solution of Tz-PEG7-AF680 in DMSO. !CAUTION DMSO is a flammable liquid. DMSO may cause slight skin and eye irritation.

3. Place the solution on a dry block heating mixer and agitate it at $500 \mathrm{rpm}$ at $25^{\circ} \mathrm{C}$ for 24 hours.

4. Purify the reaction with a PD-10 desalting column and an Amicon ${ }^{\circledR}$ Ultra-4 centrifugal filter.

a. Equilibrate PD-10 desalting column (see Equipment Setup).

b. Add the reaction mixture $(0.3 \mathrm{~mL})$ to the PD-10 desalting column and allow the solution to enter the packed bed completely.

c. Discard the flow-through. 
d. Add $2.2 \mathrm{~mL}$ of $1 \times$ PBS pH 7.4 to each column and allow the solution to enter the packed bed completely.

e. Discard the flow-through.

f. Elute the column with $2.0 \mathrm{~mL}$ of $1 \times \mathrm{PBS}$ pH 7.4 into an Amicon ${ }^{\circledR}$ Ultra-4 centrifugal filter.

g. Centrifuge the Amicon ${ }^{\circledR}$ Ultra-4 centrifugal filters at $3500 \mathrm{~g}$ for $15 \mathrm{~min}$ and discard the flow-through.

h. Transfer the remaining solution $(\sim 0.1 \mathrm{~mL})$ from the Amicon ${ }^{\circledR}$ Ultra-4 centrifugal filters into a microcentrifuge tube and vortex gently. Wash out the Amicon ${ }^{\circledR}$ Ultra-4 centrifugal filter using $0.2 \mathrm{~mL}$ of $1 \times \mathrm{PBS} \mathrm{pH} 7.4$ and combine this with the antibody solution in the microcentrifuge tube, bringing the total volume up to $\sim 0.3 \mathrm{~mL}$

5. Measure the absorbance at $280 \mathrm{~nm}$ and $680 \mathrm{~nm}$.

6. Calculate the degree of labeling using the absorbances of the antibody at 280 and $680 \mathrm{~nm}$ using the equation below. Alternatively, the BioSpec Nano UV-Vis spectrophotometer can automatically report the degree of labeling (DOL).

$$
\begin{gathered}
\mathrm{A}_{\mathrm{mAb}}=\mathrm{A}_{280}-\mathrm{A}_{\max }(\mathrm{CF}) \\
\mathrm{DOL}=\left[\mathrm{A}_{\max } * \mathrm{MW}_{\mathrm{mAb}}\right] /\left[[\mathrm{mAb}]^{*} \varepsilon_{\mathrm{AF} 680}\right]
\end{gathered}
$$

where the correction factor $(\mathrm{CF})$ for AF680 was given as 0.05 by the supplier, $\mathrm{MW}_{\mathrm{huA} 33}=$ $150,000 \mathrm{Da}, \varepsilon_{\mathrm{AF} 680}=82,030 \mathrm{~cm}^{-1} \mathrm{M}^{-1}$, and $\varepsilon_{280, \text { huA33 }}=210,000 \mathrm{~cm}^{-1} \mathrm{M}^{-1}$.

\section{End of Box 1}




\section{FIGURES AND FIGURE CAPTIONS}

Figure 1. In vivo pretargeting based on the inverse electron demand Diels-Alder reaction. (A) The inverse electron demand Diels-Alder (IEDDA) ligation between 1,2,4,5-tetrazine and transcyclooctene; (B) Schematic of in vivo pretargeting based on the inverse electron demand Diels-Alder reaction. Adapted with permission from Membreno, R., Cook, B. E., Fung, K., Lewis, J. S. \& Zeglis, B. M. Click-mediated pretargeted radioimmunotherapy of colorectal carcinoma. Mol Pharm 15, 1729-1734, (2018). Copyright 2018 American Chemical Society.

A.
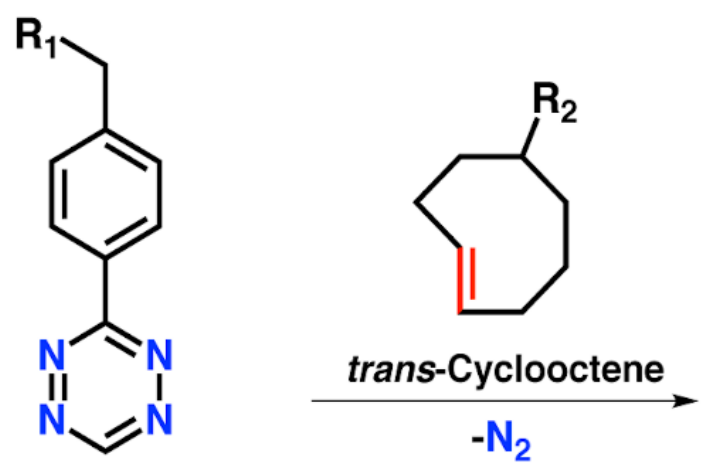

\section{1,2,4,5-Tetrazine}

B.

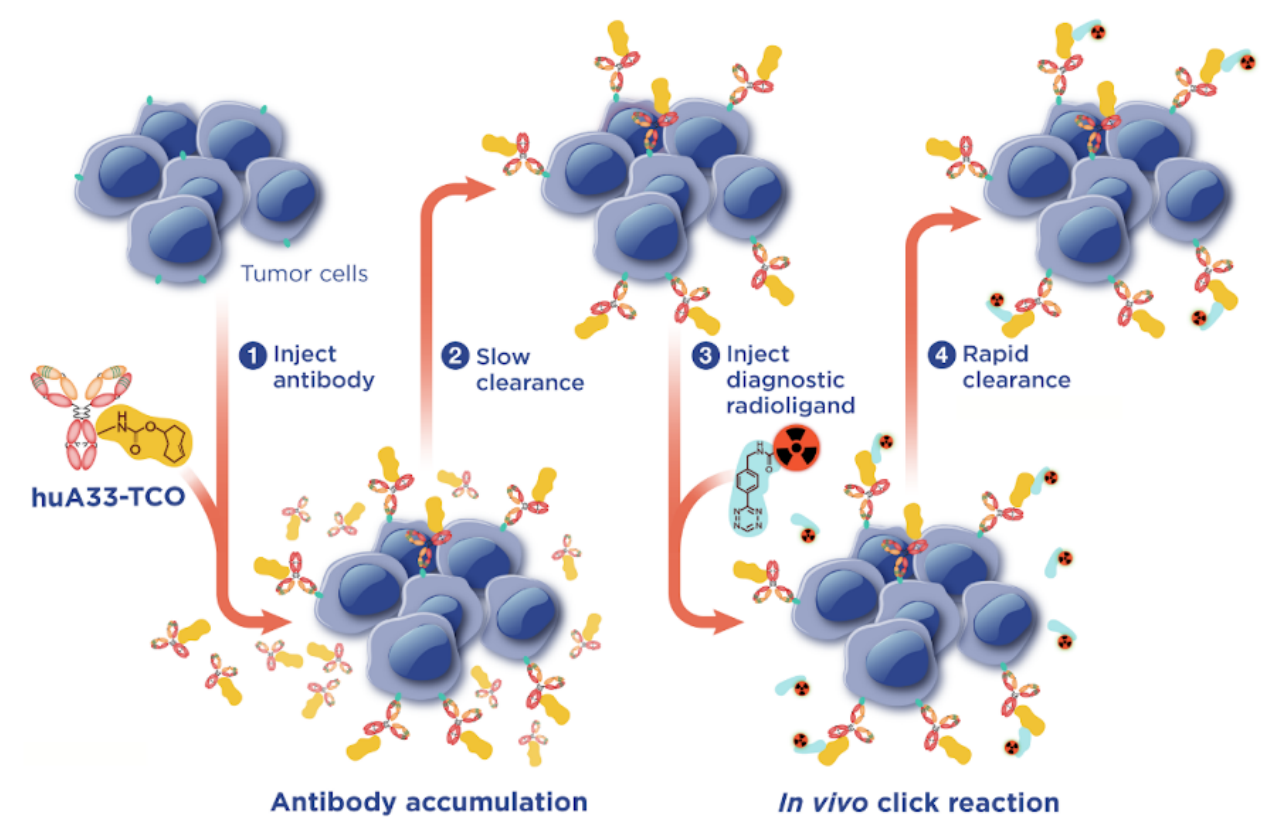


Figure 2. Several ligation mechanisms have been leveraged to facilitate in vivo pretargeting: (A) the inverse electron demand Diels-Alder reaction; (B) the interaction between streptavidin and biotin; (C) the ability of bispecific antibodies to bind both a cancer antigen and a hapten; (D) the hybridization of complementary oligonucleotides; (E) the Staudinger ligation; (F) the strainpromoted azide-alkyne click reaction; and $(\mathrm{G})$ the host-guest relationship between adamantane and cucurbituril.

a.

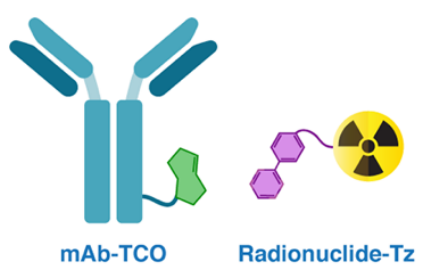

b.

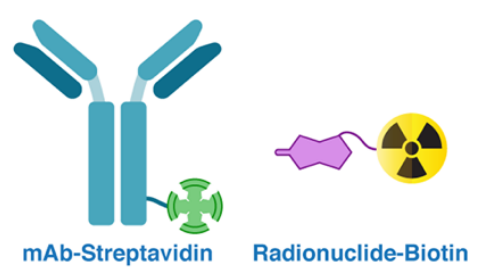

e.

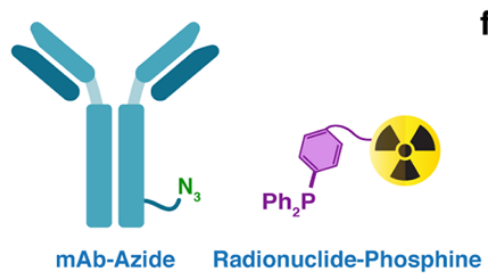

c.

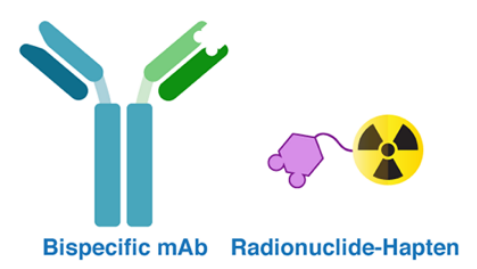

f.

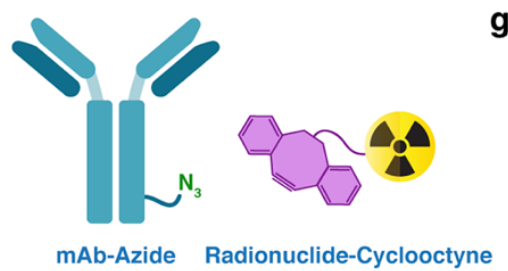

d.

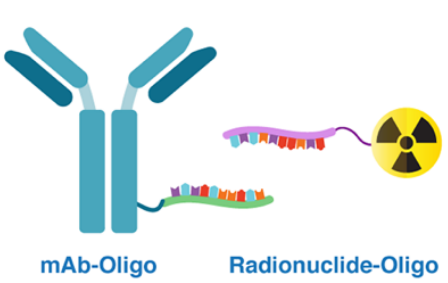

g.

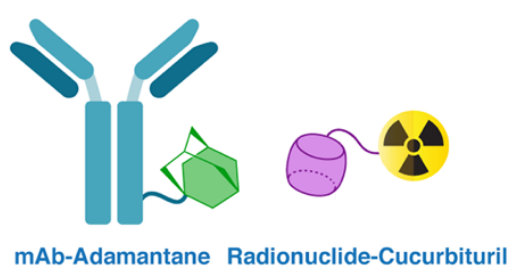


Figure 3. The synthesis of $\left[{ }^{64} \mathrm{Cu}\right] \mathrm{Cu}-\mathrm{Sar} \mathrm{Ar}-\mathrm{Tz}$
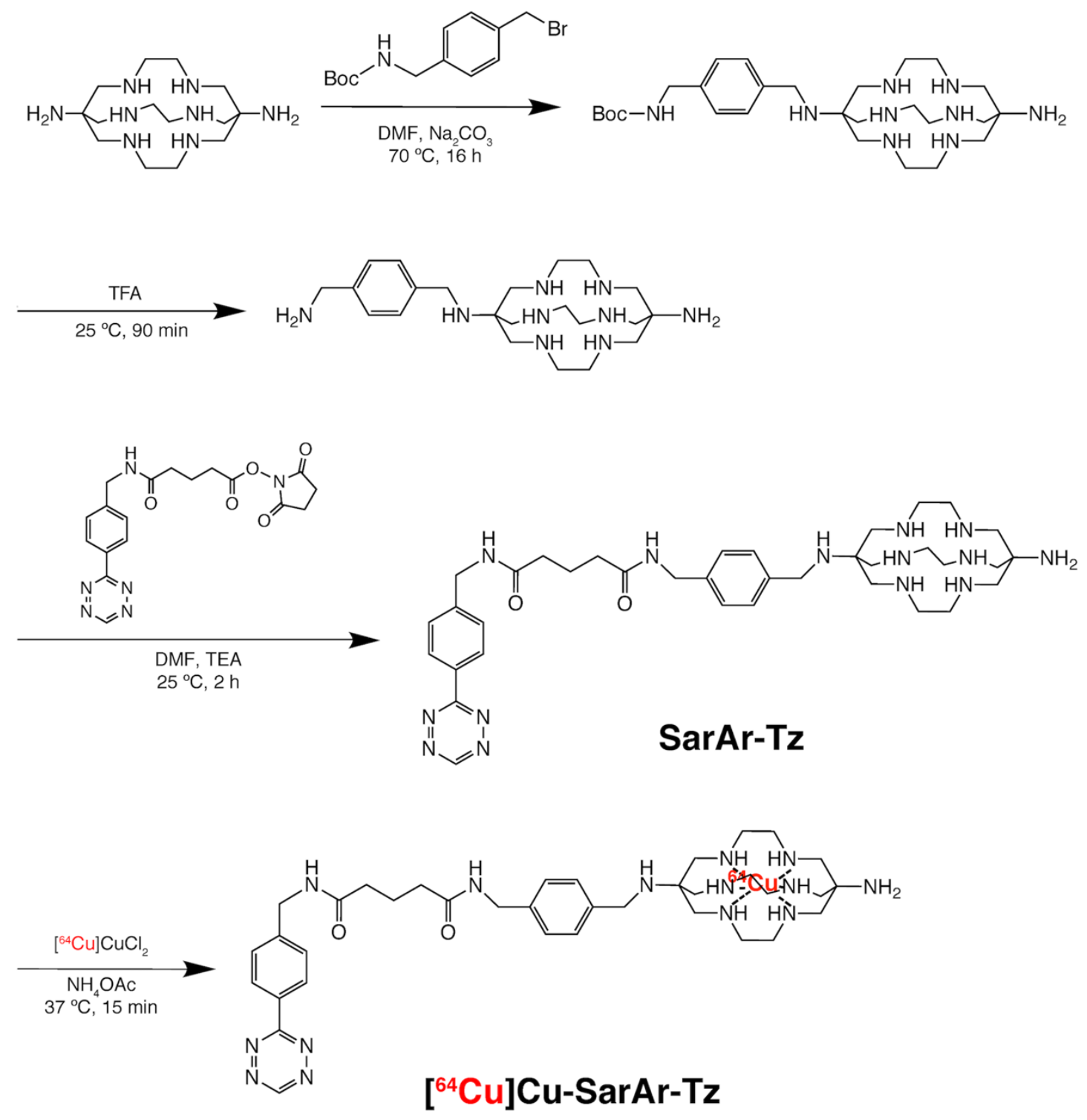
Figure 4. The synthesis of $\left[{ }^{177} \mathrm{Lu}\right] \mathrm{Lu}-\mathrm{DOTA}-\mathrm{PEG}_{7}-\mathrm{Tz}$.

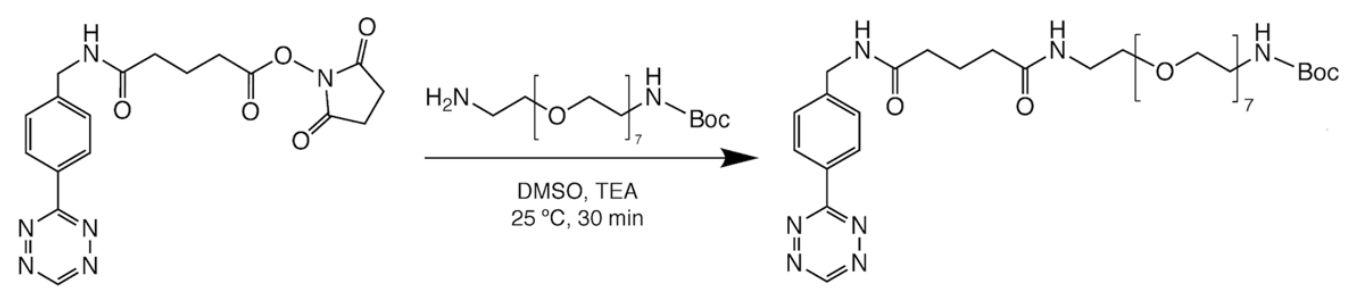<smiles>CC(C)(N)COCCNC(=O)CCCC(=O)NCc1ccc(-c2nncnn2)cc1</smiles>

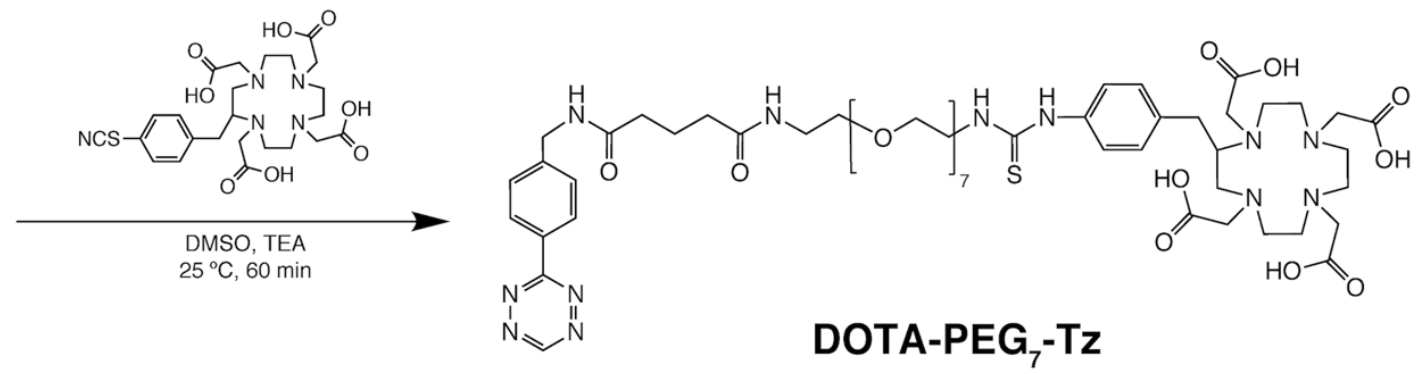

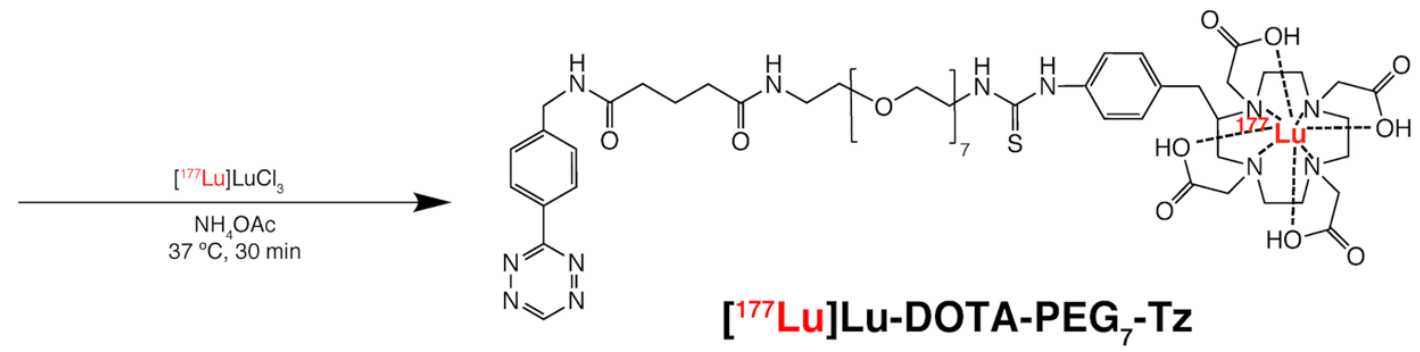




$$
\overline{8}=8
$$


Figure 6. Representative radio-iTLC chromatograms for the radiosynthesis of $\left[{ }^{64} \mathrm{Cu}\right] \mathrm{Cu}-\mathrm{SarAr}-\mathrm{Tz}$ (left) and $\left[{ }^{177} \mathrm{Lu}\right] \mathrm{Lu}-\mathrm{DOTA}-\mathrm{PEG}_{7}-\mathrm{Tz}$ (right) after reaction times of 15 and $30 \mathrm{~min}$, respectively.
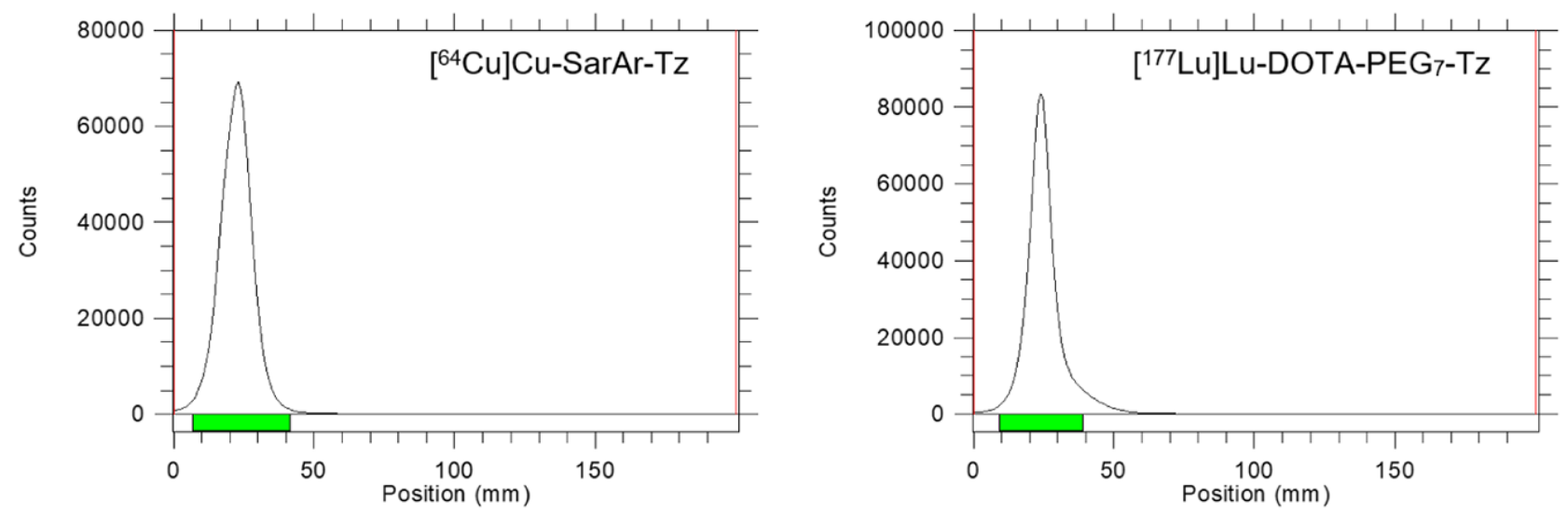
Figure 7. Representative pretargeted PET images using $\left[{ }^{64} \mathrm{Cu}\right] \mathrm{Cu}-\mathrm{SarAr}-\mathrm{Tz}$ and huA33-TCO with $24 \mathrm{~h}(\mathrm{~A}) 48 \mathrm{~h}(\mathrm{~B})$, and $120 \mathrm{~h}(\mathrm{C})$ interval times between the two injections. (D) Biodistribution data for in vivo pretargeting with huA33-TCO and $\left[{ }^{64} \mathrm{Cu}\right] \mathrm{Cu}-\mathrm{SarAr}-\mathrm{Tz}$ in athymic nude mice bearing subcutaneous SW1222 human colorectal cancer xenografts $(n=4)$ using pretargeting intervals of 24 (red), 48 (blue), or 120 (grey) h. At each interval, mice were sacrificed at 4, 12, and 24 hours after the administration of the radioligand. Reprinted with permission from Zeglis, B. M. et al. Optimization of a pretargeted strategy for the PET imaging of colorectal carcinoma via the modulation of radioligand pharmacokinetics. Mol Pharm 12, 3575-3587, (2015). Copyright 2015 American Chemical Society.

A.
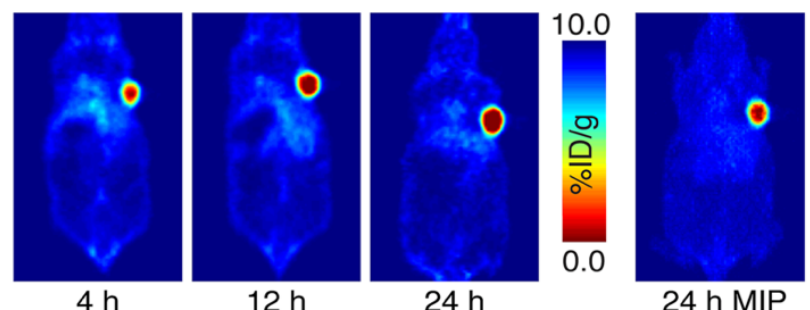

B.
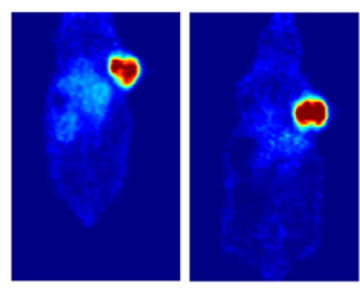

$12 \mathrm{~h}$

C.
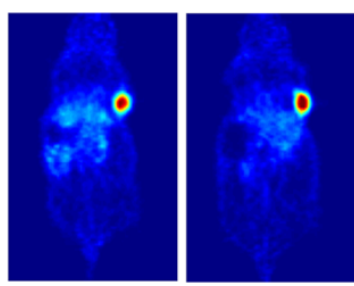

$12 \mathrm{~h}$

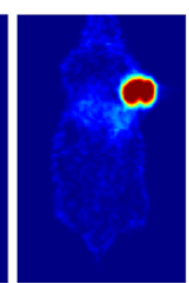

$24 \mathrm{~h}$

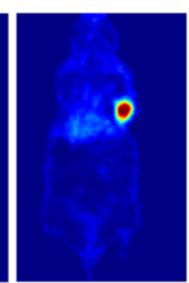

$24 \mathrm{~h}$

D.

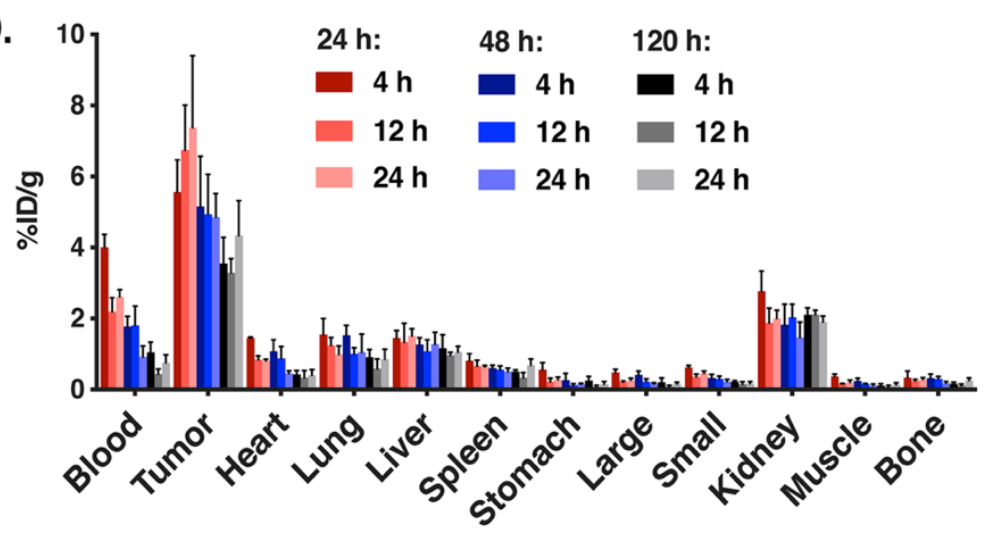

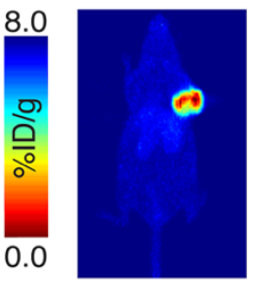
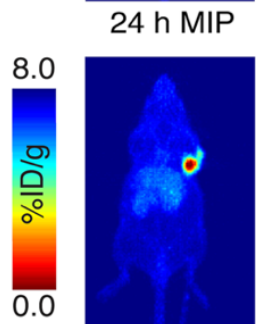

24 h MIP 
Figure 8. (A) Biodistribution data for in vivo pretargeting with huA33-TCO and $\left[{ }^{177} \mathrm{Lu}\right] \mathrm{Lu}-\mathrm{DOTA}-$ $\mathrm{PEG}_{7-\mathrm{Tz}}$ in athymic nude mice $(\mathrm{n}=4$ per cohort) bearing subcutaneous SW1222 human colorectal cancer xenografts using pretargeting intervals of 24 (purple), 48 (light blue), or 72 (orange) hours. For each pretargeting interval, the mice were sacrificed at 4, 24, 48, and $120 \mathrm{~h}$ after the administration of the radioligand. The data is presented as the uptake value in $\% \mathrm{ID} / \mathrm{g} \pm \mathrm{S}$.D. (B) Longitudinal therapy study of five groups of mice $(n=10$ each) bearing subcutaneous SW1222 tumors depicted in a graph of normalized tumor volume as a function of time and $(\mathrm{C})$ the corresponding Kaplan-Meier survival curve. The control groups received either the immunoconjugate without the radioligand (blue) or the radioligand without the immunoconjugate (red). The three treatment groups received huA33-TCO (100 $\mu \mathrm{g}, 0.7 \mathrm{nmol}$ ) followed $24 \mathrm{~h}$ later by 18.7 (light blue), 37.0 (purple), or 55.5 (orange) MBq (0.5, 1.0 , or $1.5 \mathrm{mCi}$, respectively) ( 0.7 nmol in each case) of $\left[{ }^{177} \mathrm{Lu}\right] \mathrm{Lu}-\mathrm{DOTA}-\mathrm{PEG} 7-\mathrm{Tz}$. By log-rank (Mantel-Cox) test, survival was significant $(\mathrm{p}<0.0001)$ for all treatment groups. Reprinted with permission from Membreno, R., Cook, B. E., Fung, K., Lewis, J. S. \& Zeglis, B. M. Click-mediated pretargeted radioimmunotherapy of colorectal carcinoma. Mol Pharm 15, 1729-1734, (2018). Copyright 2018 American Chemical Society. 
a.

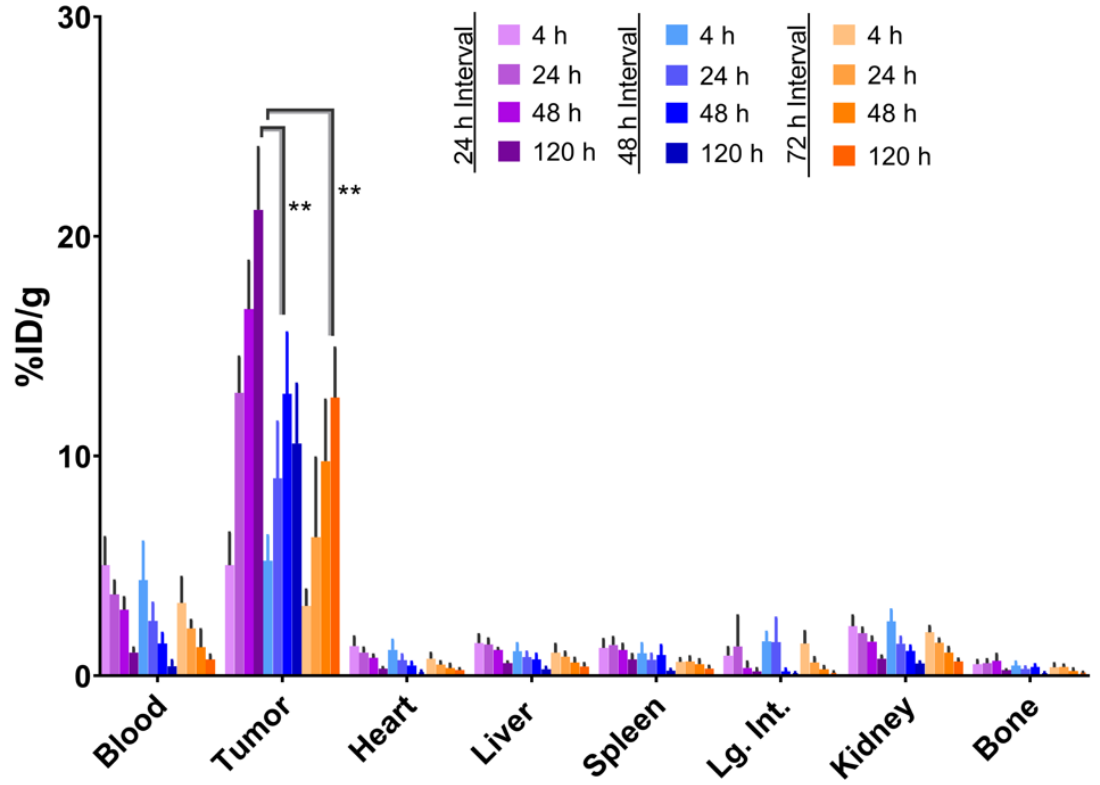

b.

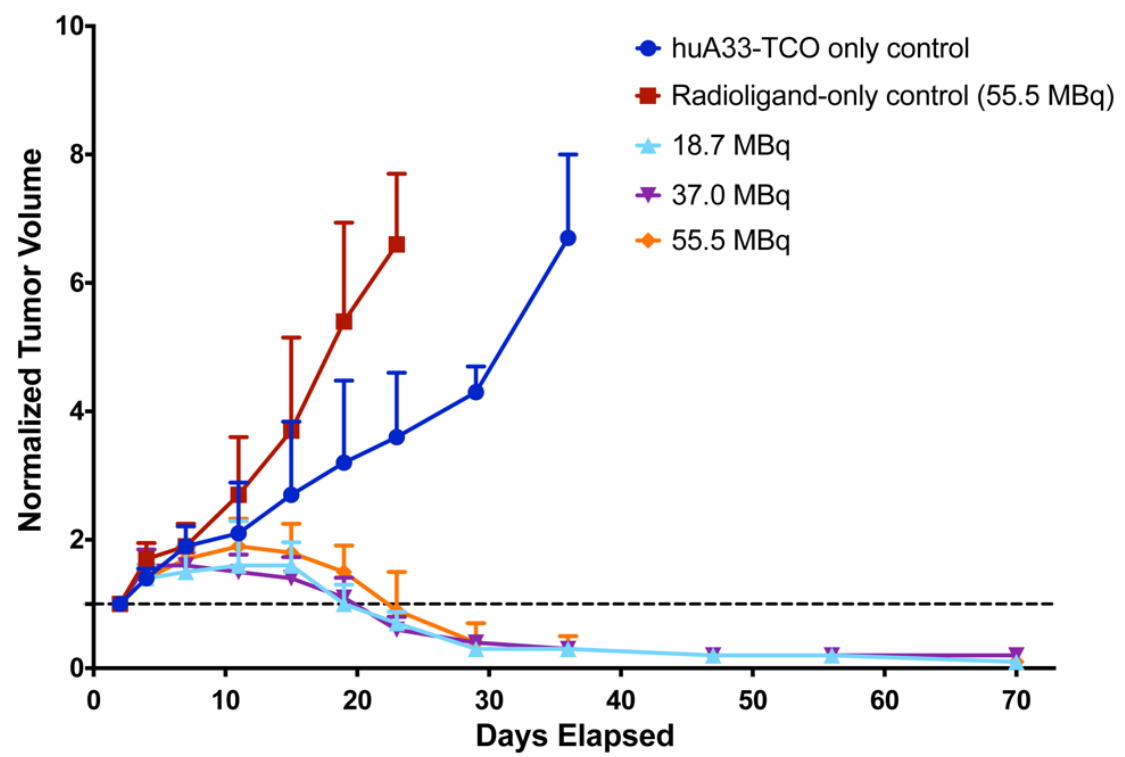

c.

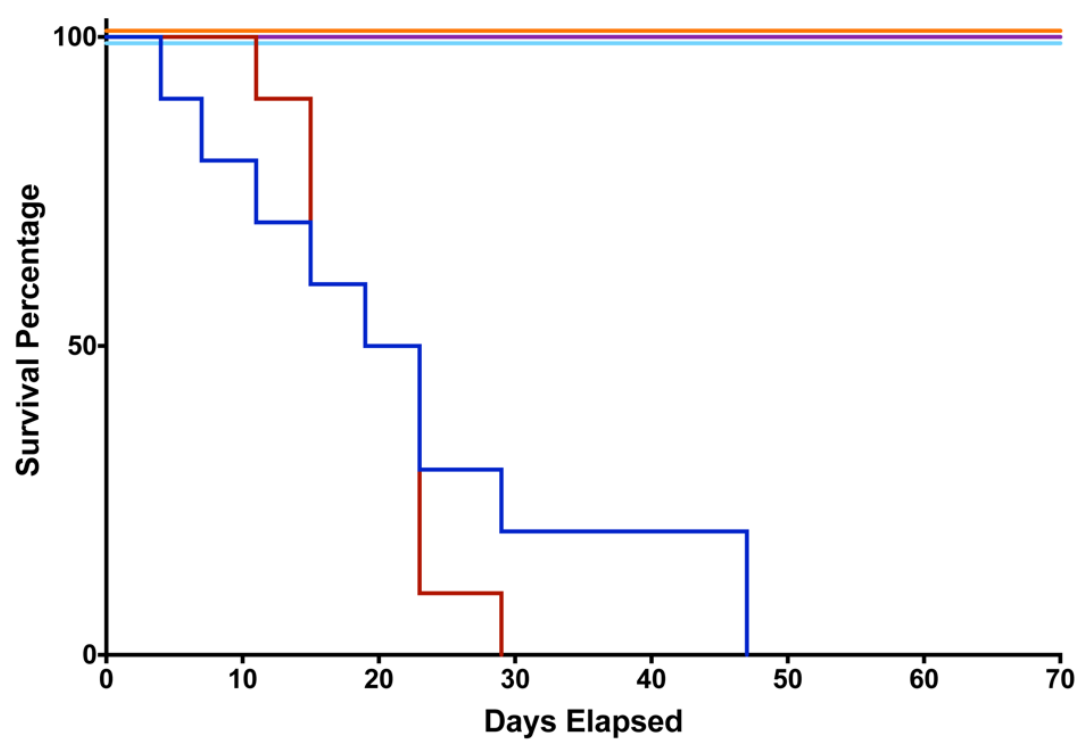




\section{REFERENCES}

1 Deri, M. A., Zeglis, B. M., Francesconi, L. C. \& Lewis, J. S. PET imaging with 89Zr: from radiochemistry to the clinic. Nuclear Medicine and BIology 40, 3-14, doi:10.1016/j.nucmedbio.2012.08.004 (2013).

2 Verel, I. et al. Long-lived positron emitters zirconium-89 and iodine-124 for scouting of therapeutic radioimmunoconjugates with PET. Cancer Biotherapy and Radiopharmaceuticals 18, 655-661, doi:10.1089/108497803322287745 (2003).

3 Stillebroer, A. B. et al. Phase 1 radioimmunotherapy study with lutetium 177-labeled anticarbonic anhydrase IX monoclonal antibody girentuximab in patients with advanced renal cell carcinoma. European Urology 64, 478-485, doi:10.1016/j.eururo.2012.08.024 (2013).

4 Kramer, K. et al. Phase I study of targeted radioimmunotherapy for leptomeningeal cancers using intra-ommaya 131-I-3F8. Journal of Clinical Oncology 25, 5465-5470, doi:10.1200/JCO.2007.11.1807 (2007).

5 Zeglis, B. M., Houghton, J. L., Evans, M. J., Viola-Villegas, N. \& Lewis, J. S. Underscoring the influence of inorganic chemistry on nuclear imaging with radiometals. Inorganic Chemistry 53, 1880-1899, doi:10.1021/ic401607z (2014).

6 Kramer, K. et al. A phase II study of radioimmunotherapy with intraventricular (131) I-3F8 for medulloblastoma. Pediatric Blood and Cancer 65, doi:10.1002/pbc.26754 (2018).

7 van Loon, J. et al. PET imaging of zirconium-89 labelled cetuximab: A phase I trial in patients with head and neck and lung cancer. Radiotherapy and Oncology 122, 267-273, doi:10.1016/j.radonc.2016.11.020 (2017).

8 Pandit-Taskar, N. et al. A phase I/II study for analytic validation of 89Zr-J591 immunoPET as a molecular imaging agent for metastatic prostate cancer. Clinical Cancer Research 21, 5277-5285, doi:10.1158/1078-0432.CCR-15-0552 (2015).

9 Maloney, R., Buuh, Z. Y., Zhao, Y. \& Wang, R. E. Site-specific antibody fragment conjugates for targeted imaging. Methods in Enzymology 638, 295-320, doi:10.1016/bs.mie.2020.02.023 (2020).

10 Jain, M., Venkatraman, G. \& Batra, S. K. Optimization of radioimmunotherapy of solid tumors: biological impediments and their modulation. Clin Cancer Res 13, 1374-1382, doi:10.1158/10780432.CCR-06-2436 (2007).

11 Hnatowich, D. J., Virzi, F. \& Rusckowski, M. Investigations of avidin and biotin for imaging applications. Journal of Nuclear Medicine 28, 1294-1302 (1987).

12 Leonidova, A. et al. In vivo demonstration of an active tumor pretargeting approach with peptide nucleic acid bioconjugates as complementary system. Chemical Science 6, 5601-5616, doi:10.1039/c5sc00951k (2015).

13 Salaun, P. Y. et al. Phase II trial of anticarcinoembryonic antigen pretargeted radioimmunotherapy in progressive metastatic medullary thyroid carcinoma: biomarker response and survival improvement. Journal of Nuclear Medicine 53, 1185-1192, doi:10.2967/jnumed.111.101865 (2012).

14 Rondon, A. \& Degoul, F. Antibody pretargeting based on bioorthogonal click chemistry for cancer imaging and targeted radionuclide therapy. Bioconjugate Chemistry 31, 159-173, doi:10.1021/acs.bioconjchem.9b00761 (2020).

15 Reiner, T. \& Zeglis, B. M. The inverse electron demand Diels-Alder click reaction in radiochemistry. Journal of Labelled Compounds and Radiopharmaceuticals 57, 285-290, doi:10.1002/jlcr.3149 (2014).

16 Keinanen, O. et al. Dual radionuclide theranostic pretargeting. Molecular Pharmaceutics 16, 4416-4421, doi:10.1021/acs.molpharmaceut.9b00746 (2019). 
17 Keinänen, O. et al. Harnessing $64 \mathrm{Cu} / 67 \mathrm{Cu}$ for a theranostic approach to pretargeted radioimmunotherapy. Proceedings of the National Academy ot Sciences of the United States of America 117, 28316-28327, doi:10.1073/pnas.2009960117 (2020).

18 Rossin, R., Lappchen, T., van den Bosch, S. M., Laforest, R. \& Robillard, M. S. Diels-Alder reaction for tumor pretargeting: in vivo chemistry can boost tumor radiation dose compared with directly labeled antibody. Journal of Nuclear Medicine 54, 1989-1995, doi:10.2967/jnumed.113.123745 (2013).

19 Rossin, R. et al. In vivo chemistry for pretargeted tumor imaging in live mice. Angewandte Chemie International Edition English 49, 3375-3378, doi:10.1002/anie.200906294 (2010).

20 Zeglis, B. M. et al. A pretargeted PET imaging strategy based on bioorthogonal Diels-Alder click chemistry. Journal of Nuclear Medicine 54, 1389-1396, doi:10.2967/jnumed.112.115840 (2013).

21 Zeglis, B. M. et al. Optimization of a pretargeted strategy for the PET imaging of colorectal cancer via the modulation of radioligand pharmacokinetics. Molecular Pharmaceutics 12, 3575-3587 (2015).

22 Meyer, J. P. et al. (18)F-based pretargeted PET imaging based on bioorthogonal Diels-Alder click chemistry. Bioconjugate Chemistry 27, 298-301, doi:10.1021/acs.bioconjchem.5b00504 (2016).

23 Meyer, J. P. et al. Exploring structural parameters for pretargeting radioligand optimization. Journal of Medicinal Chemistry 60, 8201-8217, doi:10.1021/acs.jmedchem.7b01108 (2017).

24 Houghton, J. L. et al. Establishment of the in vivo efficacy of pretargeted radioimmunotherapy utilizing inverse electron demand Diels-Alder click chemistry. Molecular Cancer Therapeutics 16, 124-133, doi:10.1158/1535-7163.MCT-16-0503 (2017).

25 Membreno, R., Cook, B. E., Fung, K., Lewis, J. S. \& Zeglis, B. M. Click-mediated pretargeted radioimmunotherapy of colorectal carcinoma. Molecular Pharmaceutics 15, 1729-1734, doi:10.1021/acs.molpharmaceut.8b00093 (2018).

26 Poty, S. et al. Leveraging bioorthogonal click chemistry to improve 225Ac-radioimmunotherapy of pancreatic ductal adenocarcinoma. Clinical Cancer Research 25, 868-880, doi:10.1158/10780432.CCR-18-1650 (2019).

27 Membreno, R., Cook, B. E. \& Zeglis, B. M. Pretargeted radioimmunotherapy based on the inverse electron demand Diels-Alder reaction. Journal of Visualized Experiments, doi:10.3791/59041 (2019).

28 Cook, B. E., Membreno, R. \& Zeglis, B. M. Dendrimer scaffold for the amplification of in vivo pretargeting ligations. Bioconjugate Chemistry 29, 2734-2740, doi:10.1021/acs.bioconjchem.8b00385 (2018).

29 Siegl, S. J., Galeta, J., Dzijak, R., Dracinsky, M. \& Vrabel, M. Bioorthogonal fluorescence turnon labeling based on bicyclononyne-tetrazine cycloaddition reactions that form pyridazine products. ChemPlusChem 84, 493-497, doi:10.1002/cplu.201900176 (2019).

30 Meyer, J. P. et al. Bioorthogonal masking of circulating antibody-TCO groups using tetrazinefunctionalized dextran polymers. Bioconjugate Chemistry 29, 538-545, doi:10.1021/acs.bioconjchem.8b00028 (2018).

31 van Duijnhoven, S. M. et al. Diabody pretargeting with click chemistry in vivo. Journal of Nuclear Medicine 56, 1422-1428, doi:10.2967/jnumed.115.159145 (2015).

32 Yazdani, A. et al. A bone-seeking trans-cyclooctene for pretargeting and bioorthogonal chemistry: A proof of concept study using $(99 \mathrm{~m}) \mathrm{Tc}$ - and (177)Lu-labeled tetrazines. Journal of Medicinal Chemistry 59, 9381-9389, doi:10.1021/acs.jmedchem.6b00938 (2016).

33 Algar, W. R. et al. The controlled display of biomolecules on nanoparticles: a challenge suited to bioorthogonal chemistry. Bioconjugate Chemistry 22, 825-858, doi:10.1021/bc200065z (2011).

34 Lesch, H. P., Kaikkonen, M. U., Pikkarainen, J. T. \& Yla-Herttuala, S. Avidin-biotin technology in targeted therapy. Expert Opinion on Drug Delivery 7, 551-564, doi:10.1517/17425241003677749 (2010). 
35 Paganelli, G. et al. Antibody-guided three-step therapy for high grade glioma with yttrium-90 biotin. European Journal of Nuclear Medicine 26, 348-357, doi:10.1007/s002590050397 (1999).

36 Breitz, H. B. et al. Clinical optimization of pretargeted radioimmunotherapy with antibodystreptavidin conjugate and 90Y-DOTA-biotin. Journal of Nuclear Medicine 41, 131-140 (2000).

37 Schoffelen, R. et al. Pretargeted immuno-positron emission tomography imaging of carcinoembryonic antigen-expressing tumors with a bispecific antibody and a $68 \mathrm{Ga}-$ and $18 \mathrm{~F}-$ labeled hapten peptide in mice with human tumor xenografts. Molecular Cancer Therapeutics $\mathbf{9}$, 1019-1027, doi:10.1158/1535-7163.MCT-09-0862 (2010).

38 Goldenberg, D. M., Chatal, J. F., Barbet, J., Boerman, O. \& Sharkey, R. M. Cancer imaging and therapy with bispecific antibody pretargeting. Update on Cancer Therapeutics 2, 19-31, doi:10.1016/j.uct.2007.04.003 (2007).

39 Hall, H. et al. In vitro autoradiography of carcinoembryonic antigen in tissue from patients with colorectal cancer using multifunctional antibody TF2 and (67/68Ga)-labeled haptens by pretargeting. American Journal of Nuclear Medicine and Molecular Imaging 2, 141-150 (2012).

40 Bodet-Milin, C. et al. Immuno-PET using anticarcinoembryonic antigen bispecific antibody and 68Ga-labeled peptide in metastatic medullary thyroid carcinoma: clinical optimization of the pretargeting parameters in a first-in-human trial. Journal of Nuclear Medicine 57, 1505-1511, doi:10.2967/jnumed.116.172221 (2016).

41 Bodet-Milin, C. et al. Pharmacokinetics and dosimetry studies for optimization of pretargeted radioimmunotherapy in CEA-expressing advanced lung cancer patients. Frontiers of Medicine $\mathbf{2}$, 84, doi:10.3389/fmed.2015.00084 (2015).

42 Sharkey, R. M., Rossi, E. A., McBride, W. J., Chang, C. H. \& Goldenberg, D. M. Recombinant bispecific monoclonal antibodies prepared by the dock-and-lock strategy for pretargeted radioimmunotherapy. Seminars in Nuclear Medicine 40, 190-203, doi:10.1053/j.semnuclmed.2009.12.002 (2010).

43 Liu, G. et al. 90Y labeled phosphorodiamidate morpholino oligomer for pretargeting radiotherapy. Bioconjugate Chemistry 22, 2539-2545, doi:10.1021/bc200366t (2011).

44 Gupta, A., Mishra, A. \& Puri, N. Peptide nucleic acids: Advanced tools for biomedical applications. Journal of Biotechnology 259, 148-159, doi:10.1016/j.jbiotec.2017.07.026 (2017).

$45 \mathrm{Kim}, \mathrm{K}$. L. et al. Supramolecular latching system based on ultrastable synthetic binding pairs as versatile tools for protein imaging. Nature Communications 9, 1712, doi:10.1038/s41467-01804161-4 (2018).

46 Sundhoro, M., Jeon, S., Park, J., Ramstrom, O. \& Yan, M. Perfluoroaryl azide staudinger reaction: a fast and bioorthogonal reaction. Angewandte Chemie International Edition English 56, $12117-$ 12121, doi:10.1002/anie.201705346 (2017).

47 Agard, N. J., Prescher, J. A. \& Bertozzi, C. R. A strain-promoted [3 + 2] azide-alkyne cycloaddition for covalent modification of biomolecules in living systems. Journal of the American Chemical Society 126, 15046-15047, doi:10.1021/ja044996f (2004).

48 Carroll, L., Evans, H. L., Aboagye, E. O. \& Spivey, A. C. Bioorthogonal chemistry for pretargeted molecular imaging--progress and prospects. Organic and Medicinal Chemistry 11, 57725781, doi:10.1039/c3ob40897c (2013).

49 Ackerman, M. E. et al. A33 antigen displays persistent surface expression. Cancer Immunology and Immunotherapy 57, 1017-1027, doi:10.1007/s00262-007-0433-x (2008).

50 Keinanen, O. et al. Pretargeting of internalizing trastuzumab and cetuximab with a (18)F-tetrazine tracer in xenograft models. EJNMMI research 7, 95, doi:10.1186/s13550-017-0344-6 (2017).

51 Houghton, J. L. et al. Pretargeted immuno-PET of pancreatic cancer: overcoming circulating antigen and internalized antibody to reduce radiation doses. Journal of Nuclear Medicine 57, 453459, doi:10.2967/jnumed.115.163824 (2016). 
52 Rossin, R., van Duijnhoven, S. M., Lappchen, T., van den Bosch, S. M. \& Robillard, M. S. Transcyclooctene tag with improved properties for tumor pretargeting with the diels-alder reaction. Molecular Pharmaceutics 11, 3090-3096, doi:10.1021/mp500275a (2014).

53 Royzen, M., Yap, G. P. \& Fox, J. M. A photochemical synthesis of functionalized transcyclooctenes driven by metal complexation. Journal of the American Chemical Society 130, 3760-3761, doi:10.1021/ja8001919 (2008).

54 Rondon, A. et al. Antibody PEGylation in bioorthogonal pretargeting with transcyclooctene/tetrazine cycloaddition: in vitro and in vivo evaluation in colorectal cancer models. Scientific Reports 7, 14918, doi:10.1038/s41598-017-15051-y (2017).

55 Maggi, A. et al. Development of a novel antibody-tetrazine conjugate for bioorthogonal pretargeting. Organic and Biomolecular Chemistry 14, 7544-7551, doi:10.1039/c6ob01411a (2016).

56 Billaud, E. M. F. et al. Micro-flow photosynthesis of new dienophiles for inverse-electrondemand Diels-Alder reactions. Potential applications for pretargeted in vivo PET imaging. Chemical Science 8, 1251-1258, doi:10.1039/c6sc02933g (2017).

57 Billaud, E. M. F. et al. Pretargeted PET imaging using a bioorthogonal (18)F-labeled transcyclooctene in an ovarian carcinoma model. Bioconjugate Chemistry 28, 2915-2920, doi:10.1021/acs.bioconjchem.7b00635 (2017).

58 Steen, E. J. L. et al. Improved radiosynthesis and preliminary in vivo evaluation of the (11)Clabeled tetrazine [(11)C]AE-1 for pretargeted PET imaging. Bioorganic and Medicinal Chemistry Letters 29, 986-990, doi:10.1016/j.bmcl.2019.02.014 (2019).

59 Edem, P. E. et al. Evaluation of a (68)Ga-labeled DOTA-tetrazine as a PET alternative to (111)InSPECT pretargeted imaging. Molecules 25, doi:10.3390/molecules25030463 (2020).

60 Edem, P. E. et al. Evaluation of the inverse electron demand Diels-Alder reaction in rats using a scandium-44-labelled tetrazine for pretargeted PET imaging. EJNMMI research 9, 49, doi:10.1186/s13550-019-0520-y (2019).

61 Keinänen, O. et al. A new highly reactive and low lipophilicity fluorine-18 labeled tetrazine derivative for pretargeted PET imaging. ACS Medicinal Chemistry Letters 7, 62-66, doi:10.1021/acsmedchemlett.5b00330 (2016).

62 Reiner, T., Lewis, J. S. \& Zeglis, B. M. Harnessing the bioorthogonal inverse electron demand Diels-Alder cycloaddition for pretargeted PET imaging. Journal of Visualized Experiments, e52335, doi:10.3791/52335 (2015).

63 Altai, M. et al. Feasibility of affibody-based bioorthogonal chemistry-mediated radionuclide pretargeting. Journal of Nuclear Medicine 57, 431-436, doi:10.2967/jnumed.115.162248 (2016).

64 Vito, A. et al. A ${ }^{99 \mathrm{~m} T c-l a b e l l e d ~ t e t r a z i n e ~ f o r ~ b i o o r t h o g o n a l ~ c h e m i s t r y . ~ s y n t h e s i s ~ a n d ~}$ biodistribution studies with small molecule trans-cyclooctene derivatives. PloS one 11, e 0167425, doi:10.1371/journal.pone.0167425 (2016).

65 Zhou, Z., Devoogdt, N., Zalutsky, M. R. \& Vaidyanathan, G. An efficient method for labeling single domain antibody fragments with (18)F using tetrazine- trans-cyclooctene ligation and a renal brush border enzyme-cleavable linker. Bioconjugate Chemistry 29, 4090-4103, doi:10.1021/acs.bioconjchem.8b00699 (2018).

66 Litau, S., Seibold, U., Wangler, B., Schirrmacher, R. \& Wangler, C. iEDDA conjugation reaction in radiometal labeling of peptides with $(68) \mathrm{Ga}$ and $(64) \mathrm{Cu}$ : unexpected findings. ACS Omega $\mathbf{3}$, 14039-14053, doi:10.1021/acsomega.8b01926 (2018).

67 Lindmo, T., Boven, E., Cuttitta, F., Fedorko, J. \& Bunn, P. A., Jr. Determination of the immunoreactive fraction of radiolabeled monoclonal antibodies by linear extrapolation to binding at infinite antigen excess. Journal of Immunological Methods 72, 77-89, doi:10.1016/00221759(84)90435-6 (1984). 
68 Sharma, S. K. et al. A rapid bead-based radioligand binding assay for the determination of targetbinding fraction and quality control of radiopharmaceuticals. Nuclear Medicine and Biology 71, 32-38, doi:10.1016/j.nucmedbio.2019.04.005 (2019). 